\title{
GNREL
}

\section{Airborne Wind Energy}

Jochem Weber, Melinda Marquis, Aubryn Cooperman, Caroline Draxl, Rob Hammond, Jason Jonkman, Alexsandra Lemke, Anthony Lopez, Rafael Mudafort, Mike Optis, Owen Roberts, and Matt Shields

National Renewable Energy Laboratory

NREL is a national laboratory of the U.S. Department of Energy

Office of Energy Efficiency \& Renewable Energy

Operated by the Alliance for Sustainable Energy, LLC

This report is available at no cost from the National Renewable Energy Laboratory (NREL) at www.nrel.gov/publications.
Technical Report

NREL/TP-5000-79992

August 2021 


\section{GNREL}

\section{Airborne Wind Energy}

Jochem Weber, Melinda Marquis, Aubryn Cooperman, Caroline Draxl, Rob Hammond, Jason Jonkman, Alexsandra Lemke, Anthony Lopez, Rafael Mudafort, Mike Optis, Owen Roberts, and Matt Shields

\section{National Renewable Energy Laboratory}

\section{Suggested Citation}

Weber, Jochem, Melinda Marquis, Aubryn Cooperman, Caroline Draxl, Rob Hammond, Jason Jonkman, Alexsandra Lemke, Anthony Lopez, Rafael Mudafort, Mike Optis, Owen Roberts, and Matt Shields. 2021. Airborne Wind Energy. Golden, CO: National

Renewable Energy Laboratory. NREL/TP-5000-79992.

https://www.nrel.gov/docs/fy21osti/79992.pdf.

NREL is a national laboratory of the U.S. Department of Energy Office of Energy Efficiency \& Renewable Energy Operated by the Alliance for Sustainable Energy, LLC

This report is available at no cost from the National Renewable Energy Laboratory (NREL) at www.nrel.gov/publications.

Contract No. DE-AC36-08GO28308
Technical Report NREL/TP-5000-79992 August 2021

National Renewable Energy Laboratory 15013 Denver West Parkway Golden, CO 80401 303-275-3000 • www.nrel.gov 


\section{NOTICE}

This work was authored by the National Renewable Energy Laboratory, operated by Alliance for Sustainable Energy, LLC, for the U.S. Department of Energy (DOE) under Contract No. DE-AC36-08GO28308. Funding provided by the U.S. Department of Energy Office of Energy Efficiency and Renewable Energy Wind Energy Technologies Office. The views expressed herein do not necessarily represent the views of the DOE or the U.S. Government.

This report is available at no cost from the National Renewable Energy Laboratory (NREL) at www.nrel.gov/publications.

U.S. Department of Energy (DOE) reports produced after 1991 and a growing number of pre-1991 documents are available free via www.OSTI.gov.

Cover Image by John Frenzl, NREL

NREL prints on paper that contains recycled content. 


\section{Acknowledgments}

The National Renewable Energy Laboratory would like to acknowledge all the workshop participants and individuals who shared their expertise in airborne wind energy with the authors of this report. This report was sponsored by the U.S. Department of Energy's Wind Energy Technologies Office. 


\section{List of Acronyms}

AEP

annual energy production

ATB

Annual Technology Baseline

AWE

airborne wind energy

CapEx

capital expenditure(s)

DOD

U.S. Department of Defense

DOE

U.S. Department of Energy

FAA Federal Aviation Administration

FCR fixed charge rate

GW gigawatt

IEA International Energy Agency

km kilometer

$\mathrm{kW} \quad$ kilowatt

LCOE levelized cost of energy

LLJ low-level jet

m meter

$\mathrm{m} / \mathrm{s} \quad$ meters per second

MW megawatt

MWh megawatt-hour

$\mathrm{NCF} \quad$ net capacity factor

NREL National Renewable Energy Laboratory

O\&M operation and maintenance

OpEx operational expenditure(s)

R\&D research and development

TPL technology performance level 
TRL technology readiness level

WRF Weather Research and Forecasting 


\section{Executive Summary}

Airborne wind energy (AWE) is "the conversion of wind energy into electricity using tethered flying devices" (Schmehl 2020.) Pursuit of AWE and airborne wind energy systems began in 1980 (Loyd 1980). Interest and investment in AWE have grown substantially in the last decade, with approximately 70 active research entities including over 20 technology developers globally. This report describes technical analyses of various aspects of AWE and insight gained from dedicated outreach ${ }^{1}$ provided to the U.S. Department of Energy's Wind Energy Technologies Office to underpin its response to the congressional request in the Energy Act of 2020 for a report on the "potential for, and technical viability of, airborne wind energy systems to provide a significant source of energy in the United States."

A wide variety of AWE technology concepts, operational principles, and designs have been under development primarily over the last two decades and in Europe and the United States. Developments target a diverse range of applications and markets and are currently at low-tointermediate technology readiness levels. Generally, they have not yet achieved market-entry requirements; particularly, with respect to reliability and techno-economics, although developers have started delivering early-adopter market pilot projects (Brabeck 2021) and are offering preorders (Peschel 2021) that are both in the 100-kilowatt $(\mathrm{kW})$ unit capacity range. AWE technology developments targeting land-based and offshore competitive grid markets have achieved higher levels of technical sophistication. However, reliable, large-scale megawatt-class technology market rollout may require more than 10 years of dedicated research and development, depending on the level of support and effort provided. Overall, the technology development has not converged toward a single preferred archetype, and the design space has not been fully explored. AWE technology is fundamentally different from traditional wind technology, specifically wind energy produced by wind turbines that have towers, hereafter referred to as "traditional wind," in nearly every aspect and over the entire life cycle. AWE can thus be considered as a separate renewable energy branch, and its success will hinge on the technology's ability to generate power in a cost-effective and reliable manner over the long term.

The ability of airborne wind energy to be cost competitive with other generation sources at a commercial scale by 2030 , the time frame of interest in the congressional request, depends primarily on the achievable power rating, maximum tether length, and capacity density. Airborne wind power plants across the United States comprising 5-megawatt (MW) devices may require capital expenditures of under $\$ 1,000 / \mathrm{kW}$ to produce the same levelized cost of energy as traditional wind turbines that are anticipated to have capital costs of around $\$ 1,200 / \mathrm{kW}$ for commercial deployment in 2030. Airborne wind power plants with smaller, 500-kW devices may have higher capacity factors than the reference 5-MW traditional technology in broad regions of the United States. When coupled with potential capital expenditure reductions, AWE has the potential for low-levelized-cost-of-energy devices; however, commercial-scale deployment may be limited because of an estimated capacity density between 0.4 and $4 \mathrm{MW} /$ square kilometer $\left(\mathrm{km}^{2}\right)$, which are typically lower than the average $3 \mathrm{MW} / \mathrm{km}^{2}$ of traditional wind. The ability of

\footnotetext{
${ }^{1}$ Other contributors to this report include a literature review, 2-day workshop with more than 90 participants, 14 meetings with technology developers, and more than 20 individual stakeholder meetings, with more than 50 experts from industry and academia.
} 
airborne wind energy technology to achieve these performance metrics is currently unknown because of a lack of cost and operational data, which represents a significant source of uncertainty for the viability of the technology at a commercial scale.

The wind energy resource potential relevant to AWE (primarily targeting heights between 200 and 800 meters $[\mathrm{m}]$ ) in the United States is significant. AWE's land-based technical potential for the conterminous United States varies drastically with AWE system design — between 420 and 34,573 gigawatts (GW) and 1,615 and 92,469 terawatt-hours. For comparison in 2018, the total U.S. consumption of electricity was 4,222.5 terawatt-hours. Positive wind shear above $200 \mathrm{~m}$ was not found consistently in our analyses, and selected sites and wind profiles appeared to be rather flat, with more evidence of positive shear on land than offshore. Using power curve projections of assumed mature, fully developed, and commercially operated AWE technology based on generic models and an overview of pilot experiment experience, we determined significant energy output at selected sites, showing annual energy production per installed capacity like traditional wind. The exploitation of high-altitude (200 $\mathrm{m}$ and higher) winds is strongly dependent on and influenced by technology-archetype-driven design constraints, such as the experience or avoidance of high-tether drag and power-to-weight ratios.

The technical airborne wind energy potential in the Unites States considering social, environmental, and licensing constraints is substantial. The analysis is critically dependent on per-unit installed capacity and tether length, which is directly related to the setback assumptions employed. For example, the rigid-wing, 500-kW AWE device with a 227-m tether length could yield 9,029 $\mathrm{GW}$ of technical potential, which is comparable to the 7,827 $\mathrm{GW}$ of technical potential for traditional land-based-wind technology. The absolute potential of airborne and traditional wind should not be interpreted as additive, as there is significant spatial overlap between the two estimates. The available and targeted wind resources of both traditional wind and airborne wind energy technology are vast, many times greater than the U.S. demand for electricity (Lopez et al. 2021; Musial et al. 2016). Technical potential for AWE and traditional wind occur in similar areas spatially and further investigation into where AWE may represent an increase in technical potential is recommended. The technical potential estimates are based on hypothetical, fully commercialized AWE technology, which are compared against traditional wind systems expected to be operational in the year 2030. To supplement the findings in this document, further research could investigate opportunities for AWE that might not be feasible for traditional wind and vice versa. The statements on resource potential and technical potential from the land-based considerations can be extrapolated to offshore environments.

A variety of markets have been identified for AWE technologies, ranging from early-adopter applications to microgrids, distributed wind, and offshore fixed or floating. The research and development challenges of AWE are similar in complexity to those in other precommercial renewable energy technologies, wherein a variety of technological solutions are under development and convergence has not been reached and would require a similar magnitude of dedicated investment to harvest the significant technical potential.

Based on the extensive stakeholder input gathered in the interviews and workshop mentioned earlier, and on our analyses and assessment of AWE systems, resource potential, technoeconomic potential, technical potential, and commercialization, we believe it is worth considering a 10-year research plan. 
The following research, development, demonstration, and commercialization recommendations outline a conceptual 10-year program to examine and validate the technical and economic viability of AWE technologies.

\section{Near-Term - Years 1 to 4: Initiate Fundamental Research and Craft a Plan for Commercialization}

- Develop a national AWE research, development, and flight research facility

- Facilitate collaboration among stakeholders to address airspace restrictions, radar impacts, device lighting, avian impact studies, and social perception

- Develop complete sets of functional requirements of AWE systems for diverse applications and markets to fully capture the problem and opportunity statements

- Support national and regional cost and feasibility studies

- Develop methods and tools to identify potential technology showstoppers and critical areas of attention and drive innovation

- Initiate fundamental research on critical issues regarding aerodynamics, controls, materials, siting, cost and feasibility drivers, environmental issues, reliability, safety, flight optimization, and social acceptance

- Attract global expertise and technology developers through accelerator programs

- Develop open-source, multifidelity simulation capabilities that model AWE systems

- Establish reference models for various AWE technologies and sizes

- Support hardware development of next-generation industry AWE systems

- Perform policy scenario development and evaluation to identify and facilitate the most effective research, development, demonstration, and deployment strategies along with related assistance and support mechanisms

- Coordinate aspects of the AWE research development agenda with the new International Energy Agency Wind task on AWE.

\section{Midterm - Years 3 to 10: Evaluation Campaigns and Research To Accelerate Technology Development}

- Foster industry engagement by funding industry research and development, supporting the use of new simulation capabilities, and providing a research facility site with space, instrumentation, and expert personnel to get flying time on prototypes and precommercial systems

- Establish an international working group to develop international design requirements to ensure the integrity of the promising AWE technologies.

\section{Long Term - Years 6 to 10: Technology Advancement and Fundamental Research}

- Select the most promising concepts for long-term reliability evaluation at the national research facility to prove system durability

- Fund development of demonstration projects in commercial early-adopter markets, like remote communities, agriculture, microgrids, and progressive utilities 
- Continue fundamental research on aerodynamics, controls, materials, siting, cost and feasibility drivers, environmental issues, reliability, safety, flight optimization, and social acceptance. 


\section{Table of Contents}

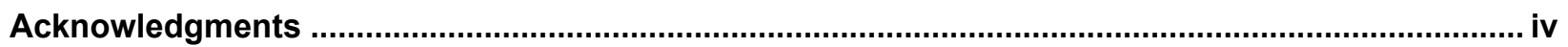

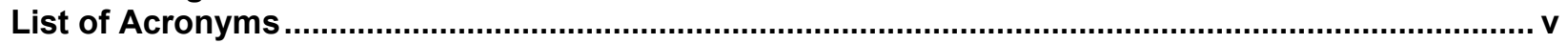

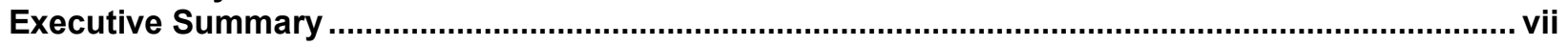

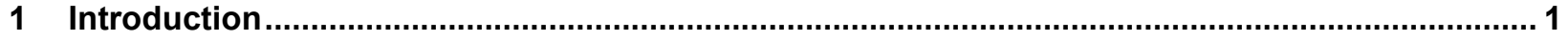

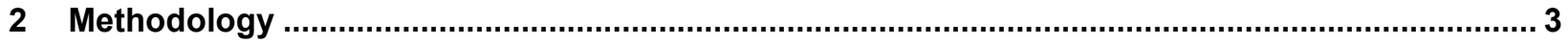

2.1 Addressing the Congressional Request: Focus and Scope ..................................................... 3

2.2 Relationship to Traditional Wind Energy .............................................................................. 4

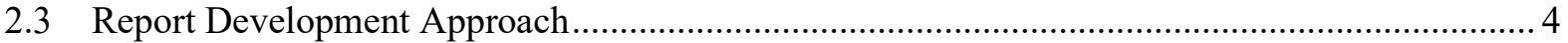

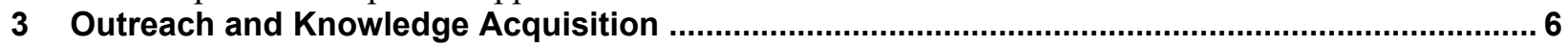

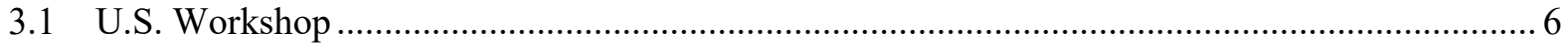

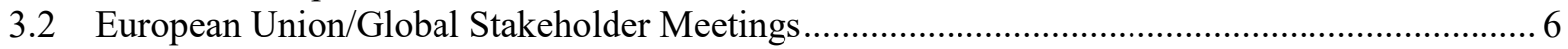

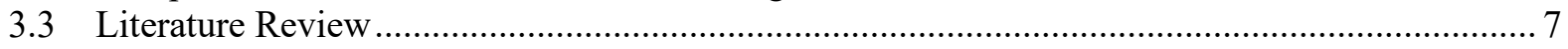

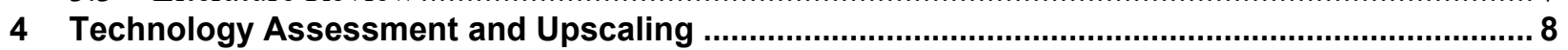

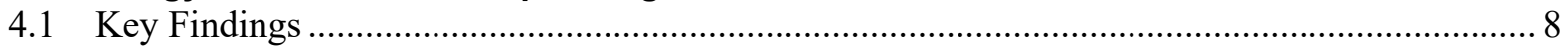

4.2 Background in AWE Technology and Upscaling ............................................................ 9

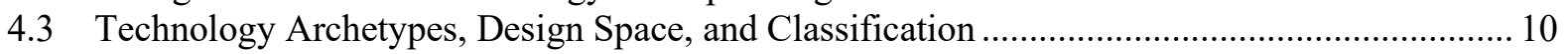

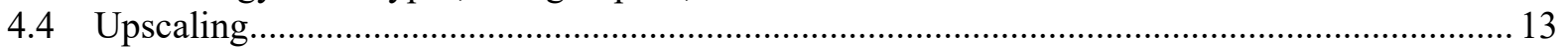

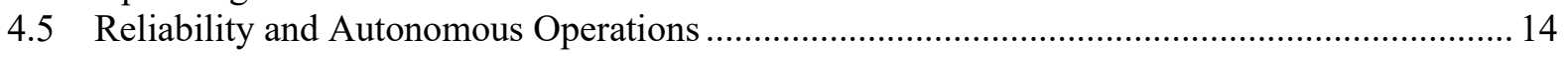

4.6 AWE Technology Characteristics and Relationship to Traditional Wind Energy ..................... 15

4.7 AWE Technology Development - Sector Status ........................................................... 17

4.8 Conclusions on Technology Assessment and Upscaling .................................................. 20

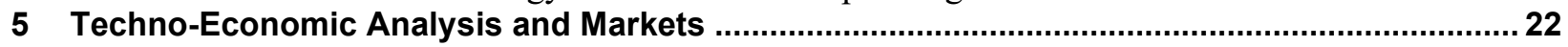

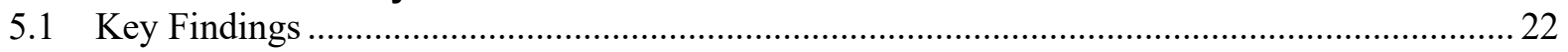

5.2 Background in AWE Techno-Economic Assessment and Markets ......................................... 23

5.3 Definition of Potential AWE System Characteristics ......................................................... 24

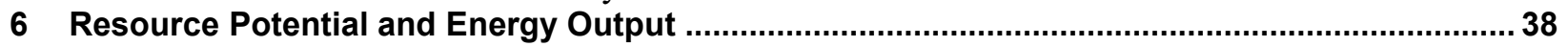

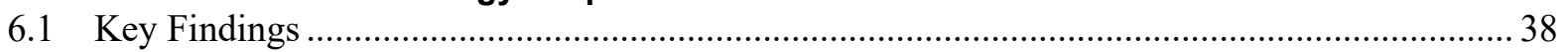

6.2 Introduction to AWE Resource Potential and Energy Output.............................................. 38

6.3 Airborne Wind Energy Potential Worldwide ............................................................................... 39

6.4 Wind Shear and Airborne Wind Energy Resource in the United States ................................... 40

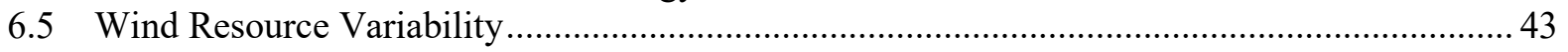

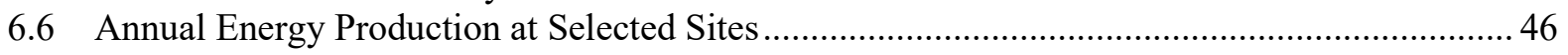

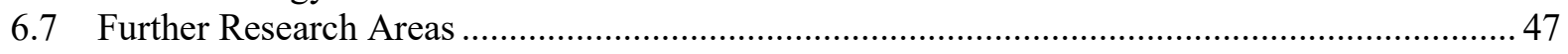

6.8 Conclusion on Resource Potential and Energy Output ....................................................... 48

7 Technical Potential, Social and Environmental Considerations, and Permitting ....................... 49

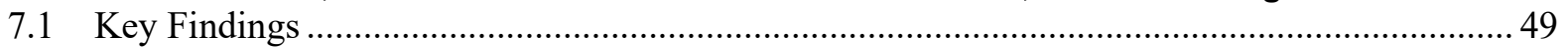

7.2 Background in AWE Technical Potential, Social and Environmental Considerations, and

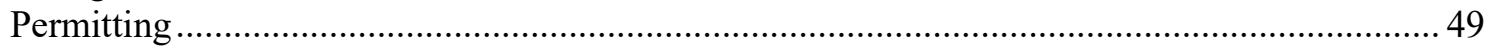

7.3 Environmental and Ecological Siting Considerations ...................................................... 51

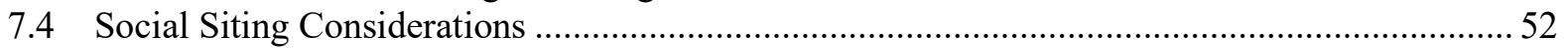

7.5 Department of Defense, Radar, and Federal Aviation Administration Siting Considerations .... 52

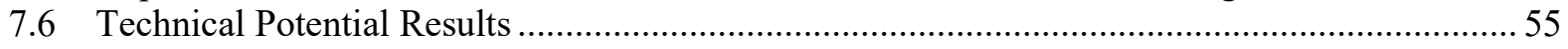

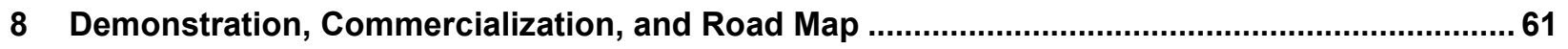

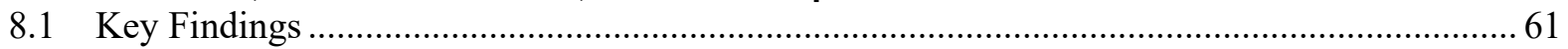

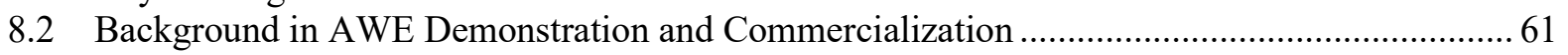

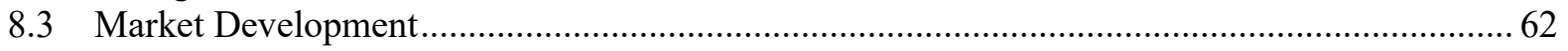

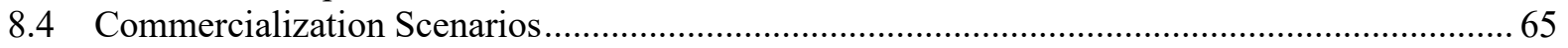

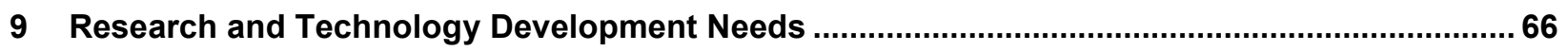

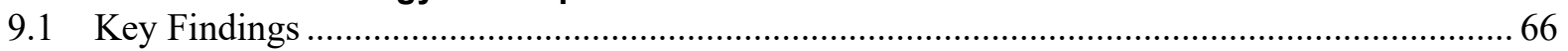

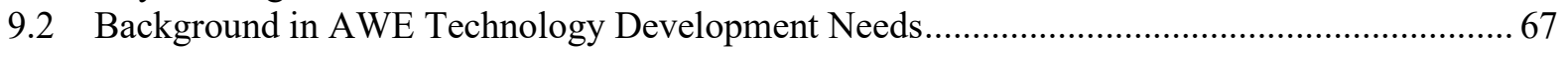




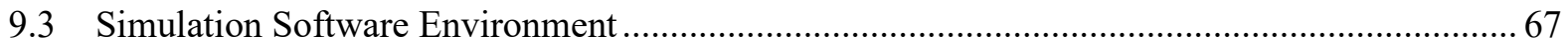

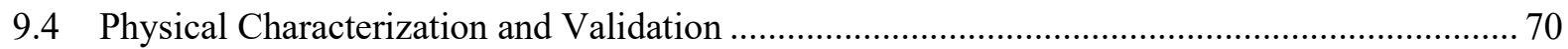

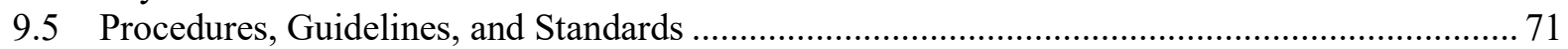

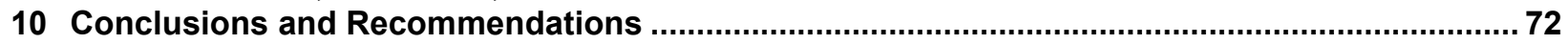

Years 1 to 4: Initiate Fundamental Research and Craft a Plan for Commercialization ...................... 73

Years 3 to 10: Evaluation Campaigns and Research to Accelerate Technology Development ............ 74

Years 6 to 10: Technology Advancement and Fundamental Research .......................................... 74

\section{List of Figures}

Figure 1. Report development approach, starting at the bottom and moving up............................ 5

Figure 2. Global R\&D landscape. Image courtesy of Roland Schmehl .............................................. 7

Figure 3. AWE U.S. stakeholder map. Image created by John FrenzI, NREL ................................. 7

Figure 4. Operational principles of fly-gen (left) and ground-gen (right) crosswind AWE systems in an offshore setting. Images created by Besiki Kazaishvili, NREL ........................................... 10

Figure 5. AWE system prototypes currently under development (in flight). Images based on

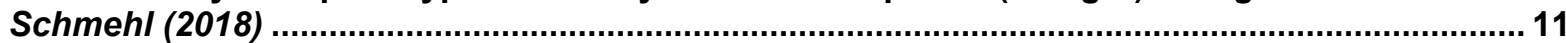

Figure 6. Classification of traditional AWE technology archetypes investigated based on Faggiani and Schmehl (2018), Echeverri et al. (2020), Eijkelhof et al. (2020), and Vimalakanthan et al. (2018) Note: GS = ground station ............................................................................................. 12

Figure 7. Technology readiness levels (TRLs) and technology performance levels (TPLs) of the main technology development status groups (left) across the global AWE sector................... 18

Figure 8. Target power curves for commercial-scale AWE systems in 2030. The NREL 5-MW reference wind turbine (RWT; traditional) power curve is also shown.

Figure 9. Breakeven CapEx in $\$ / \mathrm{kW}$ for a 5-MW (top) and 500-kW (bottom) rigid-wing AWE system deployed throughout the United States. Lower values of breakeven CapEx indicate a more stringent target for AWE to be cost competitive with the ATB 5-MW reference traditional wind turbine. Spatial maps of the breakeven CapEx data points are shown on the right..................30

Figure 10. Breakeven CapEx component breakdown for a 5-MW rigid wing (top left), a 500-kW rigid wing (top right), and a 500-kW flexible wing (bottom) .................................................................. 32

Figure 11. Sensitivity of breakeven CapEx to a range of low, mid, and high OpEx values for a 5-MW rigid wing (left) and a 500-kW rigid wing (right). Mid-OpEx corresponds to the ATB 5-MW traditional wind turbine value of $\$ 39.0 / \mathrm{kW} / \mathrm{yr}$, low OpEx corresponds to an optimistic scenario of $50 \%$ lower costs $(\$ 19.5 \mathrm{~kW} / \mathrm{yr})$, and high OpEx corresponds to a conservative value of $50 \%$ higher costs $(\$ 58.4 / \mathrm{kW} / \mathrm{yr})$.

Figure 12. (left) Maximum wind speeds between $100 \mathrm{~m}$ and $500 \mathrm{~m}$ averaged over 20 years (20002020) and (right) 20-year differences between $500-\mathrm{m}$ and $100-\mathrm{m}$ wind speeds from NREL's WRF simulations (top row) over Hawaii, (middle row) the Pacific Northwest, and (bottom row) the mid-Atlantic Coast. The green symbols denote locations at which wind profiles were extracted and the annual energy production and gross capacity factor calculated................... 41

Figure 13. 20-year average wind speed profiles at selected points shown in the difference maps in Figure 10 from NREL's offshore WRF simulations. (Left) over the Pacific Northwest, (right) over Hawaii, and (bottom) over the Atlantic.

Figure 14. (left) Simulated wind speed profiles at four locations in the WRF modeling domain over the central United States. (right) Difference between wind speeds $[\mathrm{m} / \mathrm{s}]$ at $500 \mathrm{~m}$ and $100 \mathrm{~m}$ over the modeling domain on June 1, 2018, at 0600 UTC. The symbols denote locations at which wind speed profiles are taken.

Figure 15. (left) Histogram of simulated wind speed differences from one hour to the next over 20 years at latitude 18.9 and longitude -155.7 (Hawaii, offshore) (right) average hourly wind speed differences as a function of month and time of day [UTC] at latitude $\mathbf{4 0 . 8}$ and longitude $\mathbf{- 7 2 . 1}$ (mid-Atlantic, offshore).

Figure 16. Maximum simulated wind speeds between 80 and $400 \mathrm{~m}$ and at $100 \mathrm{~m}$ as a function of month and time of day at latitude 21.2 and longitude -157.1 (Hawaii, offshore)......................... 44

Figure 17. Maximum simulated wind speeds between 80 and $400 \mathrm{~m}$ and at $100 \mathrm{~m}$ as a function of 
month and time of day at latitude 39.5 and longitude -74.1 (mid-Atlantic, offshore)

Figure 18. Maximum simulated wind speeds between 80 and $400 \mathrm{~m}$ and at $100 \mathrm{~m}$ as a function of month and time of day at latitude 42.8 and longitude -124.8 (Pacific Northwest, offshore)....... 45

Figure 19. Maximum simulated wind speeds between 80 and $400 \mathrm{~m}$ and at $100 \mathrm{~m}$ as a function of month and time of day at latitude 47.7 and longitude -124.7 (Pacific Northwest, offshore)....... 45

Figure 20. (left) AEP estimates and (right) gross capacity factor (averaged over 20 years) for selected locations over land (Figure 12). The calculations assume $100 \%$ availability. (GWh $=$ gigawatt-hour[s])

Figure 21. (top) AEP estimates and (bottom) gross capacity factor (averaged over 20 years) for selected locations offshore (indicated by longitude/latitude, see Figure 12). The calculations assume $100 \%$ availability.

Figure 22. Renewable energy potential. Image from Brown et al. (2016)...

Figure 23. Low-level military flight paths. Image from the Military Aviation and Installation, Assurance Siting Clearing House.

Figure 24. Four maps demonstrating the influences of tether length and setback on developable areas. Blue represents developable areas for AWE: a) all exclusions except setbacks, b) all exclusions plus a $250-\mathrm{m}$ setback requirement, c) all exclusions plus a $750-\mathrm{m}$ setback, and d) all exclusions plus a $1,250-\mathrm{m}$ setback requirement.

Figure 25. Developable areas for AWE considering all exclusions and a $750-\mathrm{m}$ setback requirement from civil infrastructure....

Figure 26. Capacity (left) and capacity factor (right) maps for select AWE technologies

Figure 27. Funding needs increase and risks (perceived and real) decrease as prototype evaluation advances to demonstrations, but a "valley of death" gap exists, wherein funding needs and perceived risk by investors is also high. Image from Petrick (2018)

Figure 28. The sequence and types of financial support mechanisms used to support a potential AWE industry. Image from Zillmann (2020)

\section{List of Tables}

Table 1. Conceptual Design Attributes and Variants To Determine the Design Space and Possible Combinations of Concept and Design Options (includes input from Brabeck [2021], Kruijff [2021], Peschel [2021], Harklau [2021], Ippolito [2021], and Isensee [2021]) ............................ 13

Table 2. Wing and Flight Properties for Rigid and Flexible Wings at 5-MW and 500-kW Rated Power

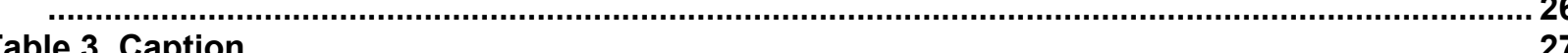

Table 4. Cost Estimates From Literature for AWE Systems and Traditional Wind Energy Systems in 2030.

Table 5. How the Breakeven CapEx Is Distributed Among Different Cost Categories Based on LCOE Models for Rigid Wings.

Table 6. Siting Restrictions for AWE Technical Potential Estimation ............................................... 55

Table 7. Technical Potential Results for Modeled AWE Technologies with Varying Tether Lengths 


\section{Introduction}

The concept of airborne wind energy (AWE) conversion—whereby tethered flying devices are used to convert wind energy into electricity — was first investigated and originally formulated through theoretical modeling (Loyd 1980). Since then, a wide variety of technology concepts, operational principles, and designs have been considered and technology development efforts have strongly increased in intensity over the last two decades. The main developments have been primarily in Europe, across a multitude of technology developers (Bechtle and Zilmann 2021; Cherubini et al. 2015) and in the United States, with the flagship development by Makani (Echeverri 2020) that ended in early 2020 when Alphabet discontinued support.

These five topics provided a framework for the research performed for this report:

- Technology assessment and upscaling addresses airborne wind energy technology systems across technology archetypes including concept of operations, design space, flight, structure, power conversion chain, takeoff, and landing and considers the state of the art as well as challenges and opportunities for upscaling the various systems to deliver significant energy.

- Techno-economic analysis and markets considers the cost, logistics, and supply-chain considerations for a future, commercial-scale AWE system to identify market share opportunities. The relative benefits and drawbacks of a mature AWE system are compared with expected characteristics of traditional land-based and offshore wind systems for megawatt-scale machines and hundred-megawatt-scale projects. Comparing AWE to traditional wind and offshore wind systems requires defining a representative full-scale AWE system, which draws from the technical potential and technology assessment analyses within this project, as well as from the existing AWE literature and conversations with industry experts.

- Resource potential and energy output estimates the wind resource across the United States based on existing literature, over land and offshore, and at altitudes viable for AWE. In addition, this topic considers whether the AWE resource is overlapping or complementary to traditional wind, whether AWE would impact climate, and the estimated impact of wakes from AWE devices, which ultimately provide an estimated potential energy output.

- Technical potential, social and environmental impacts, and permitting explores the siting opportunities and challenges for AWE regarding social and environmental considerations. In addition, this topic explores the land-use requirements of different AWE technologies These siting considerations led to the development of possible siting restrictions and land-use/ocean requirements. Assumptions developed in this area, combined with the resource potential and technology assessments, were used to estimate the overall technical potential of airborne wind energy systems effectively, as well as the quantity (megawatts [MW]) and quality (megawatt-hours [MWh]) of available wind resource for AWE development. 
- Research, development, demonstration, and commercialization needs addresses potential pathways for commercializing AWE, from demonstration to scaled concepts, and for both land-based and offshore AWE applications. This topic covers the potential overlap of AWE and traditional wind turbines, and it identifies opportunities for developing AWE technologies in locations where traditional wind turbines may not apply. It also covers recommendations for future research, potential approaches for AWE technology development and demonstration, and commercialization approaches. 


\section{Methodology}

This section briefly describes the way in which this report addresses the congressional request regarding focus and scope, the consideration of AWE in relation to traditional wind energy, and the approach taken to develop the report.

\subsection{Addressing the Congressional Request: Focus and Scope}

This report describes technical analyses of various aspects of AWE provided to the U.S. Department of Energy (DOE) Wind Energy Technologies Office to underpin DOE's response to the congressional request for a report on AWE in the Energy Act of 2020, which states:

"(i) IN GENERAL. - Not later than 180 days after the date of the enactment of this Act, the Secretary shall submit to the Committee on Science, Space, and Technology of the House of Representatives and the Committee on Energy and Natural Resources of the Senate a report on the potential for, and technical viability of, airborne wind energy systems to provide a significant source of energy in the United States.

(ii) CONTENTS. - The report under paragraph (1) shall include a summary of research, development, demonstration, and commercialization needs, including an estimate of Federal funding requirements, to further examine and validate the technical and economic viability of airborne wind energy concepts over the 10-year period beginning on the date of the enactment of this Act."

To support DOE's response to the congressional request for a report on AWE, the National Renewable Energy Laboratory (NREL) performed basic analyses, primarily in the areas of resource potential and energy output, technical potential based on the resource potential and estimates of siting constraints, and techno-economic analysis based on the technological potential and technology assessments. Expectations of demonstration requirements and paths to commercialization are also provided.

Thus, it is important that the assessments aim to identify the knowns and the known unknowns, and a high-level understanding of both, and point to the unknowns regarding the challenges and opportunities.

Given the level of research and technology developments underway globally, the diversity of considered and possible AWE system archetypes, and the specific characteristics of this technology field, the findings of this report may not be final. They do, however, provide an increased understanding of the potential that AWE can contribute to the U.S. energy mix, its growth, and its significant transformation. 


\subsection{Relationship to Traditional Wind Energy}

By using wind as its energy source, AWE may appear, at first glance, to be in direct competition with traditional wind energy technology (defined as wind turbines built on towers. To assess if this assumption is valid or could reduce the scope of the value proposition associated with AWE, this study aims to address the following questions when reflecting upon the congressional request:

Is AWE in direct competition with traditional wind energy? Influencing factors may include:

- Desired access to identical and mutually exclusive installation locations

- Significant direct or secondary technology cost implications, such as raw material consumption

- Strongly different cost implications on foundations and support structures (such as in offshore floating wind), respectively, or other reasons to be identified.

Is AWE complementary to traditional wind energy? Influencing factors may include:

- Temporal characteristics of the wind resource

- Capacity-factor-related characteristics of either technology

- Possibilities of co-location, with levels of system integration, or other reasons to be identified.

Is AWE independent of and thus supplementary to traditional wind energy? Influencing factors may include:

- Capability to access different wind resources. Reasons may be associated with location, level of resource intensity, and inherent access to resource at different heights above ground

- Type of markets and applications targeted (e.g., microgrid, distributed wind, deployment speed, plant operational duration, adaptability, visual impact, social benefit)

- Independent supply chains or other reasons to be identified.

\subsection{Report Development Approach}

To begin the study, NREL performed a literature review and reviewed the publications. The team led and participated in a 2-day workshop that included presentations, a panel discussion, and breakout group discussions covering the following topics, as described in Section 3:

- Resource potential and energy output

- Technical potential, social and environmental impacts, and permitting

- Techno-economic analysis and markets

- Technology assessment and upscaling

- Research and development (R\&D), demonstration, and commercialization needs.

In addition, the NREL team performed baseline analyses in resource potential, technical potential, and techno-economic potential. Furthermore, we conducted individual meetings with experts from industry and academia, including AWE technology developers to gather information on the range of technology types under development and the sector status and needs. 
Figure 1 illustrates the fundamental approach we took to develop the report. The core topics of resource, markets, technology, and R\&D activities are common threads and considered in all phases of the report development, from outreach and knowledge acquisition to scientific assessment and recommendations.

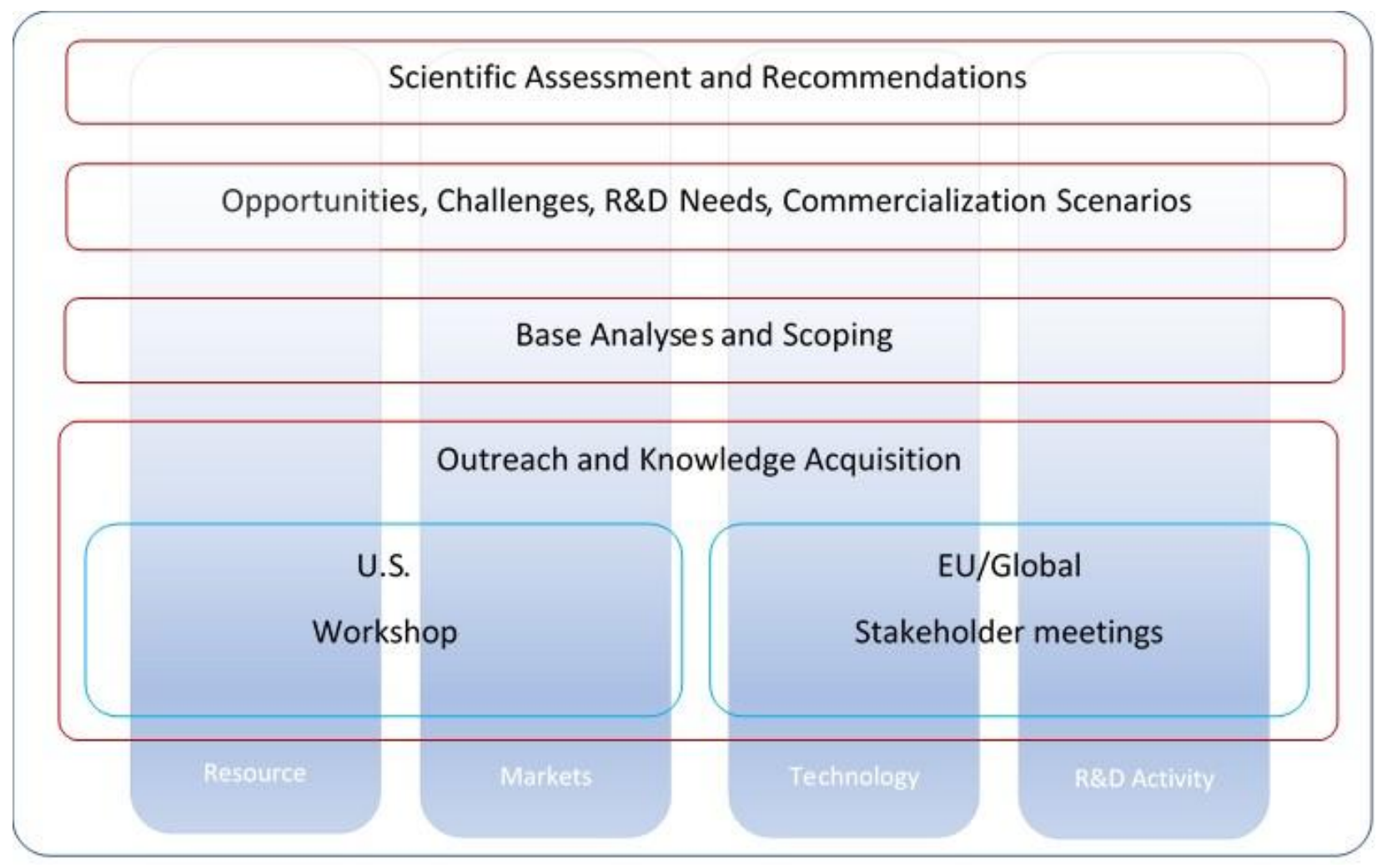

Figure 1. Report development approach, starting at the bottom and moving up

Note: EU is the European Union 


\section{Outreach and Knowledge Acquisition}

\subsection{U.S. Workshop}

The workshop (Weber et al. 2021) focused on U.S. stakeholders in AWE, with approximately 100 experts from AWE technology developers, operators, engineering or consulting firms, governmental organizations, national laboratories, and universities. The event began with an explanation from the Wind Energy Technologies Office regarding the context and purpose of the workshop, including the report to Congress noted earlier. Next, three presentations provided overviews of the AWE workshop held in September 2020 by the International Energy Agency (IEA) Wind Task 11 (Hayek 2020), European AWE R\&D efforts, and U.S. R\&D efforts, respectively. In addition, five panelists discussed a variety of AWE aspects including markets, systems, technology deployment status challenges, opportunities, and needs. The second day was devoted to two sessions of five parallel breakout groups to discuss the five themes described in Section 3. Outcomes from each of the breakout group discussions were summarized and published in the workshop proceedings (Weber et al. 2021).

\subsection{European Union/Global Stakeholder Meetings}

Separate from the workshop, we reached out to over 50 stakeholders and met with 14 different technology developers (four from the United States and 10 from the European Union [EU]) including Abound, Ampyx Power, Enerkite, eWindSolutions, KiteGen, KiteKraft, Kitemill, KitePower, kPower, Makani (former), Saipem, Skypull, Skysails, and Windlift.

With a focus on gathering input for the congressional request, the main agenda covered:

- Key characteristics of each developer's technology

- Targeted markets and intended rollout

- Technology development status regarding technological readiness level and technoeconomic performance

- Status and challenge of the sector

- R\&D needs such as capabilities, tools, and infrastructure

- Suitable support types and mechanisms.

Additionally, we engaged with a small number of academic research entities in the United States and Europe including the Delft University of Technology, NC State University, and University of Delaware.

Currently, the global AWE research and development community spans about 70 players from industry, academia, and governmental research entities, as shown in Figure 2. An updated map of AWE stakeholders based in the United States is shown in Figure 3. 


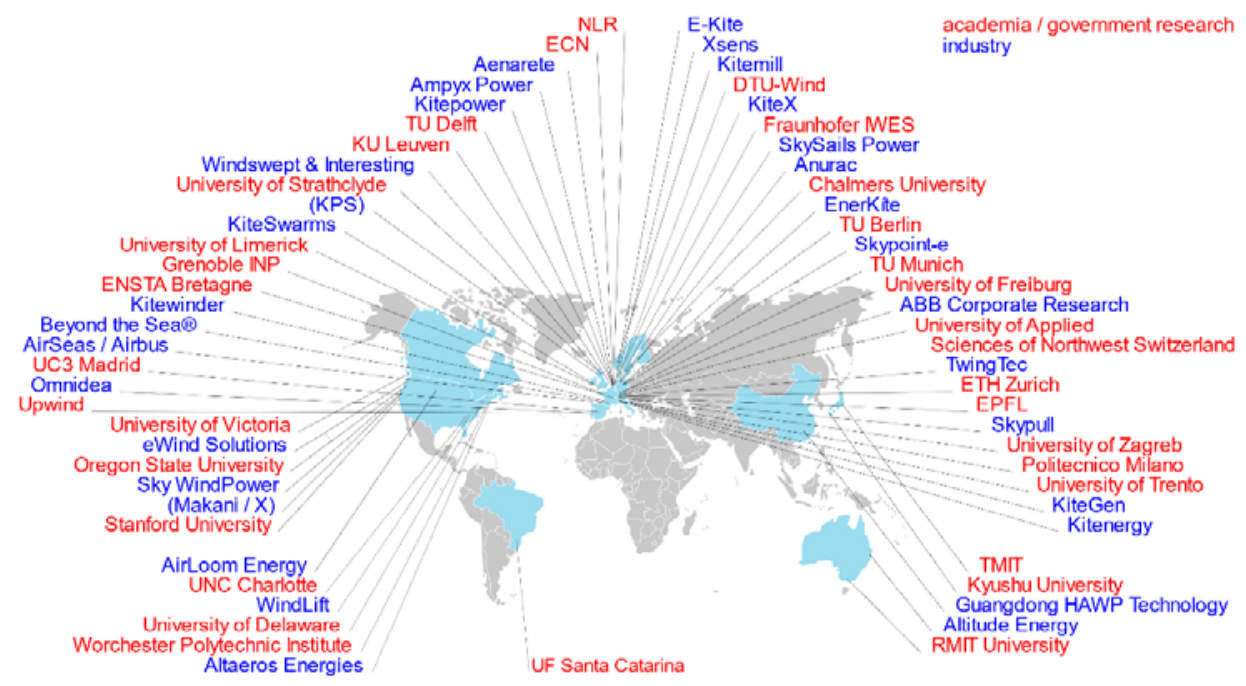

Figure 1. Global R\&D landscape. Image courtesy of Roland SchmehI

\section{U.S. Organizations with Demonstrated Interest in AWE}

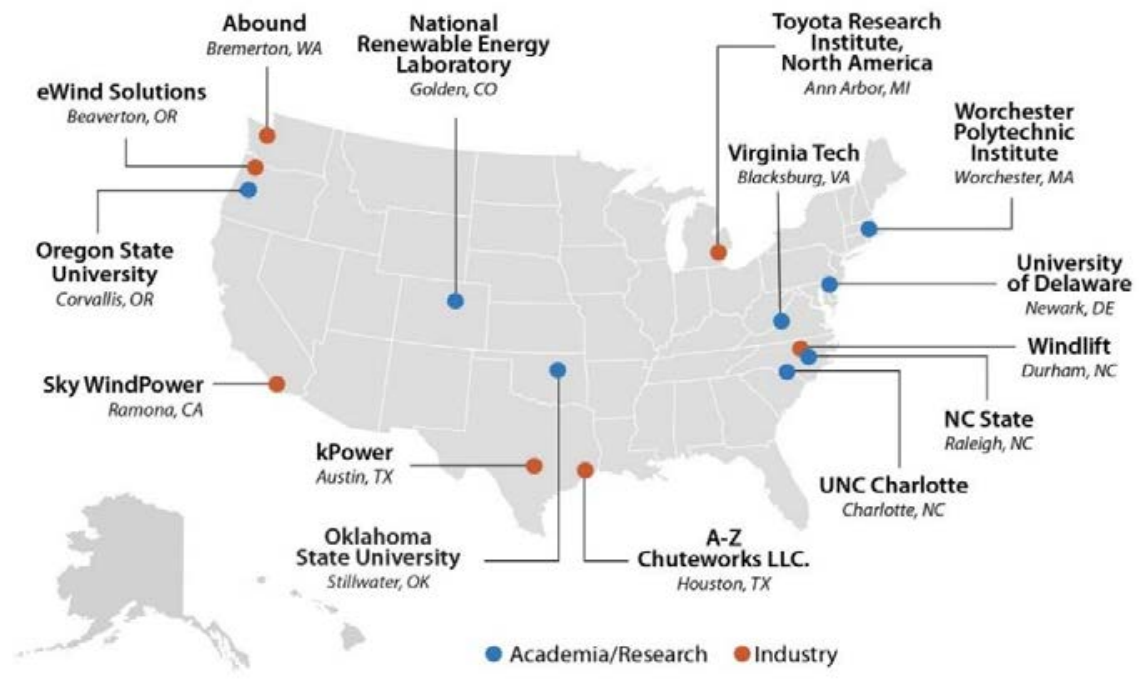

Figure 3. AWE U.S. stakeholder map. Image created by John Frenzl, NREL

Note: for additional entries, please contact the authors to update

\subsection{Literature Review}

NREL performed literature reviews on AWE. They used the Zotero online reference management tool to hold 238 publications that the team used. Further, publications for each of the five subtopics listed in the executive summary, as well as publications about AWE more generally, were collected and used by the team. This extensive literature overview was valuable to gain insight and understanding into the field; however, only a portion of key publications is directly referenced in this report. 


\section{Technology Assessment and Upscaling}

In this section, we provide a high-level perspective on the status of AWE technology development and its potential to become a viable and commercially deployed contributor to renewable energy. The emphasis here will be on the sector, rather than individual technologies. Next, we present an overview of technology archetypes and the design space followed by technology assessment criteria and status of technology with respect to techno-economic potential and technology readiness. Consideration on upscaling, reliability, autonomous flight, and specific AWE characteristics are offered before overall conclusions are drawn. This work is based on the U.S. Airborne Wind Energy Workshop, several EU and global stakeholder and industry meetings, literature study, and analysis.

\subsection{Key Findings}

Key findings in AWE technology assessment and upscaling include the following:

- Airborne wind energy technology developers are pursuing a wide variety of functional and operational concepts and design approaches. Overall, the sector has not converged to a single concept approach, which is normal when developing new, complex technology and at this precommercial stage of the industry. Based on available information, we conclude that the design space has not been fully explored or examined sufficiently.

- Over the last two decades of intensified technology development globally, some design approaches have been identified as less promising and are no longer worth pursuing, such as aerostats. Several technology developments can be categorized around a set of similar concepts with varying embodiments and realization of key functional requirements.

- The prevailing technology development branches focus on fundamental working principles and design choices, such as:

- Fly-gen, with electricity generation in the air aboard the airborne subsystem, or ground-gen, with electricity generation on the ground

○ Rigid-wing or soft-wing designs and variations thereof

$\circ$ Methods of takeoff and landing.

- The AWE technology development sector is targeting a wide range of markets, from remote microgrids and distributed wind to large-scale, land-based, fixed, and floating offshore applications with differing requirements regarding automation, reliability, durability, scale, and economics. Specifically:

- Some technology developments targeting early-adopter markets, such as island communities, have partly reached intermediate technology readiness with one developer having shipped its first commercially sold units to pilot projects this year (Brabeck 2021).

- Individual technology developments targeting large-scale power markets have partly reached high levels of sophistication yet are further away from potential market entry regarding technology readiness and meeting demanding technoeconomic requirements. 
- Overall, the AWE sector needs to advance significantly with respect to:

- Automation in all operational modes and design conditions

○ Reliability and durability supporting system availability

○ Techno-economic performance at scale.

The efforts outlined in the previous bullets will require large dedicated additional effort and time and can be supported through valuable learning and maturation in early-adopter market operations.

\subsection{Background in AWE Technology and Upscaling}

This section provides information on the background and context of assessing AWE technology and factors in scaling up the technology.

\section{Research Questions and Challenges}

The following key questions are critical in the advancement of AWE technology development:

- How can an airborne wind energy system be assessed against sectorwide, market-specific functional requirements to achieve greater technology convergence, and how can AWE progress on time-, cost-, and risk-effective technology development trajectories toward market entry?

- How can the required levels of long-term continuous operation, covering all operational modes, be achieved to gain significant operational experience and trigger the onset of learning curves with respect to system reliability and economics?

- How can airborne wind energy technology best be scaled up to achieve significant contributions to the U.S. energy system? What is the role and importance of a) upscaling AWE unit size and capacity, b) upscaling by airborne unit number and topological density, and c) achieving higher degrees of system integration of multiple airborne units?

\section{Methods and Tools Needed}

For AWE to advance, the following efforts need to be fulfilled:

- Combining a) experimental research and operation, both exploratory as well as long-term operation covering all control states and modes of operation with $b$ ) numerical simulation for design and optimization along with subsystem and holistic integrated system technology assessments

- Enabling fast-turnaround prototype characterization and long-term pilot project operation and validation infrastructure in dedicated research facilities and early caretaking pilot projects in combination with extensive knowledge sharing across the industry

- Developing internationally agreed-upon reference systems to serve as a common basis for comparison, along with achieving consensus on key performance indicators and establishing methods that allow for complete system assessment methods. 


\subsection{Technology Archetypes, Design Space, and Classification}

AWE systems can be classified into two basic approaches: fly-gen and ground-gen, defined here (shown in Figure 4 in an offshore setting):

- Fly-gen AWE systems fly onboard turbine-generator units that are connected to an airframe along figure-eight or circular crosswind trajectories defined by the tether length. Electricity is generated onboard the kite. The onboard-generated electrical power is transmitted to the ground station through a conductor in the tether. The system is designed to achieve high relative velocity on the flying wind turbines.

- Ground-gen AWE systems generate electricity by flying in figure-eight or circular crosswind trajectories while spiraling upward and reeling out the tether that connects the kite to a winch-generator unit on the ground station. Electricity is generated on the ground. Once the kite reaches its maximum operational altitude, it is retracted, and the tether is reeled in. The system is designed to achieve high lift on the wing for maximum mechanical power transmitted through the tether.
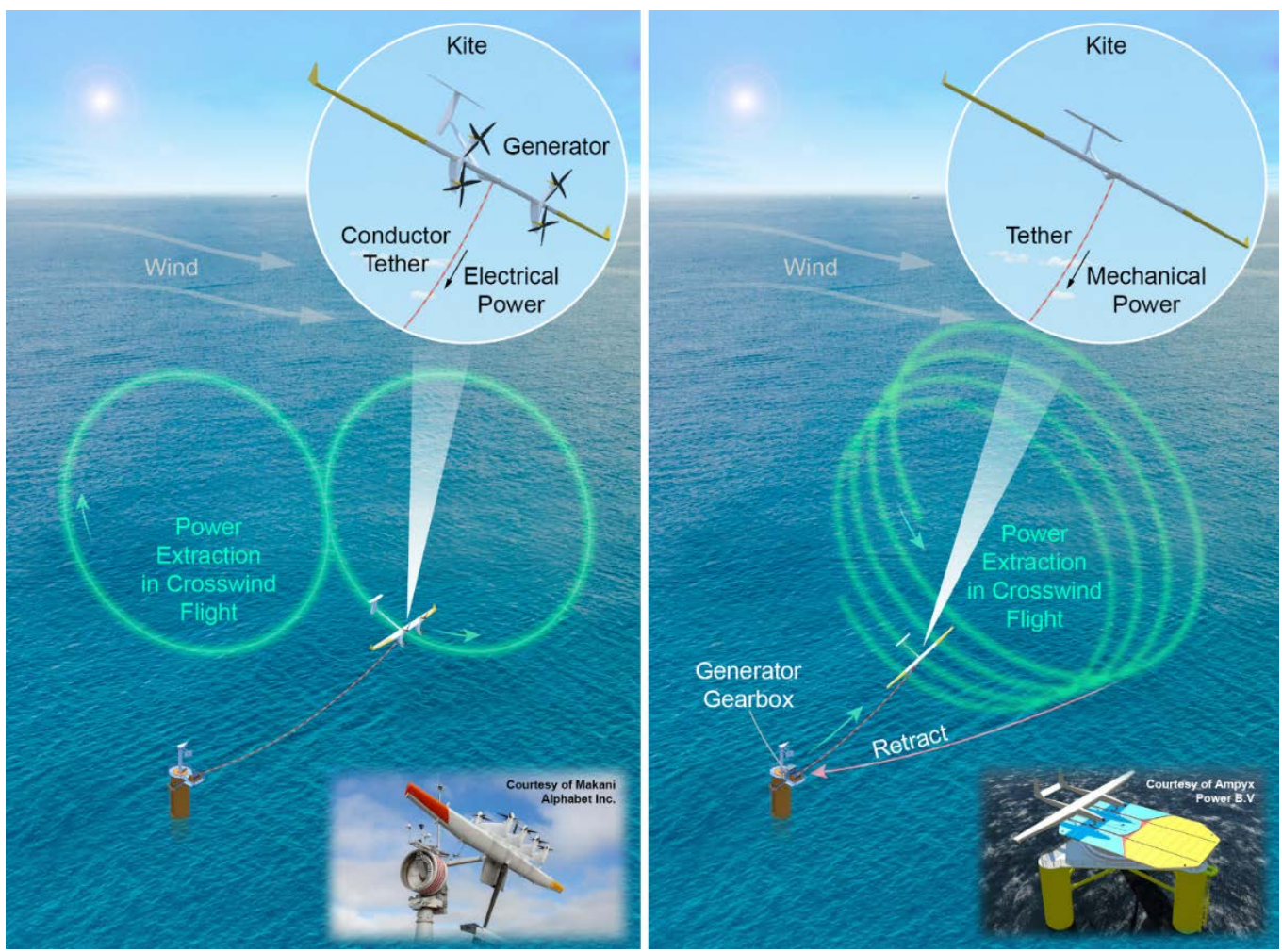

Figure 4. Operational principles of fly-gen (left) and ground-gen (right) crosswind AWE systems in an offshore setting. Images created by Besiki Kazaishvili, NREL

The range of designs and approaches used to implement AWE systems extends well beyond the simplified description of these two fundamental concepts. Figure 5 shows AWE prototypes in flight — a subset of the technologies that are currently under development. 


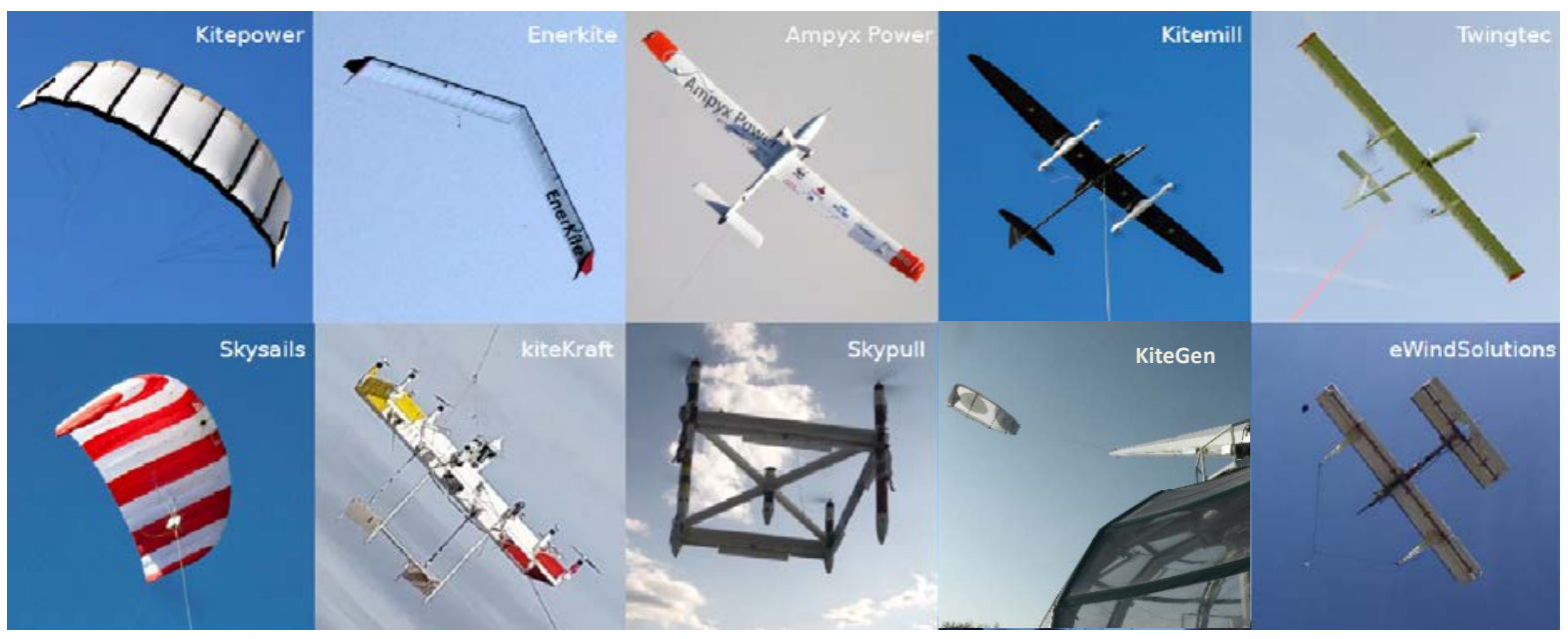

Figure 5. AWE system prototypes currently under development (in flight). Images based on Schmehl (2018)

Because AWE is aiming for deployment in a variety of markets and applications, many technology approaches, concepts of operation, and design are under consideration.

Figure 6 classifies AWE systems based on a sector overview from 2018 (Schmehl 2018). The first level of categories identifies where electrical generation takes place:

- Ground-gen: generation occurs at a ground station that is either fixed or mobile

- Fly-gen: generation occurs onboard the airborne system.

The second level of categories identifies groups with respect to flight operations:

- Crosswind: a flight path in crosswind with a large directional component that is perpendicular to the wind direction to increase relative velocity on the kite and swept harvesting area. The crosswind flight path may be implemented through flying reciprocating patterns, such as figure eights, or returning flight patterns, such as circles.

- Tether-aligned: a flight path that aligns with the tether direction, and which potentially reduces both the relevance to tether drag and the opportunity for area sweep.

- Rotational: a rotor-type system with a circular flight path of aerodynamically active kite elements.

Colors in Figure 6 indicate several additional design choices. Wings are categorized by their structural design as flexible (like parasail kites) or rigid (like traditional wind turbine blades or fixed-wing aircraft). Concepts are further classified with respect to takeoff and landing operations, distinguishing between vertical takeoff and landing and horizontal takeoff and landing. AWE concepts that are lighter than air make up an additional category. 


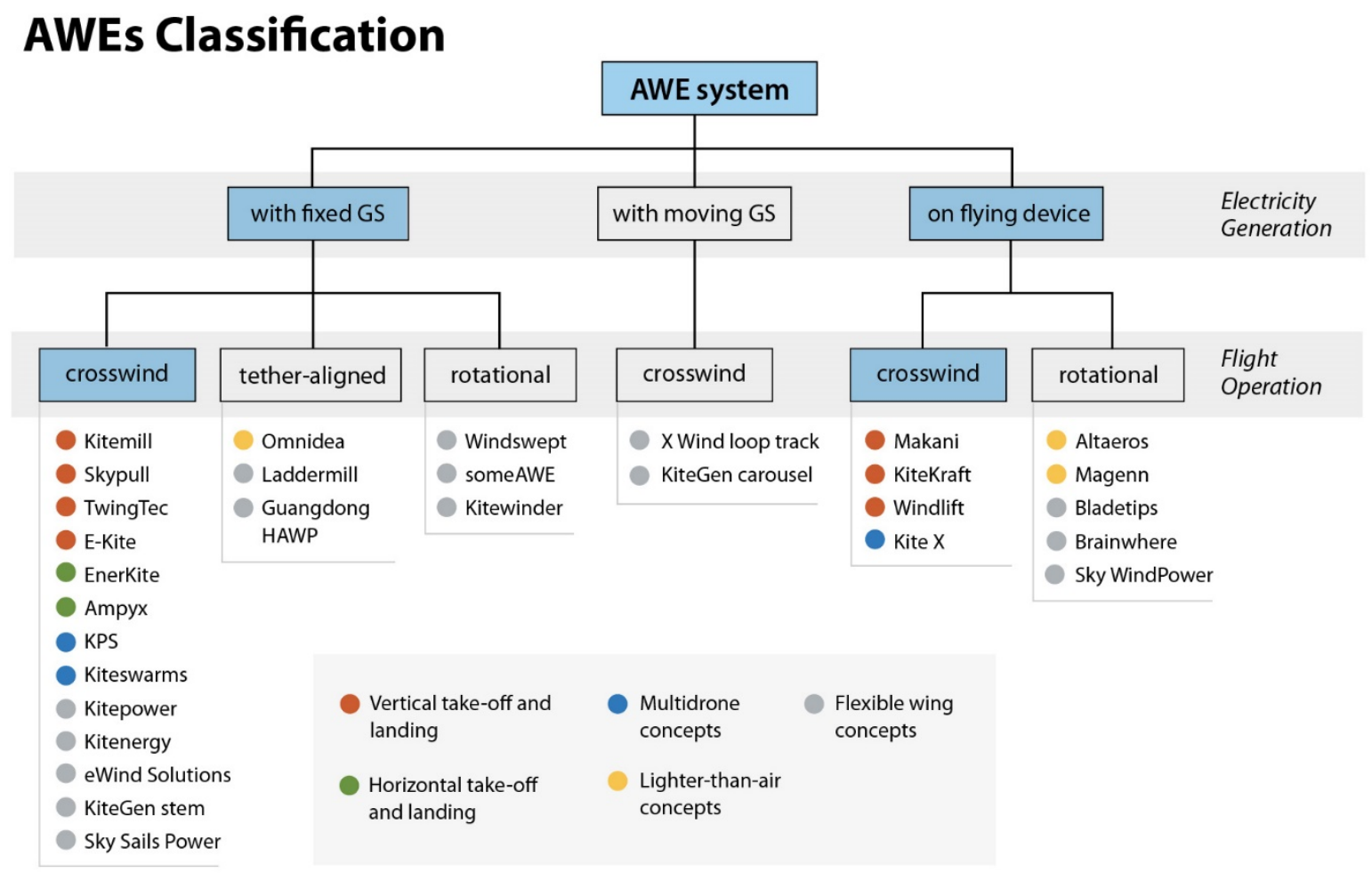

Figure 6. Classification of traditional AWE technology archetypes investigated based on Faggiani and Schmehl (2018), Echeverri et al. (2020), Eijkelhof et al. (2020), and Vimalakanthan et al. (2018). Image created by John Frenzl, NREL

Note: $\mathrm{GS}=$ ground station

Over the last two decades of global technology development, some AWE design approaches, such as lighter-than-air systems, have been identified as less promising and are no longer widely pursued.

Instead, the prevailing technology development branches are focusing on fundamental working principles such as fly-gen or ground-gen, and the fundamental flight dynamics, wing structure and wing designs, takeoff and landing methods. There are complexities in the air, on the ground, and various methods of scaling through unit size, number of units, spatial distribution, combined multisystem arrangements, and cluster density.

Airborne wind energy R\&D efforts have not converged to a single archetype and operational concept. The lack of convergence reflects the relative immaturity of the technology and may indicate uncertainty regarding the future success of the sector. At the same time, the diversity of design concepts provides ample opportunity for further improvement, as the sector is not locked into a confined design space. 
Even though a variety of concepts and related design implementations are being considered, it is also evident that the design space has not been explored fully enough to draw decisive conclusions on the probability of success of individual concepts within different market segments. To illustrate this, the classification criteria employed in Figure 6 have been extended in Table 1 by increasing the number of variants, adding new concept classification attributes, and identifying related design variants. This preliminary selection of technology concept attributes and design options is incomplete yet illuminates the size of the potential design space.

\section{Table 1. Conceptual Design Attributes and Variants to Determine the Design Space and Possible Combinations of Concept and Design Options (includes input from Brabeck [2021], Kruijff [2021], Peschel [2021], Harklau [2021], Ippolito [2021], and Isensee [2021])}

\begin{tabular}{|c|c|}
\hline Concept Attributes & Variants \\
\hline Electrical generation location & In flight, ground-based fixed, ground-based mobile, other \\
\hline Flight path & $\begin{array}{l}\text { Stationary, in tether direction, crosswind with unidirectional rotation, } \\
\text { crosswind with bidirectional rotation, other }\end{array}$ \\
\hline Wing structure & $\begin{array}{l}\text { Soft single layer, soft ram air multicell, soft with inflatable support, soft } \\
\text { with highly nonlinear elastic reinforcement, semirigid, segmented rigid, } \\
\text { rigid, multiwing, other }\end{array}$ \\
\hline Takeoff & $\begin{array}{l}\text { Vertical, horizontal, use of main aerodynamic system, use of ancillary } \\
\text { embedded aerodynamic system, centrifugal, catapult, lift system, } \\
\text { support system, fan, other }\end{array}$ \\
\hline Landing & $\begin{array}{l}\text { Vertical, horizontal, use of main aerodynamic system, use of auxiliary- } \\
\text { embedded, dedicated aerodynamic system, other }\end{array}$ \\
\hline Flight region & $\begin{array}{l}\text { Low (up to } 300 \text { meters }[\mathrm{m}] \text { ), medium ( } 300 \mathrm{~m} \text { to } 600 \mathrm{~m} \text { ), high (above } \\
600 \mathrm{~m} \text { ), combined, other }\end{array}$ \\
\hline Control & $\begin{array}{l}\text { Diverse active control surfaces: elevator, elevon, flap, wing } \\
\text { deformation; tension control; part passive, other }\end{array}$ \\
\hline Energy-conversion stages & Direct generation, mechanical, hydraulics, other \\
\hline Tether topology & Single, bridle, dual, multiple, other \\
\hline Kite topology & $\begin{array}{l}\text { Single, twin, rotor, staggered, combined (identical, varied), multiple, } \\
\text { network architectures, other }\end{array}$ \\
\hline Farm integration & Independent unity, staggered height levels, farm control, other \\
\hline Reference & Fixed, moving, single, multiple, absolute, relative, other \\
\hline Other attributes & Known, to be defined, other \\
\hline
\end{tabular}

\subsection{Upscaling}

One of the critical questions around the technological advancement of AWE is how to scale up, as stated in a recent publication: "The big issue right now in airborne wind energy is scaling" (Anderson 2019). In this context, scaling ultimately relates to the installed capacity. There are inherent scientific and engineering challenges associated with upscaling AWE technology, and these challenges vary depending on the application: fly-gen or ground-gen systems, soft or rigid wings, and overall system integration. Relevant physics and engineering relate to aspects such as tether drag, weight, tension, and fatigue; conductivity; wing loads; flight path; speed; and accelerations (Weber 2019). 
It is important to note that the requirements for upscaling installed capacity depend on the target market and application, and that upscaling may be measured in different ways. Three relevant metrics are:

- Installed capacity per unit

- Installed capacity per infrastructure

- Installed capacity per land or sea area.

Installed capacity per unit (or airborne device) is particularly relevant for AWE developers targeting utility-scale floating offshore wind farm deployment (Echeverri et al. 2020; Kruijff 2021). Maximizing the capacity in megawatts per device is critical to achieving economic viability because of the high per-unit cost of the balance of plant-including the floating substructure, mooring system, and subsea electrical cable - as well as offshore operation and maintenance $(O \& M)$. For floating offshore AWE applications, engineering design scaling analysis based on levelized cost of energy (LCOE) results in optimal device scaling between 7.5 and 15 MW per unit (Kruijff 2021). Successful upscaling of the capacity per unit will depend on fundamental physical similarity considerations for the power-to-mass ratio and most importantly, on determining achievable values through practical engineering design options (Santos 2021).

Concepts for upscaling of installed capacity per critical infrastructure focus on maximizing capacity at a single ground station, floating platform, and other balance-of-plant subsystems. Options under study or development include multikite system configurations using a common tether, and parallel single-layer or two-layer multikite layouts (De Schutter et al. 2019a, 2019b; Kiteswarms 2021). While increasing the complexity of control in operation and transitional states, such system architectures may also help reduce tether drag.

Upscaling of installed capacity per occupied area of land or sea may be implemented by staggering operational heights, thereby using AWE systems with a different tether length and inclination angles, and developing plantwide control strategies (Leuthold et al. 2017, 2018). Other concepts with higher levels of system integration have been proposed, such as rotarytorsion-based, multiwing, multilayer AWE systems (Beaupoil 2019; Read 2018; Tulloch et al. 2019) or branched tethers and large multitether kite networks (Santos 2021). Multikite system integration via a carousel-type system has also been proposed (Ippolito 2021).

In summary, upscaling is critical for grid-market applications and may be implemented by upscaling the unit capacity and through scaling by number of units or degree of system integration.

\subsection{Reliability and Autonomous Operations}

The need to advance and demonstrate system reliability and continuous long-term autonomous operation and control has been identified across the AWE sector (Fagiano 2019; Vermillion et al. 2021). As with many functional requirements, autonomous operation is required across all markets; however, at different levels of sophistication. The requirement is particularly acute for offshore AWE systems, which are highly capital- and maintenance-cost-intensive and demand the highest degree of reliability and automation to facilitate certification and long-term validation. While advancing though the precommercial development stages, developers concentrate on specific and narrow test objectives to demonstrate and validate equipment 
functionality and autonomous operation algorithms. Some systems require wind speeds of 3 to 5 meters per second $(\mathrm{m} / \mathrm{s})$ close to the surface for takeoff, whereas most AWE systems use a variety of active launch mechanisms (see Table 1). Individual flight times vary between minutes and hours and systems have performed several hundreds of operational flights (Kruijff 2021; Brabeck 2021; Harklau 2021). Individual developers have reported continuous operation over several days (Brabeck 2021; Bormann 2021). Although some developers have demonstrated autonomous flight and other critical automated functions including takeoff and landing of reduced-scale prototypes (Echeverri 2020; Brabeck 2021), achieving reliable, fully automated, long-term operation represents the most significant challenge for the industry.

Critical subsystems for functional, reliability, and durability testing and validation include power conversion units (Echeverri 2020), back-to-back tether spooling systems (Kruijff 2021), and structural maximum load and fatigue testing (Bormann 2021). SkySails Group developed, tested, validated, and commercially operated an airborne wind ship propulsion system with mechanical pulling power levels of up to $2 \mathrm{MW}$ and reported a total of over 3,000 hours of operation since the first demonstration at sea over 10 years ago (Brabeck 2021). This system does not include energy conversion to electricity; thus, it does not represent an integrated AWE system, but demonstrates the functionality of a key airborne subsystem in automated flight up to commercial readiness.

It is important to mention that fully autonomous operation is not a key requirement in many mini and microgrid applications (Zywietz 2019). In specific applications in which part-manual operation or system reset support is available - such as military operations, industrial microgrids, and remote installations - the requirement for autonomy may be somewhat softened, and criteria such as deployment transportation may dominate (Creighton 2021; Peschel 2021). Such applications could serve as early-adopter markets, providing opportunities for commercial operation of AWE systems that initiate learning curves for improving system reliability, durability, and efficiency. The electrification of significant energy markets, such as agriculture, could potentially be supported in single or hybrid energy source microgrids with AWE systems (Bormann 2021; Schaefer 2021) soon, with the first commercial 100-kilowatt (kW) systems being sold to pilot projects this year (Brabeck 2021).

\subsection{AWE Technology Characteristics and Relationship to Traditional Wind Energy}

Reflecting on the questions posed earlier on whether AWE technology can be regarded as (a) in direct competition with, (b) complementary to, or (c) independent of and thus additional to traditional wind, the following observations can be made with respect to AWE system characteristics:

- Temporal, local wind resource correlation. The temporal correlation of the wind resource targeted by traditional wind and by airborne wind technology in each location is not shown to be anticorrelated in a consistent manner (Bechtle 2019) and not of a complementary nature within the typical operational heights above ground. 
- Spatial resource access in height above ground. Traditional wind and airborne wind energy technology largely target and access the wind resource through airflows at various heights and across different height ranges, with potential overlap depending on technology concept. Most AWE technology developers target heights up to $800 \mathrm{~m}$ above ground (Brabeck 2021), with some developers targeting greater heights up to 2,000 m above ground (Ippolito 2021) and beyond (Calverley 2021).

- Spatial resource access in a location. Traditional wind and airborne wind energy technology may target and access different wind resource locations, which is driven by a variety of factors including minimal viable resource requirements (Schmehl 2021), transportation and deployment requirements (Creighton 2021), site access, farm design, and terrain complexity.

- Construction materials and processing. Traditional wind and airborne wind energy technology partly require a different raw material resource at significantly different amounts per installed capacity, with AWE requiring significantly less raw material (Schmehl 2021) estimates at around 20\% of what is required for traditional wind (Bormann 2021).

- Supply chain. Traditional wind and airborne wind energy technology require and access different and largely independent supply chains, fabrication, and manufacturing processes. For example, foundations are not required to transfer significant torque load for AWE systems (Peschel 2021).

- Installation and deployment. Traditional wind and airborne wind energy technology have very different installation and deployment requirements. AWE offers faster deployment and installation with significantly lower installation equipment requirements (Bormann 2021).

- Workforce. Traditional wind and airborne wind energy technology have different workforce requirements. While both require manufacturing employees, airborne wind is expected to require and provide a higher degree of O\&M employment opportunities because of replacement requirements for key components, such as the tether and soft kite (Peschel 2021).

- Environmental impact and adaptability. Because of the lack of operational experience, the environmental impact of airborne wind energy requires thorough investigation and is not well understood. The nature of traditional and AWE systems in operation and their control needs and options may result in different environmental interactions and adaptation, including the interruption of operation of a traditional system and grounding of an AWE system.

- Financial modeling and risk profiles. Potentially low capital investment and high component and subsystem replacement and maintenance costs during the operational life span of AWE technology requires diverse financing approaches, capital expenditure (CapEx) payback, and investment risk profiles. These circumstances may also allow shorter economically viable periods of operation than those of traditional wind technology in some specific markets such as hybrid microgrids (Zywietz 2019).

- Upgrades and technology adjustments. Replacing components and subsystems (e.g., tether, soft kite) in AWE technology over the installation's life span is an operational cost burden. At the same time, it offers the possibility of upgrading the airborne subsystems as the technology advances. It also allows adaptation to site conditions, and to increase the capacity factor for a given ground station through kite adjustment and selection. 
- Flexibility and mobility of assets. The potentially low weight per installed capacity and modest deployment effort may allow redeployment of AWE technology assets at different operational sites. Fast deployment, mobility and swift relocation of assets are highly valued properties and satisfy imperative system requirements in some markets (Creighton 2021).

\subsection{AWE Technology Development - Sector Status}

This section provides a high-level perspective of the AWE sector based on two technology development progress metrics: technology readiness level (TRL) and technology performance level (TPL). "TRL at its most basic definition describes the maturity of a given technology relative to its development cycle" (Sanchez 2011) and is considered at material, component, device, and system levels. To assess AWE systems, we draw from DOE's TRL definition (Sanchez 2011) as well as TRL definitions specific to wind energy (De Rose et al. 2017) and ocean energy (Fitzgerald et al. 2012; De Rose et al. 2017), a sector with similar technological diversity. TPL (Weber 2012; Weber et. al. 2013) describes the potential for techno-economic performance in ocean energy during precommercial technology development and similarly applies to AWE. Although TRL defines the degree of readiness toward becoming a commercially available product, TPL reflects the potential of the product to perform economically in the market. The TPL assessment of a technology is based on a holistic set of cost and performance drivers relating to capital expenditures, operational expenditures, power conversion, availability, and acceptability. The joint consideration of TRL and TPL provides a useful platform for determining the precommercial technology development status and identifying efficient technology development trajectories with respect to cost, time, and risk (Weber et al. 2017). This approach has also proven to be a valuable framework in the AWE technology sector (Weber 2019; Hayek 2020; Weber et al. 2021; Marsh 2021; Zerweckh 2021).

The TRL/TPL framework is used to assess and represent the progress and status of technology development in the AWE sector as a whole and to identify challenges and opportunities to successfully enter different markets and related applications. Figure 7 provides an overview of this high-level assessment and perspective. While individual technology development examples are included for clarification, the aim is to identify trends and segments of the sector.

Overall, evaluating technology readiness and techno-economic performance potential is a rough estimation, and is exclusively based on high-level, incomplete public domain information. It is important to note that within a specific AWE system development, different degrees of readiness and techno-economic performance can be observed across the system levels of component, subsystem, and integrated system and may vary considerably across the various performance attributes. The visual representation in Figure 7 does not specify individual developers and technology developments may be identified at a lower or higher development status when subjected to more in-depth assessments. Building on the knowledge and observations gained from direct stakeholder meetings and in the 2021 AWE workshop (Weber et al. 2021), we identified three main trends and technology development status groups across the global AWE sector and are shown in Figure 7. 
Diversity of low-TRL conceptual developments with high uncertainty and range of technoeconomic potential, varying TPL

Medium-to-large capacity units targeting on and offshore grid markets; high autonomy; reliability and availability requirements; a demanding energy cost environment; high markets entry requirements, thus reduced TPL

Small-to-medium capacity units targeting early-adopter markets; operational supported; modest availability requirements; a supportive energy cost environment; and reduced markets entry requirements; thus, reasonable TPL

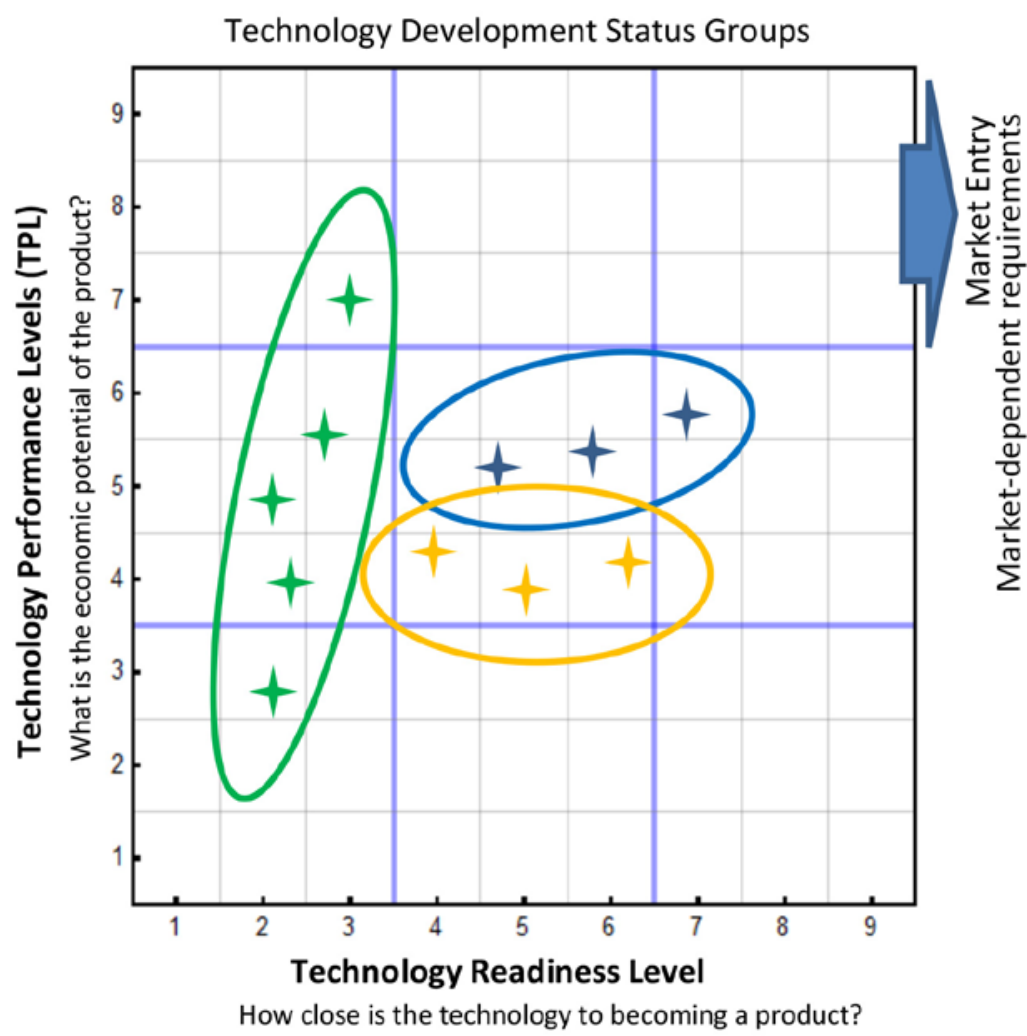

Figure 2. Technology readiness levels (TRLs) and technology performance levels (TPLs) of the main technology development status groups (left) across the global AWE sector

Figure 7 combines technology developments that target different market segments, ranging from niche markets and early-adopter markets to large-scale, land-based and offshore grid markets. It is important to note that market entry to these markets is subject to significantly diverse market entry requirements, especially in relation to fully autonomous operation, reliability, capacity, scale, and economics. Thus, technological readiness and techno-economic performance potential is expressed in relative terms to the targeted and absolute market entry requirements, as follows:

- Early stage (green). A variety of technology developments are at the conceptual stage, with low-to-medium TRLs and high uncertainty and are spread over the range of TPLs. The attributes driving techno-economic potential vary considerably. Some show high potential to satisfy market requirements with individual design concepts resolving challenges that present other systems with significant trade-offs. One example is the developments of stacked multikite systems (De Schutter et al. 2019a, 2019b). Such systems can resolve the trade-off between large tether length and associated tether drag, which is typically found in single kite developments. In some multikite systems, the long common main tether is not subject to fast lateral motion when transmitting power to the ground station, whereas individual kites with short tether branches operate at high velocities in cross-flight. Multikite configurations are considered both for fly-gen and 
ground-gen. While conceptually offering high installed capacity and power density per deployment space, such systems pose complex swarm control challenges.

- Targeting large impact (yellow). Some developers targeting land-based and offshore grid markets are preparing medium- and large-capacity units. Challenges to market entry include meeting requirements for operational autonomy, reliability, and availability in a demanding, low-energy cost environment. Some of these systems have reached higher levels of technical sophistication and detail as the technologies are refined. Technology developments are advanced and derisk prototype demonstrations through subsystem bench characterization and validation (Kruijff 2021; Echeverri et al. 2020) that are supported by custom numerical simulation and control optimization tools. Because of the demanding market entry requirements, these systems are clustered at intermediate TPLs.

- Targeting early adoption (blue). A considerable portion of AWE technology developers are targeting early-adopter markets in high-energy cost environments that may have a high level of O\&M support with somewhat less stringent automation or availability requirements, such as extended operations support to include launch preparations (Peschel 2021). Examples include microgrids, remote industrial plants, hybrid systems, military, agriculture, and others. Current devices vary from a subscale prototype to unit sizes in the 100- to 200-kW range. First developments are entering early-adopter pilot projects (Peschel 2021) and selling first units (Brabeck 2021) to strategic clients and island communities, partly in collaboration with energy companies. The reduced market entry requirements lead to these developments reaching medium to medium/high TPLs.

A consistent allocation of AWE technology types, such as fly-gen and ground-gen or rigid- or soft-wing designs, to market types or the development groups described earlier is not suggested here. However, note that most developers are pursuing ground-gen technology concepts with a variety of takeoff and landing approaches. Technologies with a reduced level of complexity in the airborne subsystem appear to have advanced closer to the targeted market requirements and have demonstrated higher operational duration and time (Brabeck 2021).

Most technology developments first aim for market entry into an early-adopter market typically associated with an installed capacity per unit of well below $500 \mathrm{~kW}$. A small number of developments have aimed (Echeverri et al. 2020), or are aiming (Kruijff 2021), for market entry into competitive grid markets with a large installed capacity per unit and in offshore applications.

While early-adopter markets may serve as niche or potentially growing end markets, it is important to note that these markets may also facilitate technological evolution in commercial operating environments toward higher capacity and significantly more competitive grid markets if supported through intensive ongoing R\&D activities. 


\subsection{Summary of Technology Assessment and Upscaling}

AWE technology is fundamentally different from traditional wind technology based on fundamental principles and through all lifecycle stages, including engineering design, procurement, financing, manufacturing, deployment, installation, operations, maintenance, upgrading, decommissioning, circular economic, environmental, and societal integration and could be regarded as a unique addition to the renewable energy sector. The available natural, potential technical, and targeted U.S. wind resources of both traditional wind and airborne wind energy technology are vast, and more than twice the U.S. energy demand (Section 7, Lopez et al. 2021; Musial et al. 2016), with a significant spatial overlap between the two estimates. However, because of this large available resource and characteristic features of the technologies, a separate deployment could be possible to provide a renewable energy contribution to the national electric energy demand and renewable energy transition when and if AWE is commercially available.

A wide variety of technology concepts, operational principles, and designs have been under development over the last two decades, originating from early theoretical modeling work in 1980 (Loyd 1980). Current technology readiness levels vary from low to medium, and in individual cases, medium-high (up to TRL 7, [Brabeck 2021]). The potential for airborne wind energy systems to achieve high techno-economic performance for market entry and to satisfy customer requirements varies significantly over technology concepts, depending on the requirements of their target markets and applications. Globally, a first developer is now entering pilot projects with sales of 100- to 200-kW units supporting remote island communities (Brabeck 2021) and another is offering preorders of mobile 100-kW AWE systems (Peschel 2021). Both technologies are ground-gen devices with flexible wing designs.

Technology developments targeting land-based and offshore competitive grid markets may have achieved higher levels of technical sophistication yet are further away from fulfilling the demanding market requirements. AWE technologies may be able to offer competitive economic performance based on the relatively low material requirements. However, achieving this performance depends on reliability, durability, survivability, and fully autonomous operations, some of which still require significant advancements to enter markets.

Early-adopter and special application market entries are starting to emerge and in the near-term for up to 3 years, whereas reliable, large-scale multimegawatt class technology for power to the grid may require 10 years for market rollout, depending on support and effort. Component, subsystem, and integrated system testing, validation, and operation will play a significant role in shaping technology development, increasing operational experience, and establishing reliability. The sector may benefit from the growth of enabling technology in related sectors such as sensors, controls, drone technologies, material science, engineering modeling, and highperformance computing.

Because of the uncertainty of technological success and the rather low global R\&D investments to date and especially in the United States (with an approximate \$13-million direct investment from federal entities), AWE technology development requires significantly more support to increase knowledge, evidence, and validation to understand the impact potential that AWE has for the U.S. electricity sector. In what form, and to what degree the AWE sector will provide a significant contribution to the U.S. renewable supply hinges on the rate of technology development and whether it can overcome the challenges associated with achieving commercial 
readiness, reliability, and techno-economic performance. The current initiation of pilot projects (Brabeck 2021) in the 100-kW class may trigger the onset of technological evolution of AWE systems through commercial operational experience gathered in diverse early-adopter markets. Higher-capacity multimegawatt AWE systems for larger land-based and offshore grid markets may evolve from early-adopter markets, in parallel with or in addition to considerable precommercial research, development, and validation activities.

Both the risk of failure as well as the risk of lost opportunity need to be considered, and further research and analysis is needed to better understand and quantify these risks - as well as the opportunities - to overcome the challenges and realize the technical potential of AWE. 


\section{Techno-Economic Analysis and Markets}

In this section, we focus on AWE systems for grid-connected, commercial-scale applications and identify relevant techno-economic challenges and opportunities for these systems. The analysis centers on land-based, multimegawatt devices that could potentially be deployed by 2030 .

\subsection{Key Findings}

Key findings in AWE techno-economic analysis and markets are:

- If airborne wind energy can achieve ambitious performance metrics (such as multimegawatt devices requiring tether lengths on the order of 200-300 meters [m]), then it has the potential to produce a lower LCOE in 2030 than land-based traditional wind because of lower capital costs; however, there has been little-to-no experimental validation of these performance goals to date. The industry needs to demonstrate the ability to achieve these metrics for AWE to be cost competitive with traditional wind.

- Site-specific capacity factors and uncertainty in operational expenses leads to a wide range of breakeven CapEx values, clustered between $\$ 500 / \mathrm{kW}$ and $\$ 1,500 / \mathrm{kW}$ for a 5 MW rigid-wing AWE device and between $\$ 1,000 / \mathrm{kW}$ and $\$ 3,000 / \mathrm{kW}$ for a $500-\mathrm{kW}$ rigid-wing device. Breakeven CapEx represents the highest acceptable CapEx for the airborne wind system to match the levelized cost of energy of commercially available traditional wind turbines in 2030 (represented by the NREL Annual Technology Baseline (ATB) 5-MW turbine (NREL 2020) and indicates that a 500-kW AWE device shows higher (i.e., more easily achievable) breakeven cost margins than a 5-MW AWE device. The broad range of values indicates that there are regions where site conditions are better suited for airborne wind than traditional wind. Improved estimates of these values (for example, through long-duration research assessment programs) will help clarify target capital costs for AWE systems to be cost competitive with traditional wind.

- The southeastern region of the United States demonstrated consistently high breakeven CapEx values, indicating that this may be a good target region for AWE.

- Smaller devices may face challenges for commercial-scale deployment because of lower capacity densities than traditional wind turbines but may have a good opportunity for deployment in early-adopter markets (e.g., off-grid, remote locations) because of potential capital cost savings. Deployment in these remote markets would require the devices to achieve high reliability to lower O\&M demands.

- The range of capacity densities for commercial-scale airborne wind power plants extends to higher capacity densities than those in existing traditional wind power plants (2-19.6 $\mathrm{MW} / \mathrm{km}^{2}$ for a 5-MW rigid-wing kite and $0.6-4.0 \mathrm{MW} / \mathrm{km}^{2}$ for a $500-\mathrm{kW}$ rigid-wing kite); however, these densities do not account for wake losses or other siting constraints. 


\subsection{Background in AWE Techno-Economic Assessment and Markets}

This section provides information on the background and objectives of our techno-economic assessment and market analysis of AWE.

\section{Research Questions and Challenges}

To guide our techno-economic assessment, we asked ourselves the following questions about AWE:

- Can future AWE systems achieve the target performance metrics outlined in this section to reach cost parity with traditional wind? What are the major technological hurdles that need to be addressed?

- Can a real-world AWE power plant achieve the high-capacity densities currently being modeled, or will they be diminished by wake interactions, siting constraints, or permitting considerations? Can technological advances such as plant-level control or stacked kites further increase capacity density?

- Is airborne wind energy best suited for a bulk energy production market where it competes with traditional wind, or for niche markets that take advantage of value streams, such as ease of installation and portability?

- Are there particular regions in which the benefits of AWE present a clear advantage over traditional wind (for example, the higher potential cost margins available in the southeastern United States)? How can an AWE system be optimized to maximize the benefits in these regions?

\section{Methods and Tools Needed}

For AWE to advance, the following efforts need to be met:

- Estimation of failure rates and maintenance schedules for commercial AWE systems.

- Improved component- and system-level cost models incorporating physics-based design, life cycle cost analysis, and learning effects from improved supply chains and industry experience.

The AWE industry is currently at a precommercial stage, with a focus on evaluating individual units at small scales. As such, comparing costs or performance between existing AWE systems and commercial-scale traditional wind turbines is not appropriate, as the latter technology has benefited from experiential learning, economies of scale, maturing supply chains, and technological advancement (Junginger and Louwen 2019). In this section, we develop potential topologies for future commercialized AWE systems and assess the relative benefits and drawbacks of a tethered wind turbine compared with a traditional wind turbine for a commercial operation date of 2030 .

This analysis assumes that AWE systems continue to grow to megawatt-scale devices that can be clustered in commercial-scale wind power plants. We prescribe hypothetical power curves for 500-kW and 5-MW AWE turbines and solve for approximate system characteristics that would be required to achieve these power ratings. We use these system properties to generate nationwide capacity factors, as described in Section 7, and subsequently find the breakeven capital costs required for systems with these capacity factors to be cost competitive with future 
traditional wind turbine systems, as described by NREL's ATB (NREL 2020). This analysis focuses primarily on how AWE can be cost competitive with commercial-scale, traditional wind energy. Although several interesting niche or distributed markets exist for AWE systems, these value propositions are based on additional considerations beyond costs and are discussed qualitatively at the end of this section and in the following sections.

Finally, this analysis focuses on land-based deployment. Although the offshore wind energy market is of interest to the AWE community, the time horizons for offshore AWE deployment are expected to be beyond 2030, as the industry focuses on commercializing the technology on land before moving to the harsher offshore environment (Weber et al. 2021).

The analysis used here does not identify a specific technology pathway or preferred technology solution. Instead, the premise is that if the AWE industry can achieve the assumed power performance and plant design characteristics, then an opportunity exists to realize the benefits of the technology and obtain significant market penetration. If these goals are not met (for example, if measured power output falls short of expected production goals as was the case with the Makani M600 prototype (Echeverri et al. 2020), airborne wind energy will face a significantly more challenging path to market.

\subsection{Definition of Potential AWE System Characteristics}

\subsubsection{Power Curves}

The power curve of a wind turbine is a critical design specification that shows the power output of the machine over a range of wind speeds. Wind turbines are characterized by their rated power, which is the maximum power a particular device can extract from the prevailing wind. Several power curves have been reported in the literature for existing airborne wind energy prototypes and planned devices (Faggiani and Schmehl 2018; Echeverri et al. 2020; Eijkelhof et al. 2020; Vimalakanthan et al. 2018); however, these power curves are highly specific to their respective designs and do not reach the 5-MW power rating that is expected to be typical of an average traditional wind power plant installed in 2030 (NREL 2020).

To use a generic power curve for this analysis, we specify two power ratings of $5 \mathrm{MW}$ and 500 $\mathrm{kW}$; assume cut-in, cut-out, and rated wind speeds; follow a wind-speed-cubed law between cutin and rated wind speeds; and assume a linear drop-off in power for wind speeds above rated. This power curve represents the output electrical power of the system after aerodynamic, mechanical, electrical, and AWE-specific losses (such as cosine and gravity losses) have been applied. These assumptions are based on power curves available in the AWE literature and were refined with input from industry experts during the 2021 Airborne Wind Energy Workshop (Weber et al. 2021). The power decrease after rated power and the relatively low cutout speeds are attributed to the adverse effects of tether drag at higher wind speeds. 


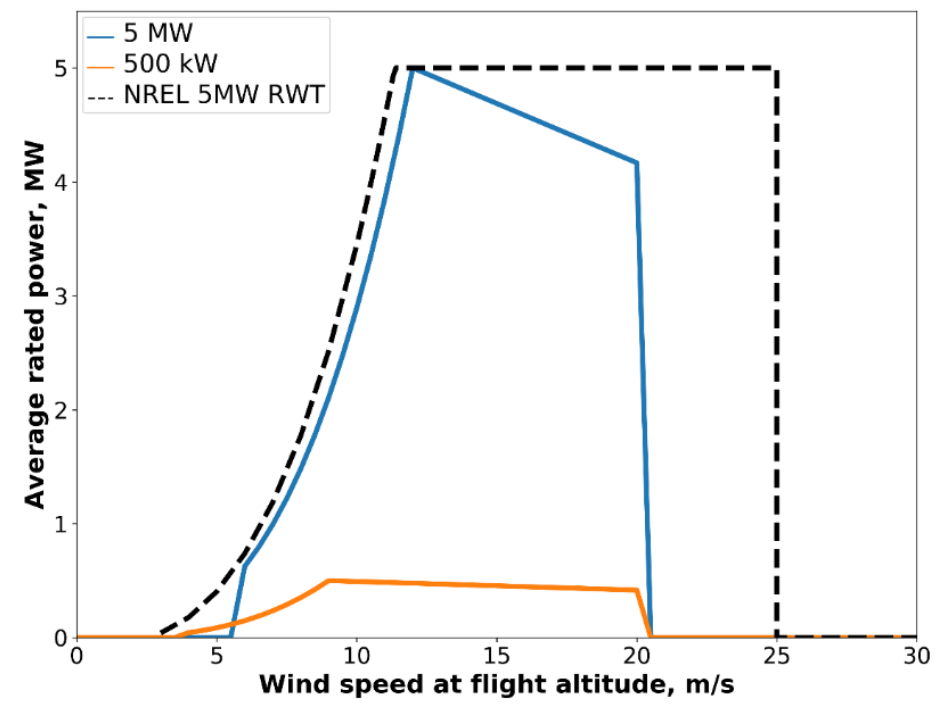

Figure 8. Target power curves for commercial-scale AWE systems in 2030. The NREL 5-MW reference wind turbine (RWT; traditional) power curve is also shown.

Although the AWE industry has developed prototypes on the 100-kW scale, achieving a 5-MW device by 2030 will require significant technological advancement from the current state of the art; however, industry experts suggest that this is an ambitious but potentially achievable goal, and that AWE devices with a rated power on the order of $1 \mathrm{MW}$ are likely necessary for airborne wind energy to be viable in a commercial setting relative to traditional wind (Weber et al. 2021). Industry experts agreed that higher power ratings for AWE, equivalent to the 15-MW traditional wind turbines expected to be deployed offshore by 2030, are not achievable in the next decade (Weber et al. 2021).

\subsubsection{Geometric and Flight Characteristics}

The size and flight path of an AWE device will dictate its ability to achieve its intended power performance; furthermore, the length of the tether required to conduct flight operations will directly impact the siting requirements and constraints for an airborne wind power plant (Faggiani and Schmehl 2018). In this analysis, we take a simplified approach to estimate the wing size and flight radius required to generate the power curves specified in Figure 8. A more detailed analysis that considers mass scaling, controller design, and the time-varying space requirements of the power generation cycle is outside the scope of this study, which limits the ability of the current method to directly evaluate the required tether length and flight path that a particular device can achieve. We address this uncertainty with a sensitivity analysis for short and long tether lengths.

Aerodynamically, AWE devices can be broadly categorized into two types: rigid wings and flexible wings, as described in Section 4.2. For each power curve in Figure 8, we determine the size of both a rigid and a flexible AWE system that would be required to achieve the rated power. The length of the tether that connects the wing to the ground station may remain nominally constant for a fly-gen AWE system in power production mode (Echeverri et al. 2020) or may vary with time as a ground-gen AWE turbine reels in and out during the power generation and retraction phases of the pumping cycle (Schmehl 2018). The maximum tether length will drive setback requirements from existing infrastructure to avoid collisions in the case 
of a crash. Directly calculating the required tether length for a particular AWE device requires simulating the time-dependent flight performance of the wing while accounting for the loads imparted by the tether as well as the aerodynamics of the wind (Eijkelhof et al. 2020) and is beyond the scope of this study. Instead, we prescribe a short and a long tether length for each wing to evaluate the range of impacts that this parameter can have on deployment potential, as described in Section 7. We derived the range of prescribed tether lengths from input from industry experts during the 2021 Airborne Wind Energy Workshop based on their proposed designs for megawatt-scale AWE devices (Weber et al. 2021).

In summary, a rigid and a flexible wing are designed for each of the two power curves in Figure 8; then, a short and a long tether length are prescribed for each of the power rating/wing type combinations, leading to eight scenarios. For each device, we specified a minimum ground clearance of $30 \mathrm{~m}$. The smaller wing spans and tighter flight circles of rigid wings permit lower average flight altitudes than flexible wings. The resulting geometric and flight characteristics are presented in Table 2 .

Table 2. Wing and Flight Properties for Rigid and Flexible Wings at 5-MW and 500-kW Rated Power

\begin{tabular}{|c|c|c|c|c|c|c|c|c|}
\hline Power Rating & \multicolumn{4}{|l|}{$5 \mathrm{MW}$} & \multicolumn{4}{|c|}{$500 \mathrm{~kW}$} \\
\hline Wing type & \multicolumn{2}{|l|}{ Rigid } & \multicolumn{2}{|c|}{ Flexible } & \multicolumn{2}{|c|}{ Rigid } & \multicolumn{2}{|c|}{ Flexible } \\
\hline Tether length (m) & 1,000 & 300 & 1,000 & 700 & 500 & 200 & 600 & 350 \\
\hline $\begin{array}{l}\text { System }{ }^{2} \text { lift/drag } \\
\text { ratio }\end{array}$ & 15 & 15 & 5 & 5 & 15 & 15 & 5 & 5 \\
\hline Wing area $\left(\mathrm{m}^{2}\right)$ & 192 & 192 & 1,637 & 1,637 & 45 & 45 & 388 & 388 \\
\hline Wingspan (m) & 43.8 & 43.8 & 127.9 & 127.9 & 21.3 & 21.3 & 62.3 & 62.3 \\
\hline $\begin{array}{l}\text { Average flight } \\
\text { altitude (m) }\end{array}$ & 200 & 200 & 414 & 414 & 200 & 200 & 217 & 217 \\
\hline Flight radius (m) & 131 & 131 & 384 & 384 & 64 & 64 & 187 & 187 \\
\hline
\end{tabular}

\subsubsection{Plant Design and Characteristics}

A common value proposition outlined in the AWE literature is the potential for tethered wind turbines to achieve higher capacity densities than traditional wind. Capacity density, measured in $\mathrm{MW} / \mathrm{km}^{2}$, refers to the generation capacity within a given amount of land area. For land-based traditional wind turbines, empirical wind farm capacities range from 1-18 MW/ $\mathrm{km}^{2}$ (HarrisonAtlas, Lopez, and Lantz, forthcoming) and offshore wind farm capacity densities range from 3.1

\footnotetext{
${ }^{2}$ Including tether drag
} 
to $18.7 \mathrm{MW} / \mathrm{km}^{2}$ (Deutsche WindGuard GmbH 2018). Drivers for these capacity densities include the required spacing between wind turbines to reduce downstream wake effects as well as siting constraints (such as terrain complexity) and accessibility or navigation through the wind plant (Musial et al. 2016). Airborne wind energy may have reduced wake interaction effects, as the relatively small surface area of the kite sweeps through a larger airspace volume than traditional wind turbine blades (Faggiani and Schmehl 2018). Theoretical capacity densities between 6 and $32 \mathrm{MW} / \mathrm{km}^{2}$ have been estimated in the literature (Faggiani and Schmehl 2018; European Commission 2018; De Lellis et al. 2016); however, further research is required to determine how the impact of wakes and other siting constraints affect the actual capacity density of airborne wind power plants (Weber et al. 2021).

We use an approach developed in the AWE literature for determining the capacity density based on the minimum geometric spacing between ground stations (Faggiani and Schmehl 2018). This methodology accounts for the elevation angle, tether length, and flight radius of the devices listed in Table 2 and outputs the minimum unit separation and resulting circular footprint for each device. Scaling the rated power of the device by the footprint produces an estimate for the capacity density of the wind power plant. We modify this approach slightly for the 500-kW AWE system, which we assume is intended to be deployed similarly to traditional distributed wind (i.e., a small number of turbines in off-grid applications), and simply assume that the footprint of each device is a circle with a radius equal to the tether length. Finally, we assign a setback of 1.25 times the tether length to each device to define the required spacing from existing infrastructure. The setback and capacity density results are provided in Table 3 and used for the spatial analysis of Section 7.

Table 3. Setback and Capacity Density

\begin{tabular}{|c|c|c|c|c|c|c|c|c|}
\hline \multirow{3}{*}{$\begin{array}{l}\text { Power Rating } \\
\text { Wing type } \\
\text { Tether length (m) }\end{array}$} & \multicolumn{4}{|c|}{$5 \mathrm{MW}$} & \multicolumn{4}{|c|}{500 kW } \\
\hline & \multicolumn{2}{|l|}{ Rigid } & \multicolumn{2}{|c|}{ Flexible } & \multicolumn{2}{|l|}{ Rigid } & \multicolumn{2}{|c|}{ Flexible } \\
\hline & 1,000 & 300 & 1,000 & 700 & 500 & 200 & 600 & 350 \\
\hline $\begin{array}{l}\text { Minimum unit } \\
\text { separation }(m)\end{array}$ & 427 & 285 & 893 & 719 & N/A & $\mathrm{N} / \mathrm{A}$ & N/A & N/A \\
\hline Footprint $\left(\mathrm{km}^{2}\right)$ & 0.57 & 0.26 & 2.50 & 1.62 & 0.79 & 0.13 & 1.13 & 0.38 \\
\hline $\begin{array}{l}\text { Capacity density } \\
\left(\mathrm{MW} / \mathbf{k m}^{2}\right)\end{array}$ & 8.7 & 19.6 & 2.0 & 3.1 & 0.6 & 4.0 & 0.4 & 1.3 \\
\hline Setback (m) & 1,250 & 375 & 1,250 & 875 & 625 & 250 & 750 & 438 \\
\hline
\end{tabular}

\subsubsection{Breakeven Capital Expenditures}

The final step in the techno-economic analysis of potential commercial-scale AWE systems is evaluating the technology costs. Several AWE researchers and developers have produced LCOE values for their designs, typically based on component-level cost estimates (European Commission 2018). Table 4 summarizes such cost estimates in the literature. Using this approach for future technologies is challenging because of the uncertainty around how component prices and supply chains may evolve in the next decade (Junginger and Louwen 2019) and the immaturity of AWE-specific supply chains (current designs borrow heavily from the aviation 
market) (Weber et al. 2021). Instead, we begin with the performance characteristics derived in Sections 5.3.1-5.3.3 and solve for the capital costs required to match the LCOE that the ATB wind turbines are anticipated to achieve in 2030 (NREL 2020). This results in the breakeven CapEx that would allow airborne wind energy systems to be cost competitive with the projected future costs of traditional wind.

Table 4. Cost Estimates From Literature for AWE Systems and Traditional Wind Energy Systems in 2030

\begin{tabular}{|c|c|c|c|c|c|c|c|}
\hline & $\begin{array}{l}\text { System } \\
\text { Type }\end{array}$ & $\begin{array}{l}\text { Rated } \\
\text { Power }\end{array}$ & $\begin{array}{l}\text { Capital } \\
\text { Expenditures } \\
(€ / k W)\end{array}$ & $\begin{array}{l}\text { Operational } \\
\text { Expenditures } \\
\text { (€/kW/year) }\end{array}$ & $\begin{array}{l}\text { Capacity } \\
\text { Factor (\%) }\end{array}$ & $\begin{array}{l}\text { LCOE } \\
\text { (€/MWh) }\end{array}$ & Source \\
\hline \multirow[t]{5}{*}{ AWE systems } & $\begin{array}{l}\text { Flexible } \\
\text { pumping } \\
\text { kite }\end{array}$ & $100 \mathrm{~kW}$ & 3,800 & 110 & $54 \%$ & 120 & $\begin{array}{l}\text { (Faggiani and } \\
\text { Schmehl 2018) }\end{array}$ \\
\hline & $\begin{array}{l}\text { Flexible } \\
\text { pumping } \\
\text { kite }\end{array}$ & $1.2 \mathrm{MW}$ & 599-956 & $27-54$ & $35 \%$ & $33-59$ & (Heilmann 2012) \\
\hline & $\begin{array}{l}\text { Land-based } \\
\text { pumping } \\
\text { kite }\end{array}$ & $2 \mathrm{MW}$ & 1,096 & & $34 \%-45 \%$ & & $\begin{array}{l}\text { (De Lellis et al. } \\
2016 \text { ) }\end{array}$ \\
\hline & $\begin{array}{l}\text { Floating } \\
\text { offshore } \\
\text { flexible kite }\end{array}$ & $2 \mathrm{MW}$ & 1,250 & & & & $\begin{array}{l}\text { (European } \\
\text { Commission } \\
\text { 2018) }\end{array}$ \\
\hline & $\begin{array}{l}\text { Floating } \\
\text { offshore } \\
\text { rigid wing }\end{array}$ & $2 \mathrm{MW}$ & 3,800 & 110 & & 120 & $\begin{array}{l}\text { (European } \\
\text { Commission } \\
\text { 2018) }\end{array}$ \\
\hline \multirow{3}{*}{$\begin{array}{l}\text { Traditional } \\
\text { systems } \\
\text { (reference) }\end{array}$} & Land-based & $5.5 \mathrm{MW}$ & 1,048 & 33 & $47 \%$ & 21 & (NREL 2020) \\
\hline & $\begin{array}{l}\text { Fixed- } \\
\text { bottom } \\
\text { offshore }\end{array}$ & $15 \mathrm{MW}$ & 2,298 & 62 & $47 \%$ & 43 & (NREL 2020) \\
\hline & $\begin{array}{l}\text { Floating } \\
\text { offshore }\end{array}$ & $15 \mathrm{MW}$ & 2,554 & 49 & $51 \%$ & 40 & (NREL 2020) \\
\hline
\end{tabular}

The levelized cost of energy is calculated using:

$$
L C O E=\frac{F C R \times C a p E x+O p E x}{8,760 \times N C F}
$$

where FCR is the fixed charge rate that must be collected annually (\%/year), CapEx are all capital expenditures including installation and soft costs $(\$ / \mathrm{kW}), \mathrm{OpEx}$ are the annual operational expenditures $(\$ / \mathrm{kW} /$ year), and NCF is the net capacity factor (scaled by the 8,760 hours in a year to yield the annual energy production). 
The steps to find the breakeven CapEx for airborne wind energy throughout the United States are as follows:

- Set the values of LCOE, OpEx, and FCR equal to the 2030 ATB moderate technology values in the LCOE equation

- Use the range of net capacity factor values for different AWE systems developed in the spatial analysis of Section 7

- Solve the LCOE equation for CapEx at each spatial location in the United States where the technology was deployed. This result represents the breakeven CapEx required for an AWE system to achieve the LCOE of the ATB wind turbine, given similar operational expenses and financing rates.

The interpretation of these results is that an actual AWE system will result in cost savings relative to the ATB reference wind turbine if it achieves a lower CapEx than the breakeven value. In other words, higher values of breakeven CapEx provide more opportunity for cost savings, whereas low values of breakeven CapEx mean that the AWE system in question has a stricter (and possibly unattainable) target cost to compete with traditional wind.

The results for rigid-wing AWE systems rated at $5 \mathrm{MW}$ and $500 \mathrm{~kW}$, both using the shorter tether lengths from Table 2, are shown in Figure 9 as spatial heat maps and as a function of wind speed at each spatial location. As this simplified analysis uses the same power curves for rigid and flexible wings, and the short tether lengths for the different topologies are relatively similar for both wing types, there are no significant differences in the results for rigid and flexible wings at $500 \mathrm{~kW}$. Results for 5-MW flexible-wing AWE systems are not shown as the lower capacity densities and long tether lengths make them less feasible at the commercial scale. The CapEx of the ATB 5-MW traditional wind turbine is also shown for reference.

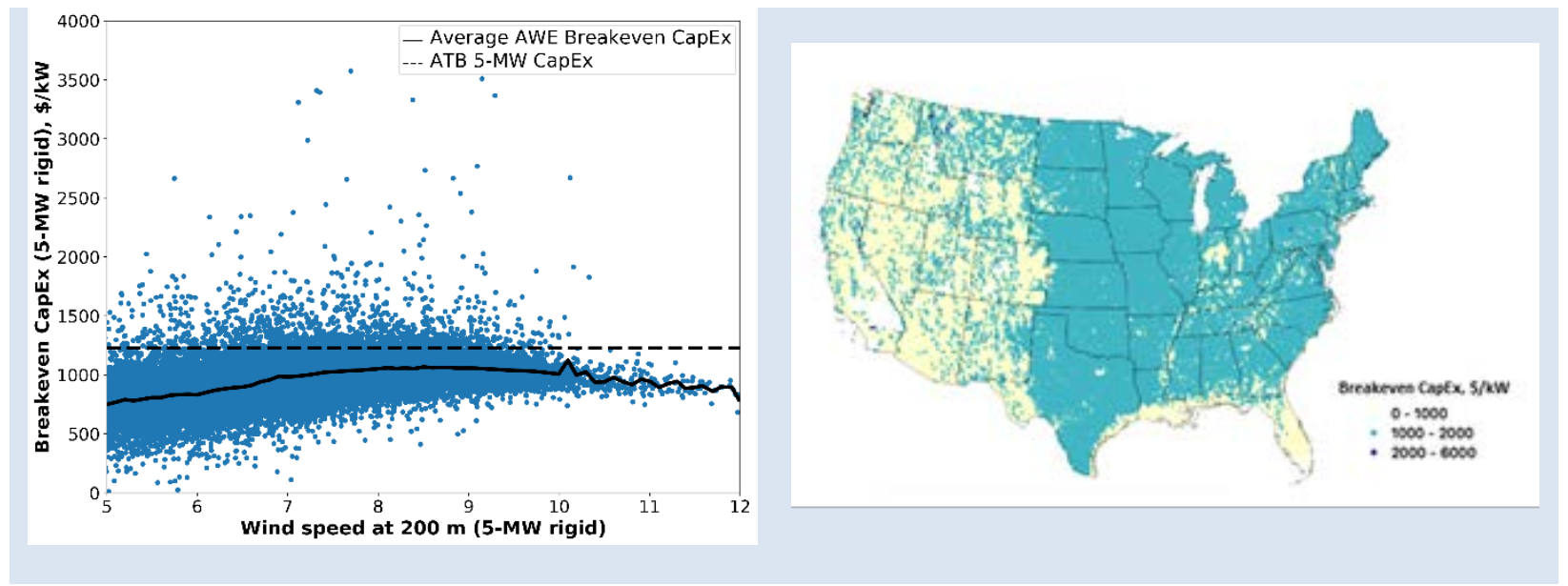



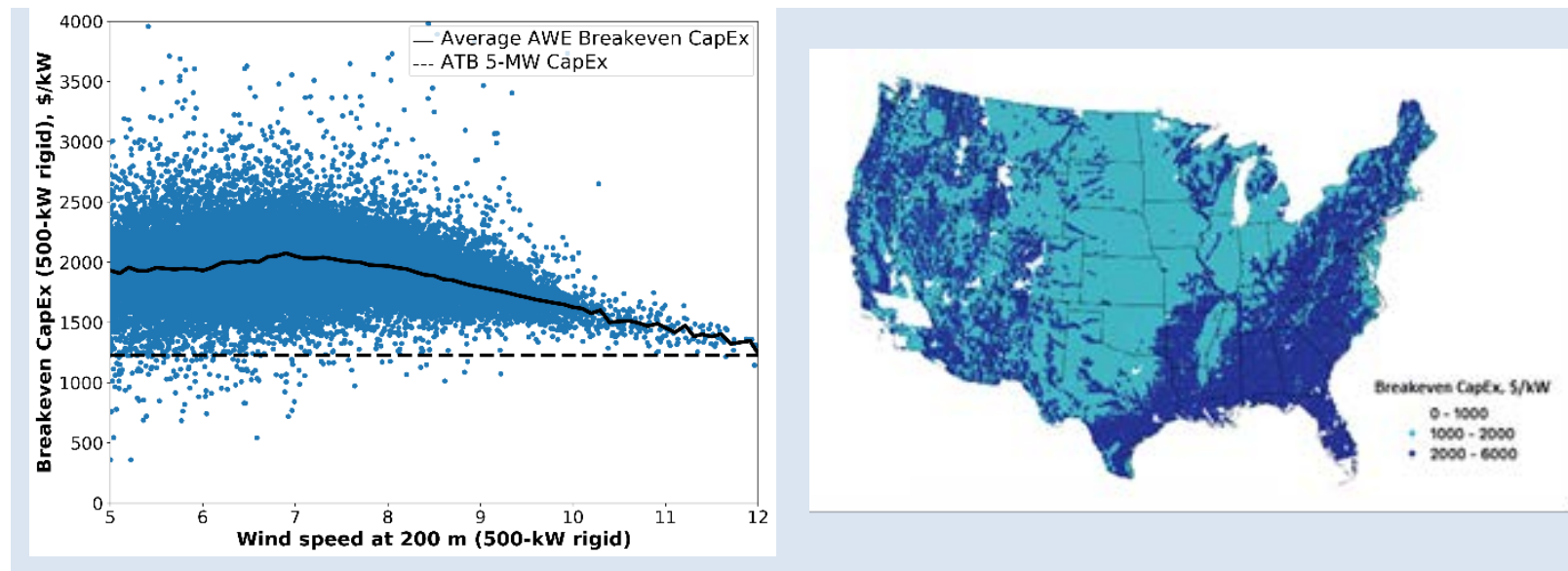

Figure 9. Breakeven CapEx in \$/kW for a 5-MW (top) and 500-kW (bottom) rigid-wing AWE system deployed throughout the United States. Lower values of breakeven CapEx indicate a more stringent target for AWE to be cost competitive with the ATB 5-MW reference traditional wind turbine. Spatial maps of the breakeven CapEx data points are shown on the right.

In Figure 9, the scatter in the results shows that the breakeven CapEx for the 5-MW rigid-wing AWE system varies significantly by location, but it has an average value of around $\$ 1,000 / \mathrm{kW}$ for wind speeds between 8 and $12 \mathrm{~m} / \mathrm{s}$; by comparison, the ATB 5-MW wind turbine has a CapEx value of $\$ 1,227 / \mathrm{kW}$. This difference indicates that the 5-MW AWE system is cheaper than the traditional wind system to produce the same cost of energy. The spatially resolved map shows that regions in the central plains are reasonably generous to airborne wind energy, with breakeven values between $\$ 1,000 / \mathrm{kW}$ and $\$ 2,000 / \mathrm{kW}$, which can be attributed to high capacity factors in the region (as shown in Figure 9). However, regions west of the Rocky Mountains tend to require lower values of breakeven CapEx for the AWE system to be competitive (indicating that these are less advantageous markets). These breakeven values are lower than reported CapEx values for conceptual AWE systems (summarized in Table 5), indicating that the AWE industry will have to achieve further cost reductions beyond these project values to be cost competitive with traditional wind.

The 500-kW wing also shows significant spatial dependencies and performs well in the central plains, with breakeven values close to the ATB wind turbine CapEx, although it shows significant advantages in breakeven CapEx in the Southeast and Northeast, where standard traditional wind turbines may underperform because of lower wind speeds (although lowspecific-power traditional wind machines may also be competitive in these regions). Again, the higher values of breakeven CapEx mean that, if an AWE system can achieve capital costs below this value, it will provide a cost savings relative to traditional wind at that location. Further, these savings represent a direction for future research efforts to better characterize the marginal value of airborne wind energy relative to traditional wind in these regions while considering sensitivities to key parameters such as flight altitude, power rating, and cost factors.

The results in Figure 10 indicate that, on average, a 5-MW AWE system will require around 18\% lower capital costs than a traditional wind turbine to produce the same LCOE because of lower capacity factors at many spatial locations. This cost of energy also assumes that the AWE system can obtain the same financing rates and operational costs as a more mature, traditional wind 
system; the bankability and OpEx costs of airborne wind energy remain a significant uncertainty facing the industry (Weber et al. 2021). These results indicate that a 500-kW system is more favorable on a per-unit LCOE basis, with breakeven CapEx values typically higher than a 5-MW traditional wind system at a given location; however, using these smaller devices at a commercial scale requires facing additional challenges because of the lower capacity densities than traditional wind, which would demand more land area for a given project capacity. These challenges would be exacerbated for a $500-\mathrm{kW}$ flexible wing system, which has longer tether lengths and lower capacity densities than a 500-kW rigid wing. It is likely that a commercially deployed AWE system would be bracketed by these two scenarios to balance the economies of scale and higher capacity densities of the 5-MW system with the better capacity factors and cost margins of the 500-kW system.

\subsubsection{Cost Category Breakdowns}

We also provide an approximation of how the breakeven CapEx is distributed among different cost categories based on LCOE models for rigid wings (Echeverri et al. 2020; Kruijff and Ruiterkamp 2018) and flexible wings (Heilmann 2012) in Table 5. As previously mentioned, some care must be taken when assessing these cost categories, as bottom-up LCOE projections for AWE systems are shrouded with uncertainty around the maturation of the supply chain for individual components. It is also important to note that the provided values are the overnight capital costs and do not include the costs to replace key components; these operational costs may be significant, as it is possible that major components such as kites and tethers may need to be replaced every 6-12 months (Weber et al. 2021). A sensitivity analysis around these operational costs is conducted in the following section. The results are then plotted in Figure 10. 
Table 5. How the Breakeven CapEx Is Distributed Among Different Cost Categories Based on LCOE Models for Rigid Wings

\begin{tabular}{|l|l|l|}
\hline Wing Type & Percentage of Overall CapEx & \\
\hline Kite & Rigid & Flexible \\
\hline Ground station & 35.7 & 10.3 \\
\hline Electrical & 19.3 & 15.5 \\
\hline Tethers & 16.7 & 41.8 \\
\hline Installation & 3.0 & 6.1 \\
\hline Foundation & 4.2 & 0.0 \\
\hline Other & 10.3 & 26.2 \\
\hline
\end{tabular}
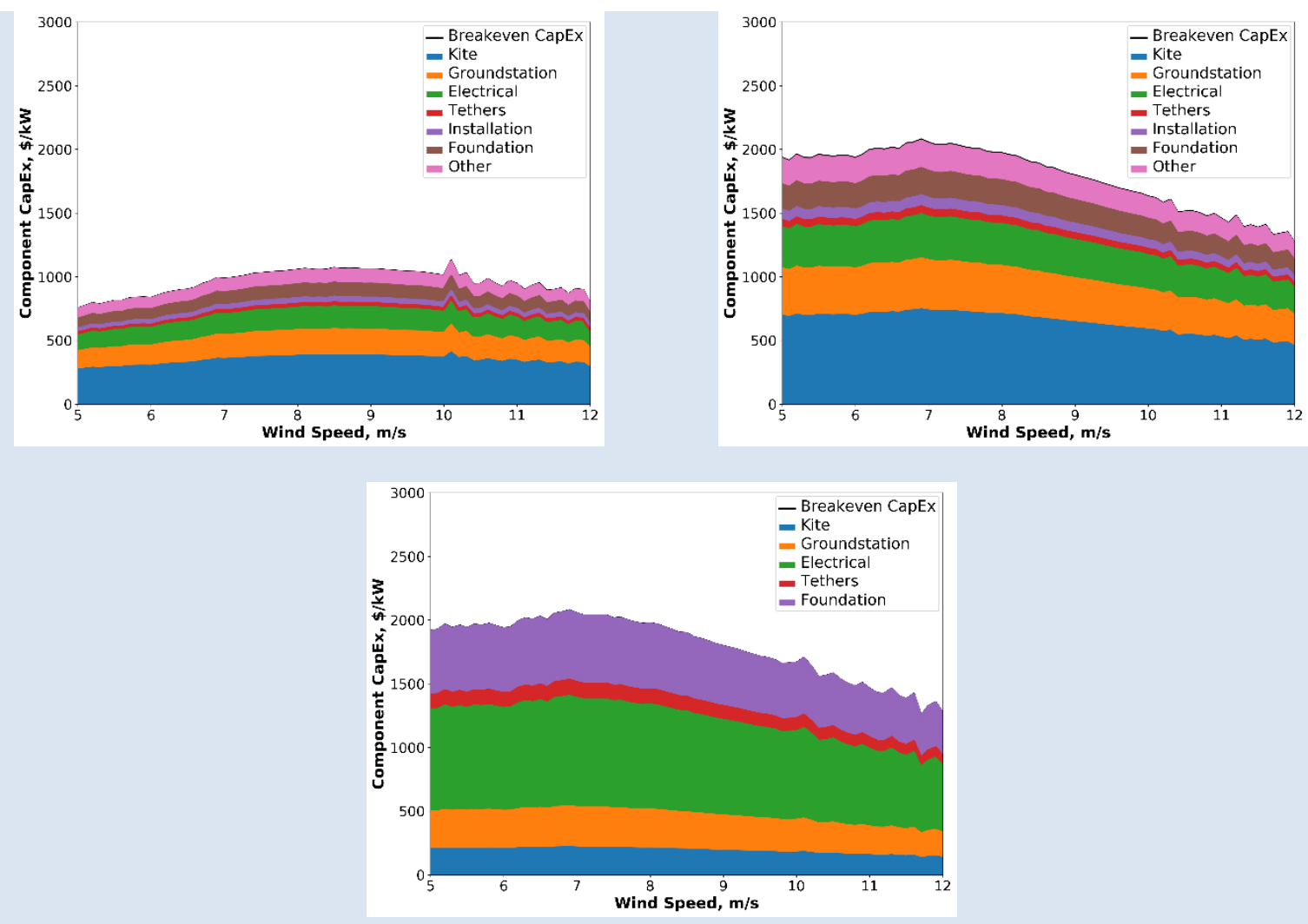

Figure 10. Breakeven CapEx component breakdown for a 5-MW rigid wing (top left), a 500-kW rigid wing (top right), and a 500-kW flexible wing (bottom)

\subsubsection{Sensitivity to Operation and Maintenance Costs}

The results for the breakeven CapEx use the same values of OpEx as the traditional ATB wind turbines; however, conversations with private developers have reflected a range of both optimistic and conservative assumptions about OpEx for AWE systems. The benefits of maintaining an AWE system relative to a traditional wind turbine are that all service operations 
can be conducted on the ground without the need for expensive cranes or vessels, and that many components are cheaper than their traditional wind equivalents; however, the drawback of AWE systems is that the high cyclic loading on the kite and tether system may result in more frequent replacement of key components (more than once per year), accruing additional cost and labor. As insufficient evaluation data or predictive models exist to effectively estimate the failure rates and associated OpEx of an AWE system, or even to definitively identify if these costs will be higher or lower than those of traditional wind systems, we also prescribe a range of OpEx values corresponding to $50 \%$ and $150 \%$ of the ATB value to demonstrate the sensitivity of breakeven CapEx to maintenance costs. These sensitivities are plotted along with the original values of breakeven CapEx against wind speed in Figure 11.
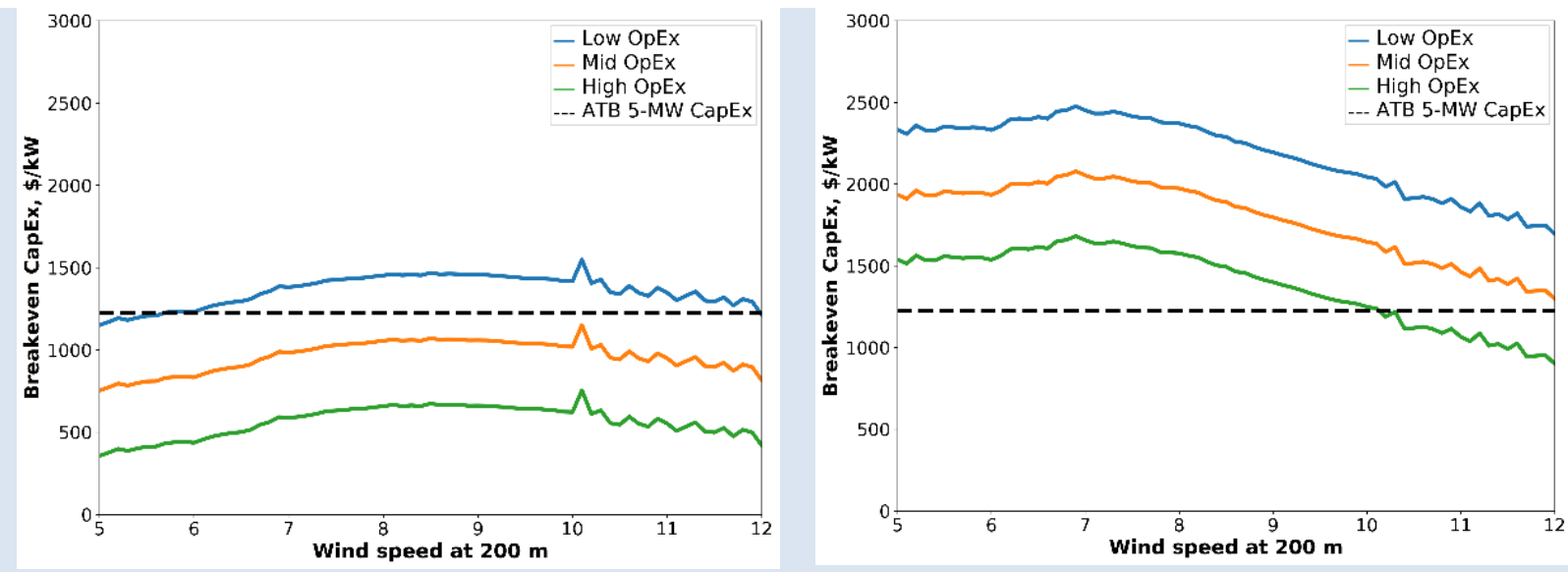

Figure 11. Sensitivity of breakeven CapEx to a range of low, mid, and high OpEx values for a 5-MW rigid wing (left) and a 500-kW rigid wing (right). Mid-OpEx corresponds to the ATB 5-MW traditional wind turbine value of $\$ 39.0 / \mathrm{kW} / \mathrm{yr}$, low OpEx corresponds to an optimistic scenario of $50 \%$ lower costs $(\$ 19.5 \mathrm{~kW} / \mathrm{yr})$, and high OpEx corresponds to a conservative value of $50 \%$ higher costs $(\$ 58.4 / \mathrm{kW} / \mathrm{yr})$.

Increasing the operational costs of a 5-MW airborne wind energy system by $50 \%$ decreases the breakeven CapEx to around $\$ 500 / \mathrm{kW}$, or around half of the expected CapEx values for multimegawatt AWE systems (Table 5). These low breakeven CapEx values indicate that it will be difficult to compensate for any unforeseen increases in OpEx with lower capital costs; however, if improved accessibility and lower component costs lead to reduced operational costs, the 5-MW AWE system may be able to realize cost savings relative to traditional wind for a wide range of wind speeds. The $500-\mathrm{kW}$ rigid-wing system retains breakeven CapEx values above the ATB 5-MW traditional wind turbine under most scenarios. 


\subsubsection{Assumptions and Caveats}

We made the following assumptions and caveats in the techno-economic assessment:

- The current analysis focused exclusively on land-based deployment. While offshore deployment is a potential target for the airborne wind energy industry, it is expected to take place on a longer time horizon than 2030 (Weber et al. 2021).

- The simplified scaling tools do not capture how mass scales with wing area, which directly impacts the ability of the wing to fly in its optimal turn circles and obtain the desired power rating. As a result, this analysis assumes that the AWE devices can successfully fly with the flight radii and tether lengths specified in Table 2 without directly modeling their ability to do so.

- The fixed charge rate in the LCOE equation is equal to that of the ATB land-based traditional wind turbine. This implicitly assumes that the less-proven AWE technology has become equally bankable and is as low risk as traditional wind technology by 2030 . LCOE is highly sensitive to FCR, and less-advantageous financing terms will significantly increase the cost of energy (Shields, Beiter, and Kleiber 2021).

- The capacity densities of airborne wind energy plants are computed without considering wake losses, siting constraints, or permitting requirements. Instead, they represent the minimum spacing required to avoid collision between neighboring kites. It is currently uncertain if real-world plants would be able to achieve these idealized capacity densities.

- Operational expenses are uncertain, as no long-term deployments currently exist; consequently, there are no data on failure rates and maintenance schedules. The AWE industry does not provide a consensus as to whether these costs will be greater or less than traditional wind systems.

The estimated power curves and flight geometries assume:

- A 50\% loss factor applied at all wind speeds because of electrical, pumping, gravity, cosine, and mechanical losses. This factor was derived from what published performance data are available (Echeverri et al. 2020; Luchsinger 2013) and was refined by conversations with industry experts. Losses will vary at different wind speeds and for different wing/tether designs. This assumption limited the study's ability to evaluate the effects of tether drag on performance.

The following power relationship is between the lift-to-drag ratio and wind speed from (Ahrens, Diehl, and Schmehl 2014):

$$
P=\frac{2}{27} \rho v_{w}^{3}\left(1+\left(\frac{L}{D}\right)^{2}\right) \sqrt{C_{L}^{2}+C_{D}^{2}}
$$

where $\rho$ is the air density, $v_{w}$ is the wind speed, $L / D$ is the lift-to-drag ratio, $C_{L}$ is the lift coefficient, and $C_{D}$ is the drag coefficient. We make the following assumptions:

- A minimum 30-m ground clearance

- A flight radius of 3 times the wingspan

- An average flight altitude of $200 \mathrm{~m}$ or the flight radius plus the ground clearance, whichever is higher. 
A detailed investigation of launch/land designs, costs, and trade-offs was outside the scope of this study; however, these systems are critical to the viability and deployment of autonomous and commercial-scale AWE systems.

\subsubsection{Technical and Economic Viability of Airborne Wind in the Next 10 Years}

The results in this section show a potential pathway for airborne wind energy to be cost competitive with traditional wind at a commercial scale if the technology can achieve the performance and sizing values presented here. Being cost competitive at the commercial scale would require the technology to attain all or some of:

- Power ratings on the order of $1 \mathrm{MW}$

- Short tether lengths on the order of a few hundred meters

- Tight flight radii of 3-4 times the device wingspan

- High capacity densities of above $10 \mathrm{MW} / \mathrm{km}^{2}$

- Low capital and/or operational expenditures

- High reliability and low replacement frequencies for major components.

A commercially viable product would not necessarily have to accomplish all of these goals; for example, a 5-MW rigid wing with costs on the same order as a 5-MW traditional wind turbine may be economically attractive if it can achieve the high-power densities provided in Table 5, whereas a $500-\mathrm{kW}$ flexible kite may be advantageous if sufficient land area exists to take advantage of the high capacity factors and low capital costs at the expense of capacity densities lower than traditional wind. The results in Figures 15, 16, and 17 (as well as Section 7) show that these pathways to economic viability are likely to be highly spatially dependent and will depend on the permitting and regulatory feasibility of AWE systems.

The airborne wind literature proposes theoretical designs that have the potential to achieve the techno-economic goals stated earlier, which is reinforced by the perspective of industry practitioners (European Commission 2018; Weber et al. 2021). However, the lack of experimental data from commercial-scale devices means that significant uncertainty exists around the performance, cost, and maintenance specifications. The most advanced prototype of a large-scale rigid-wing kite, the 600-kW Makani M600, significantly underperformed its projected power and flight performance despite having the advantage of a well-funded program (although this result may not be generalizable to the full spectrum of AWE design choices, such as ground-gen or flexible kites) (Echeverri et al. 2020). Experimental validation of the performance of large-scale AWE systems, coupled with realized capital cost reductions, advancing supply chains, and better-understood maintenance strategies and costs, will be critical to determine if airborne wind energy can directly compete with traditional wind on an LCOE basis. 
Airborne wind energy faces additional risks to commercialization, as described in European Commission (2018). In addition to the technology risk outlined earlier, major barriers facing the industry include:

- A lack of convergence on optimal system designs, particularly with regards to the kite, control system, and takeoff/landing strategies. The multiple of system designs also introduces a degree of financial risk as investors are faced with a paradox of choice and are uncertain of which technology to support.

- The need to demonstrate safe and reliable autonomous operation over extended deployment periods, including bad weather and multiple-kite systems (particularly for the yet-to-be-evaluated multimegawatt systems).

- The current immaturity of the supply chain and need to leverage economies of scale to reduce costs.

- Building trust and support with investors and external stakeholders.

- Investment risk as developers set their sights on larger machines that may never reach prototype or commercial-scale evaluation.

\subsubsection{Viability for Offshore Wind}

The value proposition for deploying AWE systems offshore is primarily related to reduced foundation size, which makes up a significant portion of the CapEx of fixed-bottom and floating traditional wind turbines (Stehly, Beiter, and Duffy 2020). The low overturning moments of a tethered system directly connected to the foundation can drastically reduce the size, and therefore the cost, of the support structure (Kruijff and Ruiterkamp 2018). Additional benefits are often cited, such as the strong offshore wind resource and the reduced demand (relative to traditional wind systems) for expensive and scarce installation vessels to construct and service an offshore AWE plant.

Despite these advantages, airborne wind energy faces several significant challenges to obtaining offshore market penetration. A primary concern is the ability of AWE systems to scale up to a nameplate capacity that can compete with the 12-15 MW traditional wind turbines that are expected to dominate the market over the next decade (Musial et al. 2020). These turbines benefit from the low shear and consistently high wind speeds offshore and require fewer devices to achieve a given generation capacity. While wake effects from these large wind turbines do reduce capacity density, current offshore projects being planned in the United States are already selecting suboptimal, increased spacing between turbines to accommodate navigational and transit lanes within the wind plant (Bureau of Ocean Energy Management 2021; Vineyard Wind 2020). If AWE systems are subject to these same spacing constraints, the much lower rated power of the kites makes it unlikely that a project developer would select the technology for new construction (for reference, an AWE plant with 5-MW turbines at 1-nautical-mile-by-1-nauticalmile spacing would have a capacity density of $1.5 \mathrm{MW} / \mathrm{km}^{2}$, roughly half that of traditional offshore wind). An additional concern is the potential for increased maintenance frequency offshore and the associated risk and safety concerns. As a result, it is likely that AWE systems would have to achieve nameplate capacities comparable to those of offshore traditional wind turbines to realize the benefits of lower costs. 


\subsubsection{Viability for Niche Markets}

Airborne wind energy offers several value propositions other than LCOE that make it attractive for certain niche markets. For example, ease of transport and installation, lack of dependency on traditional fuels, portability, and the potential for low costs make AWE systems (particularly flexible wing systems) attractive for markets such as disaster relief, distributed generation, developing countries, military bases, and highly complex terrain. These markets are discussed in more detail in Section 8.2.

In summary, the AWE industry has advanced significantly in recent years and the progress showed by many developers has garnered enthusiasm within the sector for the future of the technology and its potential to reduce costs relative to traditional wind. This analysis has shown that, if the AWE industry can achieve relatively ambitious technology and performance metrics, it can reduce capital costs and/or LCOE significantly. However, the lack of experimentally validated performance data at the multimegawatt device scale, uncertainty around achievable capacity densities, uncertainty around O\&M costs and strategies, and a myriad of risks and barriers to commercialization, coupled with rapidly declining costs and increasing capacities of traditional wind turbines, mean that significant further growth is required for airborne wind energy to be competitive at a commercial scale. If these metrics are not achieved by the industry, additional penetration into niche markets has some promising characteristics, although additional siting challenges would have to be overcome to make significant inroads into the offshore wind market. 


\section{Resource Potential and Energy Output}

Research into airborne wind energy is a multifactor challenge, with the wind resource being one of those factors. In this section, we summarize the (limited) literature that is available on the wind resource for AWE. Many of the early studies estimate the wind speed profile up to the height of the jet stream $(\sim 10 \mathrm{~km})$, which is far beyond the $500-\mathrm{m}$ height that is currently assumed to be the practical maximum height for AWE operation. This section analyzes the wind resource using NREL's 20-year Weather Research and Forecasting model (WRF) simulations, compares the wind speeds at altitudes relevant to AWE devices $(100-500 \mathrm{~m})$ with the wind resource at hub height for traditional wind turbines (currently 80-160 m), and provides preliminary estimates for annual energy production and capacity factors at selected sites.

\subsection{Key Findings}

The following are key finding on AWE resource potential and energy output:

- The wind resource at altitudes viable for airborne wind energy depends on the location and changes with time of day and during the year. In general, wind speed increases with height up to $300 \mathrm{~m}$; above $300 \mathrm{~m}$, average wind speed profiles seem to be mostly flat. Any increase in wind speeds with height may be negated by the effects of tether length and elevation angle, as they tend to reduce gains from higher heights (although this does not apply to all archetypes). Gross capacity factors calculated for 5-MW airborne wind energy devices (using the power curves developed in Section 5.3.1) are like gross capacity factors for traditional wind turbines at the sites analyzed.

- Our studies indicate that the windiest spots for traditional wind turbines are also the windiest spots for AWE devices, therefore AWE competes with traditional wind energy for sites if altitude considerations are neglected.

\subsection{Introduction to AWE Resource Potential and Energy Output}

This section provides AWE resource potential and energy output, the atmospheric conditions that drive AWE system design, as well as recommendations, and needed methods and tools.

\section{Recommendations}

The following are recommendations for improving understanding of atmospheric conditions and their relationship to AWE systems.

- Recommendations for future research include gaining a better understanding of turbulence, gusts, fluctuations, and intermittency of the airborne wind energy resource. Instrumental campaigns that can give insights into these research topics are needed.

- Experts recommend evaluating AWE devices regarding high-wind performance, highwind controls, and safety relating to gusts (e.g., how to dampen out instantaneous power surges).

- Future research should also address climate impacts on the wind resource, wakes, and extreme events. 


\section{Methods and Tools Needed}

The following are methods and tools to improve understanding of atmospheric conditions related to AWE:

- Instrumental campaigns to quantify the resource and understand turbulence, gusts, and fluctuations of the wind resource at altitudes up to $500 \mathrm{~m}$

- U.S.-wide analysis of high-altitude winds and wind shear using simulations and observations

- Wake modeling

- Climate modeling.

\subsection{Airborne Wind Energy Potential Worldwide}

According to the Monin-Obukhov theory, wind speed increases with height in the atmospheric boundary layer following a logarithmic law. Above the boundary layer height, where geostrophic winds roar in the absence of the ground's influence, winds are assumed to be faster. Even higher up, the jet stream promises very high winds at altitudes around $10 \mathrm{~km}$, which about a decade ago was deemed promising for airborne wind energy. For example, Archer and Caldeira (2009) assessed wind power at altitudes between 500 and 12,000 $\mathrm{m}$ above ground worldwide. They noted that high-altitude winds are not steady and strong all the time, and that the altitudes at which winds are the strongest depend on the weather. They concluded that the optimal wind power densities and heights are above $6 \mathrm{~km}$ and that the United States benefits from relatively high power densities $\left(>0.5 \mathrm{~kW} / \mathrm{m}^{2}\right)$, with optimal heights above $500 \mathrm{~m}$. In contrast, Miller et al. (2011) state a few years later that jet stream wind power does not have the potential to become a significant source of renewable energy.

Archer et al. (2014) identified optimal locations for airborne wind energy globally. High-altitude wind resources were modeled or analyzed for Ireland (Lunney et al. 2017), the Middle East (Yip et al. 2017), and The Netherlands (The Dutch Offshore Wind Atlas 2021). Much of the airborne wind energy resource has been analyzed in Europe. Looking at 12 locations in Germany, Gambier (2014) found strong wind shear between 200 and 1,000 $\mathrm{m}$ at night, whereas during the day the wind shear was small. Airborne Wind Europe publish high-altitude wind energy maps over Europe, based on ERA5 reanalysis data (Bechtle and Zilmann 2021). These maps consider higher wind speeds at lower altitudes and apply the highest wind speed available at a site at any given hour at any altitude up to $500 \mathrm{~m}$. This method of using the highest winds available considers the ability of airborne wind energy systems to dynamically lower their flight altitude to harvest these stronger low-level winds should they occur. Bechtle and Zillmann, the authors of the 2021 article on the Airborne Wind Europe website, claim that "winds over Europe at the best altitude up to $500 \mathrm{~m}$ are much stronger and steadier than at a fixed altitude of about $100 \mathrm{~m}$," and that in most places, the mean wind speed at high altitude is at least $1-2 \mathrm{~m} / \mathrm{s}$ higher than at the 100-m altitude.

Bechtle et al. (2019) analyze the wind resource over Europe up to $500 \mathrm{~m}$ and compare it to the wind resource at $100 \mathrm{~m}$, a height typically relevant for traditional wind turbines. Example wind speed profiles show that at times the wind resource is higher at higher altitudes, and at other times the wind resource is higher at lower altitudes. Bechtle et al. also analyzed wind power 
density. They claim that over most of Europe, the 5th percentile wind power density for variable heights increases by more than $100 \%$ compared to $100 \mathrm{~m}$.

\subsection{Wind Shear and Airborne Wind Energy Resource in the United States}

Since airborne wind energy devices fly in circles or figure- 8 configurations that span an area between $\sim 100$ and $500 \mathrm{~m}$ above ground, wind shear, which is the change in wind speed with altitude, is important to consider. Power output fluctuations related to wind shear can occur when the AWE flight path spans a range of altitudes (Roland Schmehl, personal communication).

Contrary to popular belief, wind speeds are not always higher at $500 \mathrm{~m}$ compared to $100 \mathrm{~m}$ (Bechtle et al. 2019), which was confirmed by workshop participants (Weber et al. 2021), as well as an analysis conducted at NREL with WRF simulations over Hawaii, the Pacific Northwest, and the mid-Atlantic Coast (the methodology used for California in Optis et al. [2020] was replicated for Hawaii and the Pacific Northwest). Figure 12 (left panels) shows the 20-year average maximum wind speed in the layer between $100 \mathrm{~m}$ and $500 \mathrm{~m}$, and (right) the 20-year average difference between $100-\mathrm{m}$ and $500-\mathrm{m}$ wind speeds. It is evident that the wind shear depends on the location. Some locations show a higher wind resource at $500 \mathrm{~m}$ than at $100 \mathrm{~m}$, some show the opposite. The reasons and conditions for wind shear patterns are recommended as the subject of future research. 

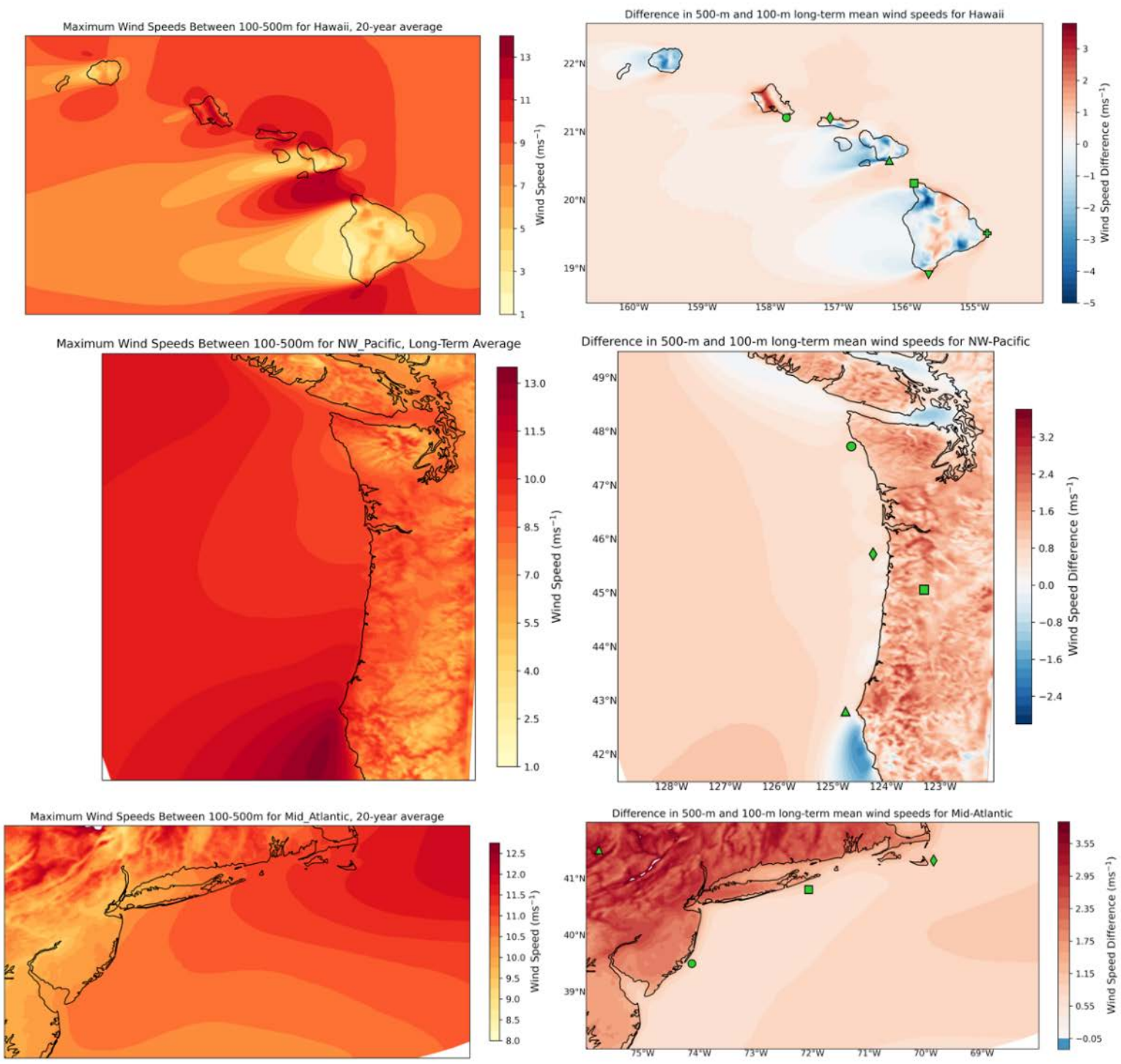

Figure 12. (left) Maximum wind speeds between $100 \mathrm{~m}$ and $500 \mathrm{~m}$ averaged over 20 years (20002020) and (right) 20-year differences between $500-\mathrm{m}$ and $100-\mathrm{m}$ wind speeds from NREL's WRF simulations (top row) over Hawaii, (middle row) the Pacific Northwest, and (bottom row) the midAtlantic Coast. The green symbols denote locations at which wind profiles were extracted and the annual energy production and gross capacity factor calculated.

We further analyzed wind speed profiles at selected locations (symbols in Figure 12, right column). The locations were randomly chosen among areas with promising characteristics for airborne wind energy: offshore and onshore, where the resource is high and shear is positive (i.e., increasing average wind speed with height). We chose more offshore sites for this analysis based on expert interviews, indicating that the most promising locations are offshore. It is evident in Figure 13 that, although wind speeds tend to increase with height at selected locations, this increase is minor. Most of the increase in wind speed happens at altitudes up to $200 \mathrm{~m}$, but above that the wind profiles are rather flat, even at the most promising locations. 

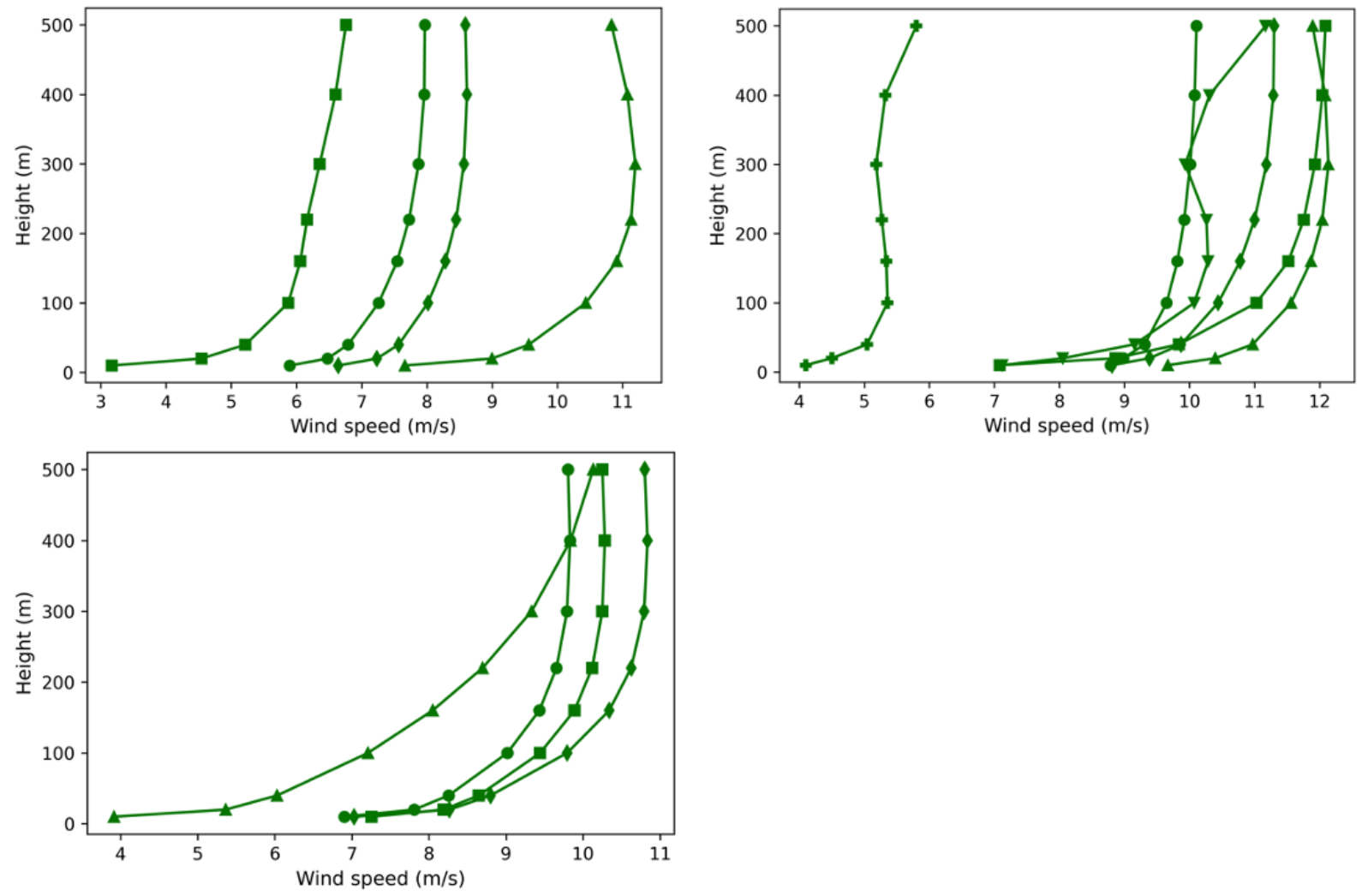

Figure 13. 20-year average wind speed profiles at selected points shown in the difference maps in Figure 10 from NREL's offshore WRF simulations. (Left) over the Pacific Northwest, (right) over Hawaii, and (bottom) over the Atlantic.

We also plotted average wind speed profiles at four locations across the central United States (Figure 14, left), based on WRF simulations at 15-minute intervals for June and July 2018. The locations are denoted in Figure 12 (right), which shows the difference between 500-m and 100-m wind speeds over the modeling domain at a selected time (June 1, 2018, at 0600 Coordinated Universal Time [UTC]) to show an example of the differences in shear across the modeling domain. At that point in time, the shear was extreme, exceeding $12 \mathrm{~m} / \mathrm{s}$ between $100 \mathrm{~m}$ and 500 $\mathrm{m}$. Average shear values across the 2 months are lower, at 3-4 m/s (Figure 14, left). Overall, we see an increase in average wind speeds between $100 \mathrm{~m}$ and $300 \mathrm{~m}$, whereas the profiles exhibit little change above $\sim 300 \mathrm{~m}$.

Wind shear was mentioned by experts in the AWE workshop as a topic of importance (Weber et al. 2021). It is unclear whether it is beneficial to pursue higher wind speeds at different heights during high shear. Positive wind shear above $200 \mathrm{~m}$ was not found consistently in our analyses, and selected sites and wind profiles appeared to be rather flat, with more evidence of positive shear on land than offshore. More research and field measurements will be required to determine if chasing higher winds will be beneficial. 

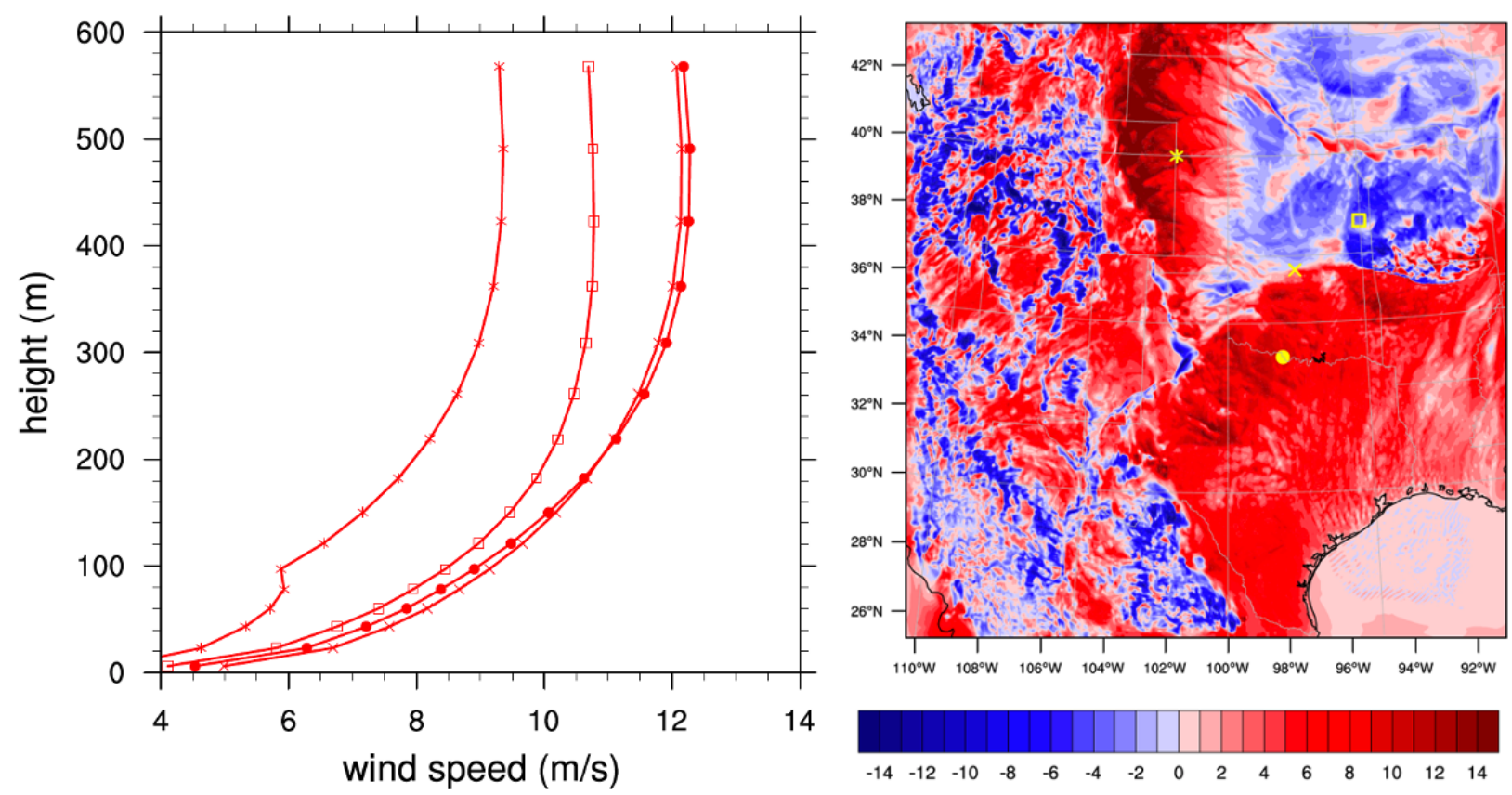

Figure 14. (left) Simulated wind speed profiles at four locations in the WRF modeling domain over the central United States. (right) Difference between wind speeds [m/s] at $500 \mathrm{~m}$ and $100 \mathrm{~m}$ over the modeling domain on June 1, 2018, at 0600 UTC. The symbols denote locations at which wind speed profiles are taken.

\subsection{Wind Resource Variability}

Wind speeds are variable in nature. Figure 12 shows that the wind resource between $100 \mathrm{~m}$ and $500 \mathrm{~m}$ varies spatially. The wind resource also varies temporally. Archer et al. (2014) discuss spatial variability of the wind resource in the U.S. Great Plains, and its variability with regards to changes in altitude and occurrence of the low-level jet (LLJ). They identify the U.S. Great Plains, among other regions, as a location with high wind power densities. The Great Plains LLJ seems to be the major driver. In the summer, it occurs at all hours. It reaches its lowest elevation, which is less than $400 \mathrm{~m}$ above ground level, and strongest wind power density (up to 3,000 $\mathrm{W} / \mathrm{m}^{2}$ ) in the evening and night hours. During the day, the LLJ rises and weakens in the morning and afternoon. The average LLJ in the afternoon is higher and weaker in the evening. In the winter, some locations experience a lower but weaker LLJ in the afternoon than at night. The authors list other appealing properties for AWE in the winter, such as a lower core height (between 300 and $700 \mathrm{~m}$ ), greater wind speeds (between 15 and $23 \mathrm{~m} / \mathrm{s}$ ), and greater wind power densities (between 2,000 and 5,500 W/ $\mathrm{m}^{2}$ ) than the summer LLJ.

Here, we analyze the temporal variability of the wind resource for selected locations over the mid-Atlantic, Hawaii, and the Pacific Northwest. Figure 15 (left) shows a histogram of the simulated maximum wind speed differences from one hour to the next over 20 years at a particular location in Hawaii. Maximum wind speeds were used between 80 and $400 \mathrm{~m}$ and 120 and $300 \mathrm{~m}$ for offshore and onshore locations, respectively. Most changes are within $0.5 \mathrm{~m} / \mathrm{s}$, although larger differences up to $5 \mathrm{~m} / \mathrm{s}$ exist. When these wind speed differences are broken down by months and time of day (Figure 15, right), we see that these differences have a diurnal 
as well as seasonal cycle. Larger differences can be found in the summer months, for example. Wind speed differences at $100 \mathrm{~m}$ show only minor differences at selected sites (not shown).
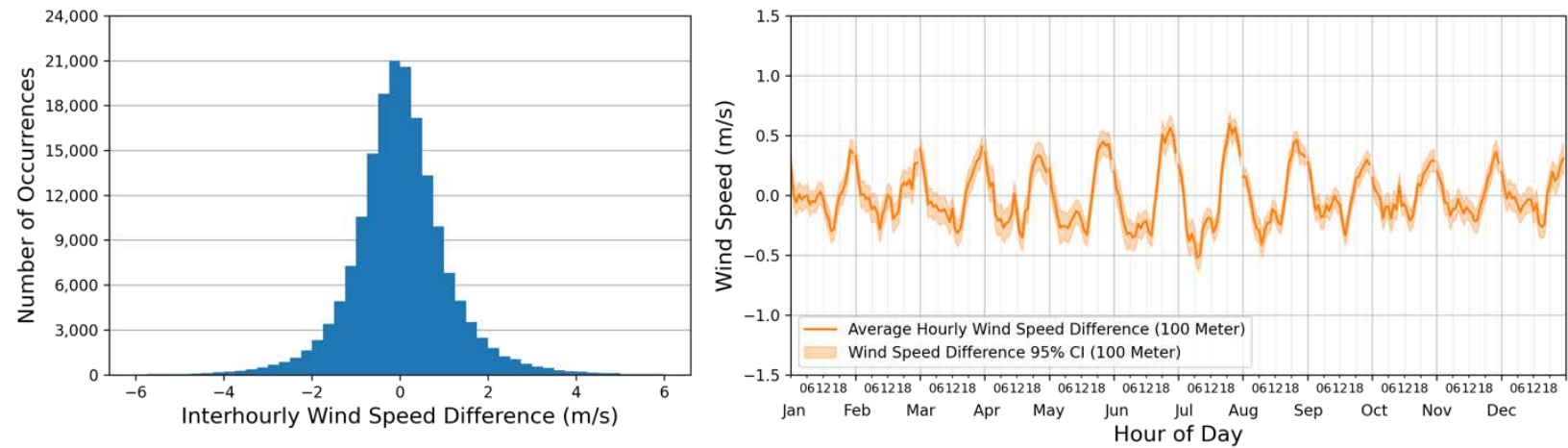

Figure 15. (left) Histogram of simulated wind speed differences from one hour to the next over 20 years at latitude 18.9 and longitude -155.7 (Hawaii, onshore) (right) average hourly wind speed differences as a function of month and time of day [UTC] at latitude $\mathbf{4 0 . 8}$ and longitude $\mathbf{- 7 2 . 1}$ (midAtlantic, offshore).

Likewise, the maximum wind speeds at certain locations change with time of year and time of day (Figure 16-Figure 19). Some sites show maximum wind speeds in the summer (Figure 16 and Figure 18), whereas others show the opposite (Figure 17 and Figure 19). The characteristics of the diurnal cycle vary by site, with some sites maintaining consistent cycles throughout the year, and others experiencing considerable variability (e.g., Figure 19). The discontinuities in Figure 16-Figure 19 arise from diurnal cycles being averaged over each month separately. Maximum wind speeds are on average higher than 100-m wind speeds, and the diurnal cycles differ slightly. The difference between average maximum and 100-m wind speeds varies over the course of a year.

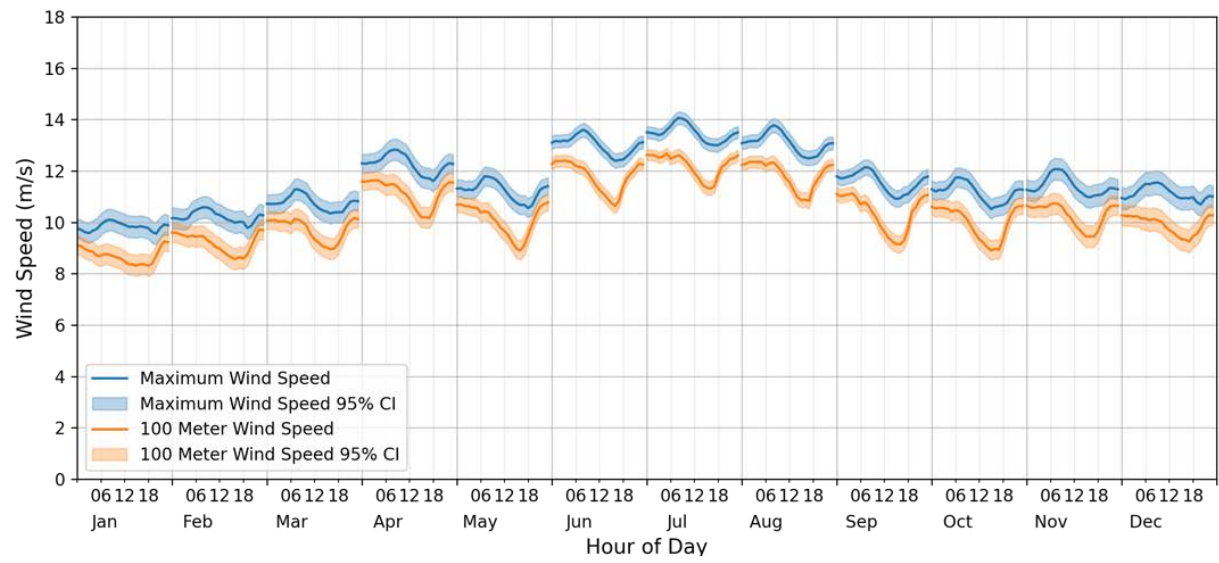

Figure 16. Maximum simulated wind speeds between 80 and $400 \mathrm{~m}$ and at $100 \mathrm{~m}$ as a function of month and time of day at latitude 21.2 and longitude -157.1 (Hawaii, offshore) 


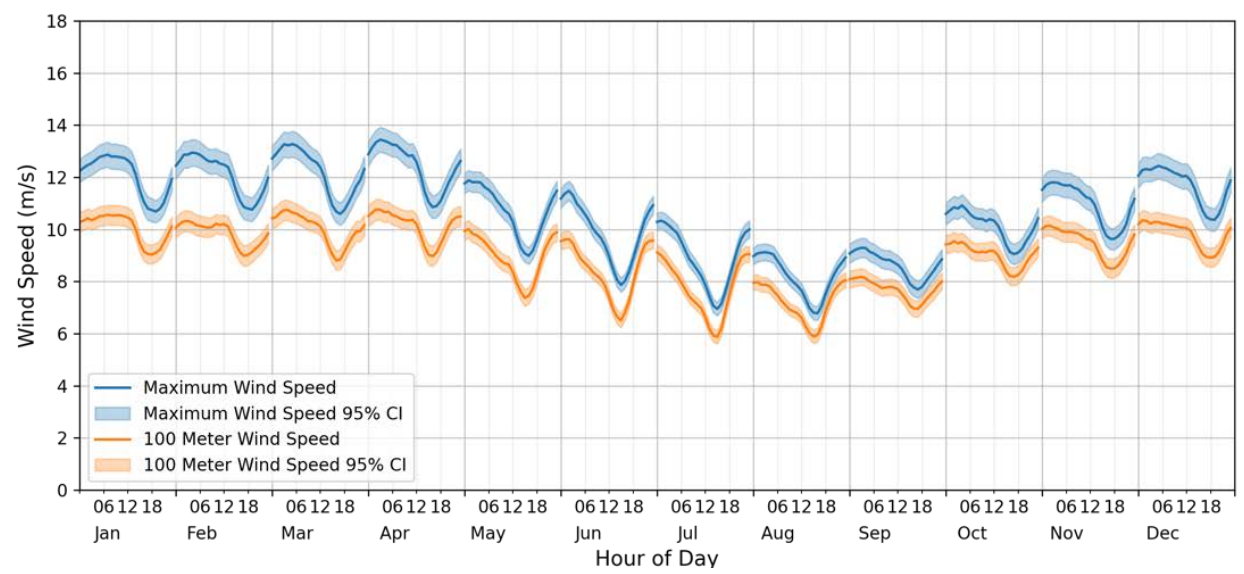

Figure 17. Maximum simulated wind speeds between 80 and $400 \mathrm{~m}$ and at $100 \mathrm{~m}$ as a function of month and time of day at latitude 39.5 and longitude $-\mathbf{7 4 . 1}$ (mid-Atlantic, offshore)

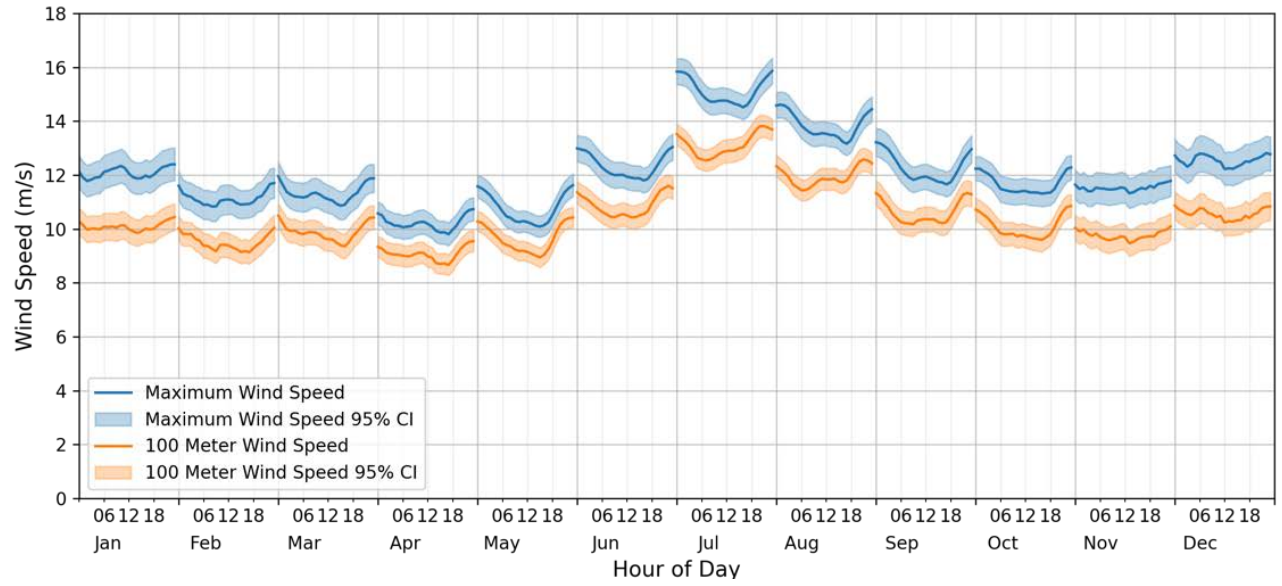

Figure 18. Maximum simulated wind speeds between 80 and $400 \mathrm{~m}$ and at $100 \mathrm{~m}$ as a function of month and time of day at latitude 42.8 and longitude -124.8 (Pacific Northwest, offshore)

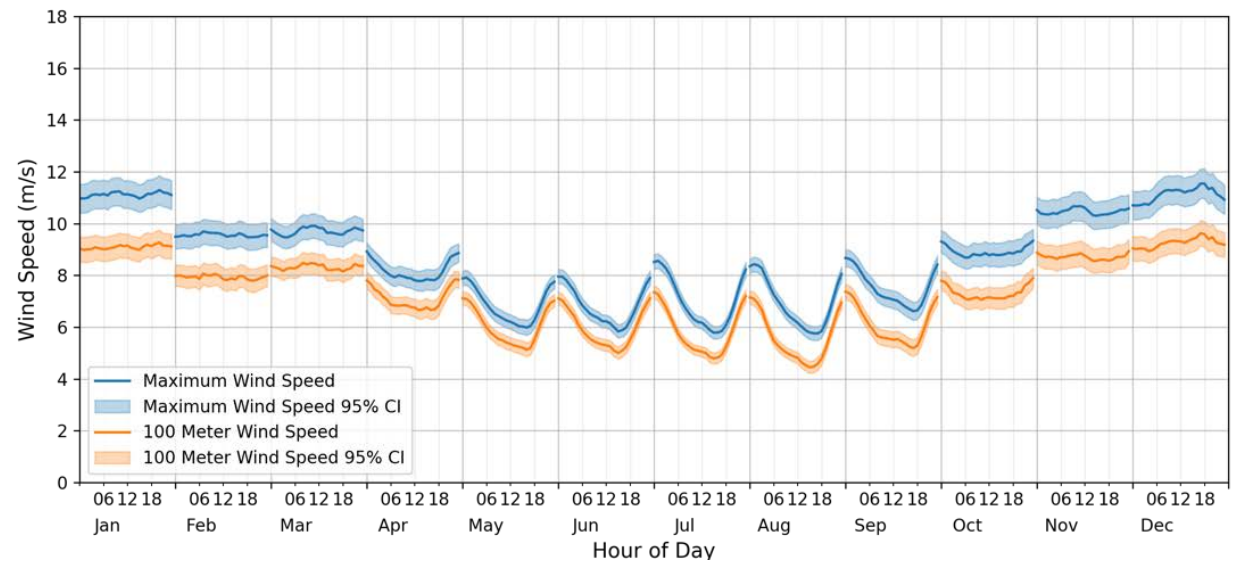

Figure 19. Maximum simulated wind speeds between 80 and $400 \mathrm{~m}$ and at $100 \mathrm{~m}$ as a function of month and time of day at latitude 47.7 and longitude -124.7 (Pacific Northwest, offshore) 


\subsection{Annual Energy Production at Selected Sites}

The calculation of energy extraction from airborne wind energy devices is different from traditional wind turbines in that the AWE devices do not have a defined swept area. In the literature, only wind speed is frequently used as input to calculate power. The harvesting volume is a consequence of the operation of the system (Roland Schmehl, personal communication).

Airborne wind energy devices have been compared to traditional devices in terms of their applicability of the Betz limit (e.g., De Lellis et al. 2018). De Lellis et al. (2018) showed that, because both traditional and AWE wind turbines harvest power through either torque or drag force, the Betz limit applies. They found that AWE drag power systems can harvest up to 16/27 of the power available in the wind, and AWE lift power systems can harvest up to 4/27. AWE systems seem very ineffective from a Betz perspective, because they sweep a large flow volume from which they capture a comparatively small amount of energy (Roland Schmehl, personal communication; De Lellis et al. 2018). It is important to note that mapping Betz's theory to AWE is difficult because there is no well-defined swept area. Therefore, Roland Schmehl and team came up with the power harvesting factor. This factor uses the wing surface area.

Here, we calculate the annual energy production (AEP) and gross capacity factors using a generic AWE power curve (Section 5.3.1) for location on land and offshore (Figure 20 and Figure 21). For airborne wind energy AEP estimates, we used the maximum power output between 80 and $300 \mathrm{~m}$ and 20 and $500 \mathrm{~m}$ for rigid and flexible devices, respectively, following the flight altitudes of these kites. We compare the results with AEP for a traditional wind turbine at the same locations, using a 5-MW wind turbine (Jonkman et al. 2009; Figure 8 for both landbased and offshore locations). For the NREL 5-MW wind turbine AEP estimates, we used the maximum power output between 80 and $120 \mathrm{~m}$ (the approximate maximum and minimum blade tip heights). The AEP estimates and gross capacity factors vary by location but are similar for rigid and flexible AWE devices as well as traditional wind turbines (Figure 20 and Figure 21; Section 5.3.1).

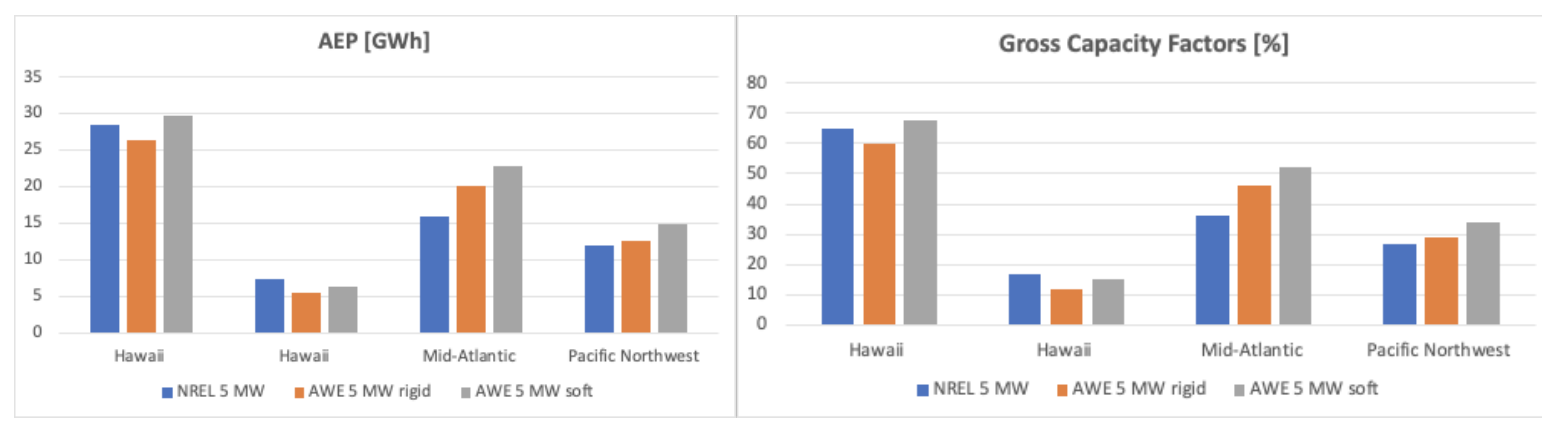

Figure 20. (left) AEP estimates and (right) gross capacity factor (averaged over 20 years) for selected locations over land (Figure 12). The calculations assume $100 \%$ availability. (GWh $=$ gigawatt-hour[s]) 


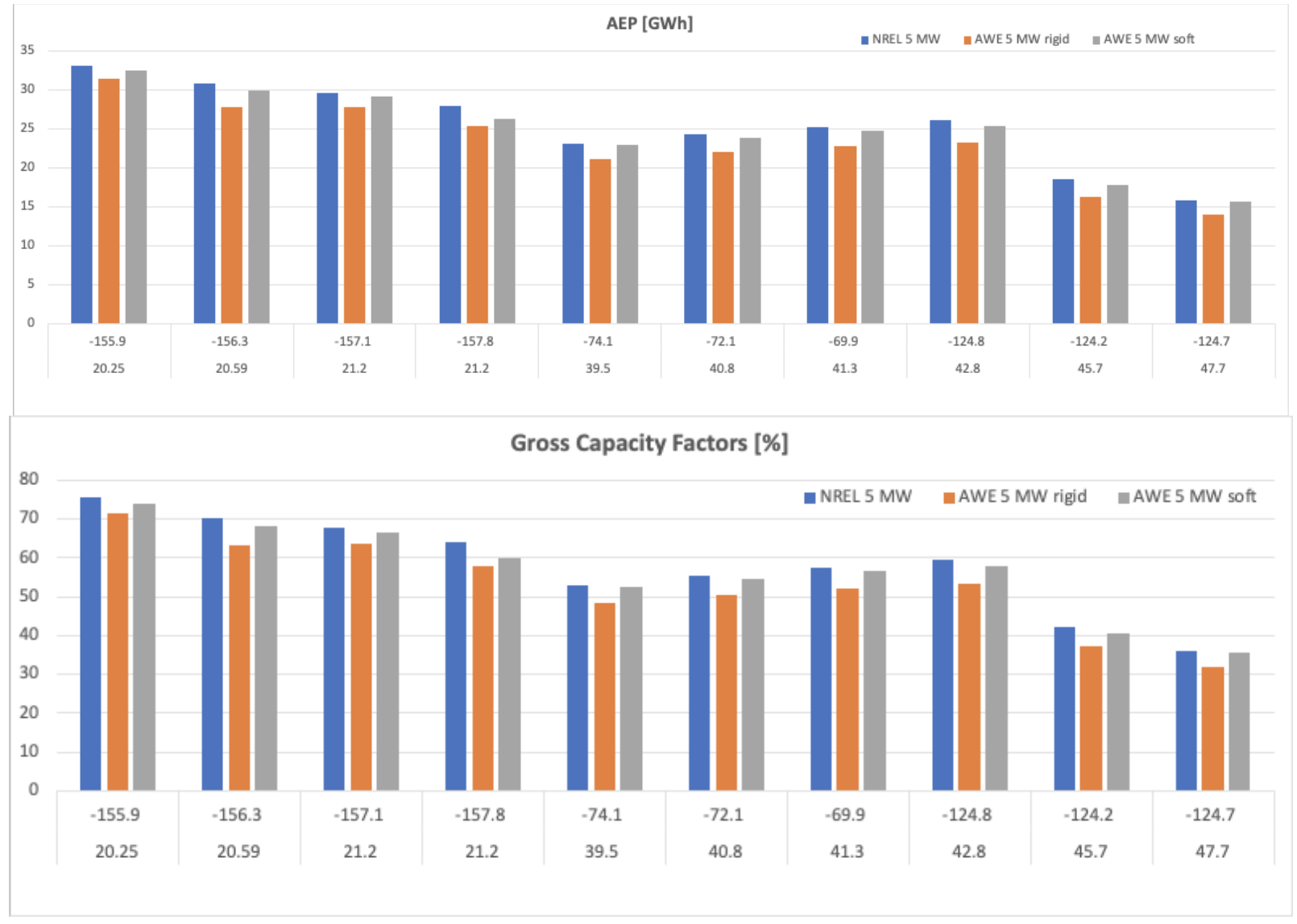

Figure 21. (top) AEP estimates and (bottom) gross capacity factor (averaged over 20 years) for selected locations offshore (indicated by longitude/latitude, see Figure 12). The calculations assume $100 \%$ availability.

All calculations assume 100\% availability. A 50\% loss factor that approximates the effects of aerodynamic, mechanical, electrical, and AWE-specific systems (such as the tether) is included in the AWE power curve and therefore implicitly considered in the energy calculations. This loss factor differs from the calculations for the NREL 5-MW wind turbine, which include electrical losses but neglect other losses (e.g., losses resulting from blade soiling, wake, and so on, representing total losses on the order of $10 \%$ of gross production). The power curve for the traditional wind turbines represents well-characterized performance values after decades of commercial technology development and refinement, whereas the ones for AWE are an estimate based on the state of research and technology development (Section 5.3.1). Note also that the assumptions for the AWE power curves might differ depending on the device.

\subsection{Further Research Areas}

Arent et al. (2011), Li et al. (2018), Miller and Keith (2018), Vautard et al. (2014), and Pryor et al. (2020) investigated the impact of wind power plants and solar farms on the climate. The impact of climate change on wind and solar power generation has also been researched (Craig et al. [2018, 2019] Losada Carreno et al. [2020], Haupt et al. [2016], Karnauskas et al. [2018]). Areas for future research include investigating the possibility that high-altitude wind power devices could alter the general circulation patterns and have significant effects on global and local climate, and the potential for climate change to alter the wind resource between 100 and 
$500 \mathrm{~m}$ above ground. Archer and Caldeira (2009) predict some changes to temperature, precipitation, and greater sea ice cover worldwide because of deploying AWE devices. They also state that further studies are necessary. Using a climate model, Marvel et al. (2013) find, in a highly theoretical study, that uniformly distributed wind turbines generating the entire global primary power demand of 18 terawatts are unlikely to substantially affect the climate.

Another area of research that is well underway for traditional wind turbines but only nascent in AWE is wake effects: whether AWE devices produce wakes, if they can affect each other in an operational setup, and whether these wakes alter local conditions and the weather. KaufmanMartin (2021) and Haas and Meyers (2017) have studied wakes for AWE. According to workshop participants, wake losses are expected to be minimal, but experts expressed a need to confirm this assumption, especially for large field deployments (Weber et al. 2021).

Extreme events should be investigated as well. It is assumed that AWE devices could be secured before the arrival of a hurricane, for example, but further research is needed.

\subsection{Conclusion on Resource Potential and Energy Output}

The wind resource at altitudes viable for airborne wind energy depends on location and experiences daily and annual variations. In general, wind speed increases with height up to 300 $\mathrm{m}$, whereas above $300 \mathrm{~m}$ the average wind speed profiles show little change. Any discussion about the wind resource should include tether length and elevation angle, as they tend to significantly reduce energy capture gains from higher heights (based on the generic technology design assumptions used here). Calculated gross capacity factors at selected sites using simulated wind speeds across 20 years (assuming 100\% availability, using power curves from Section 5.3.1) are similar.

Our studies indicate that AWE and traditional wind energy are competitors for the best resource locations (i.e., the windiest spots for traditional wind turbines are also the windiest spots for AWE devices). Malz (2020) analyzed wind profiles using ERA5 data and concludes that the annual generation profiles for AWE systems and traditional wind turbines are strongly correlated in time. They further find that "AWE is most valuable to the electricity system if installed at sites with low wind speed within a region. At greater shares of the electricity system, even if AWEs could demonstrate lower costs compared to wind turbines, AWE would merely substitute for them instead of increasing the total share of wind energy in the system."

Recommendations for future research include gaining a better understanding of turbulence, gusts, fluctuations, and intermittency of the airborne wind energy resource. Instrumental campaigns (for example, deployment of lidars) that can give insights into these research topics are needed. Experts recommend evaluating AWE devices with regards to high-wind performance, high-wind controls, and safety relating to gusts (e.g., how to dampen out instantaneous power surges). Echeverri (2020) was recommended as a rich source of ideas in this area. Design atmospheric conditions for AWE systems are another research area, (e.g., do devices need to be able to survive a gust with a 50-year return period?) Future research should also address climate impacts on the wind resource, wakes, and extreme events. 


\section{Technical Potential, Social and Environmental Considerations, and Permitting}

In this section, we identify social, environmental, and regulatory factors that may impact siting decisions for AWE systems and estimate the technical potential for land-based AWE in the United States.

\subsection{Key Findings}

The following are key findings in the technical potential; social and environmental considerations; and permitting of AWE:

- Tether lengths are an important driver for setbacks (minimum distances from civil infrastructure), and they are likely to vary between AWE designs and sites.

- Land-based technical potential in the conterminous United States varies drastically between AWE designs, ranging from 420 to 34,573 gigawatts (GW) and 1,615 to 92,469 terawatt-hours.

- The U.S. Department of Defense (DOD), Federal Aviation Administration (FAA), and North American Aerospace Defense Command (NORAD) will evaluate AWE siting considerations on a case-by-case basis.

- Evaluating the wind resource at additional heights is needed to assess the potential advantages of higher operational wind speeds.

\subsection{Background in AWE Technical Potential, Social and Environmental Considerations, and Permitting}

This section provides information on the background and context of assessing the technical potential, social and environmental considerations, and anticipated factors in permitting of AWE.

\section{Research Questions and Challenges}

The following are areas for further research related to assessing the technical potential, social and environmental considerations, and anticipated factors in permitting of AWE:

- Further research is needed to understand potential impacts of AWE on wildlife. Specifically, assessing bird and bat risk, as well as potential impacts to prairie grouse species.

- Further research is needed to assess social acceptance of AWE. Key factors include viewshed, lighting, and safety.

- Continued assessment of the potential capacity density of arrays of AWE systems will improve estimates of technical potential and further illuminate possible implications for wildlife and social interactions.

- Assessing AWE offshore technical potential is needed.

- Identifying locations where opportunities for AWE and traditional wind are spatially distinct will illuminate potential sites or markets. 


\section{Methods and Tools Needed}

The following are methods and tools needed in assessing the technical potential, social and environmental considerations, and anticipated factors in permitting of AWE:

- Assessing wildlife exposure and risk is needed first, and depending on the implications of those assessments, mitigation and avoidance strategies need to be established.

- Wind resource assessment across the range of AWE operational heights is needed. Currently, high-resolution (spatial and temporal) wind resource data for the entire United States is limited to $200 \mathrm{~m}$.

Renewable energy "potential" is often assessed in terms of resource (or geographic), technical, economic, and market potential (Figure 22). Each measure represents additional complexity and input assumptions that leverage similar data and a common analysis flow (Lopez et al. 2021). Technical potential represents the upper bound of achievable capacity and energy production given social, environmental, and regulatory spatial considerations combined with technology performance and density assumptions. Spatial considerations are represented as spatial constraints to resource potential, capturing already-occupied land (e.g., civil infrastructure, buildings, and so on), safety requirements (e.g., siting ordinances), or locations where development might be challenging because of land management strategies (e.g., national parks, conservation easements, threatened and endangered species habitats).

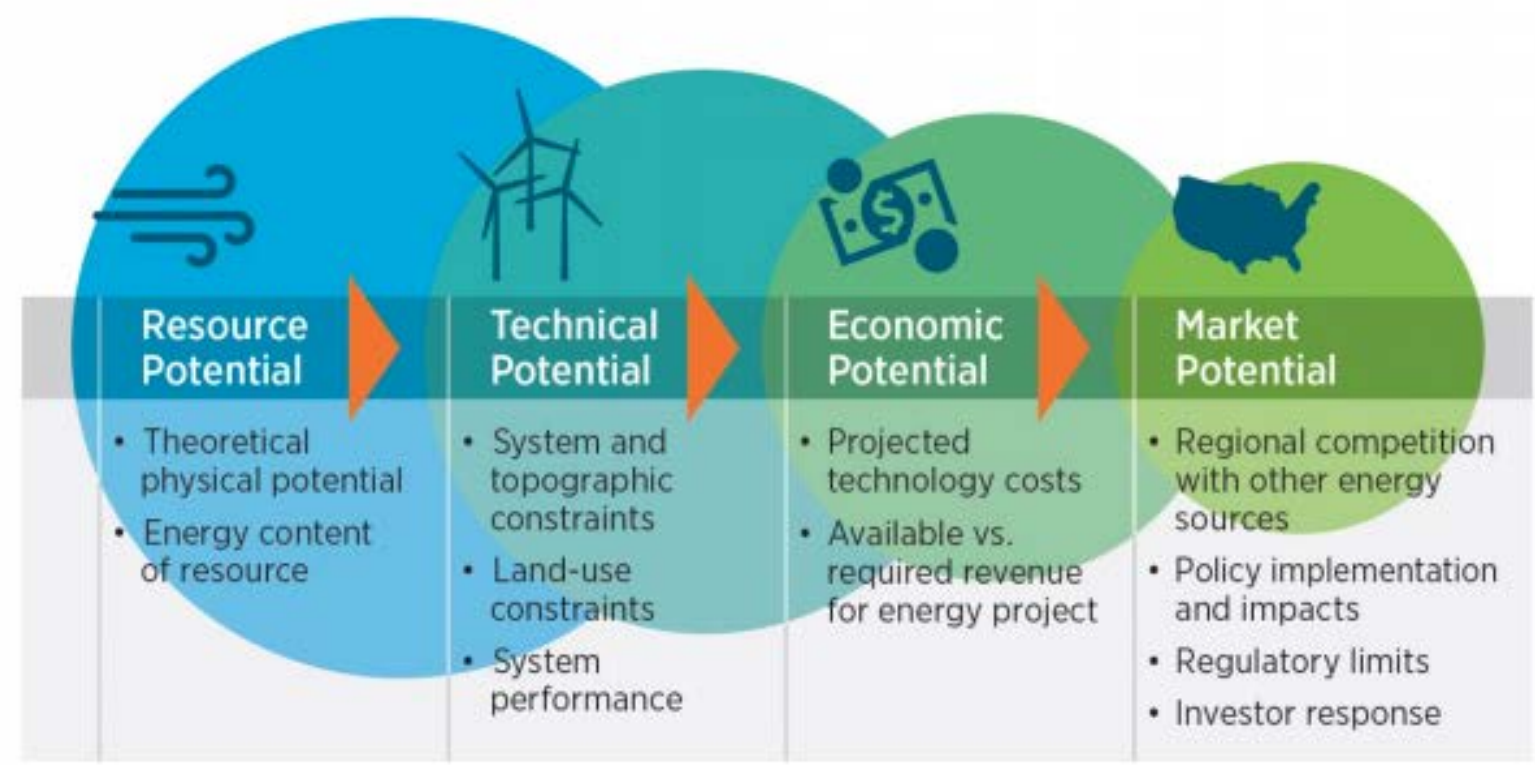

Figure 22. Renewable energy potential. Image from Brown et al. (2016)

Critical to assessing technical potential is an understanding that land-use objectives are fluid and evolving over time and space as communities prepare or react to energy development or potential wildlife impacts are identified (Lopez et al. 2021; Wu et al. 2020; Beiter et al. 2016). Further, technology is constantly evolving, leading to increased energy production (Wiser et al. 2020) and changing footprints. Current practices to capture these dynamics involve periodic updates to technical potential in addition to bracketing estimates through scenario analysis. 
As described in the following sections, given the novelty of AWE, lack of literature, and lack of existing deployment make siting considerations difficult to anticipate. Furthermore, AWE has operational characteristics that are significantly different than traditional wind technology, making it difficult to leverage or define analogs based on decades of wind, ecological, and social research. To augment what little is known, NREL conducted interviews and held a workshop with leading wind researchers in the ecological and social domains, experts in military and civil radar regulatory requirements, and AWE technology experts.

From a siting perspective, airborne wind energy could provide additional opportunities for deployment in areas that are difficult for traditional wind turbine technology (e.g., steep terrain, or remote locations with limited transportation infrastructure). However, critical questions remain as to the potential environmental and social impacts of AWE. In the following sections, we synthesize high-level research needs and potential impacts gathered through the workshop and interviews. In the final section, we present the technical potential for eight different AWE technologies with plausible siting constraints.

\subsection{Environmental and Ecological Siting Considerations}

Of critical concern is how wildlife, particularly bird and bat populations, might interact with AWE. Little is known about how wildlife will interact with AWE; however, two studies represent a first attempt to quantify potential interactions. First, a study from Norway (Håland 2018) examined the interaction between AWE and local bird species, providing a single study of potential impacts. In that study, it was found that overall, the potential impact of AWE is low; however, it recommended further studies and exploration of mitigation measures. Second, a study by AMPYX Energy (Schmehl 2018) developed a theoretical model and predicted that their system would cause an average of 2-13 bird kills because of the kite and 11 bird kills because of the tether per year of continuous operation. The author concludes that this is within the range of bird kills at traditional wind facilities (0.6-63 fatalities per year; median value 7).

Given the significant operational differences between AWE and traditional wind turbine technology, few analogs for expected impacts are available. However, existing research into traditional wind turbine technology and interactions with wildlife help to formulate first-order siting considerations and critical research questions for AWE. In addition, research into wildlife interactions with power lines, aircraft, lighthouses, TV towers, and various communications facilities/towers can provide a useful perspective for research on AWE (Håland 2018). Because of limited literature on potential environmental impacts, NREL conducted expert interviews with leading wind and wildlife biologists and ecologists to identify possible concerns and research needs.

A primary concern is better understanding possible lighting requirements for AWE, originating from the FAA. Current lighting recommendations for traditional wind turbines have been shown not to increase collision risk to bats and migrating songbirds (National Wind Coordinating Collaborative 2010). Thus, it can be reasonably assumed that if the FAA allowed similar lighting practices (e.g., momentary flashes 3 seconds in duration) for AWE, attraction of wildlife would be similarly low. Another primary concern is the collision risk associated with the AWE tether or secondary entanglement (e.g., with marine mammals) from a failed operation. (This risk was found to be minimal in the Norwegian study but may depend on context). Further, grassland habitat loss is a concern for prairie grouse species, and they may see increased predation because 
of any towers or transmission lines associated with development. In addition, consistent with recommended practice for traditional wind, ecologists and biologists recommended avoiding known sensitive or high-abundance locations, including bat roost locations, orographic uplift areas preferred by eagles, and prairie grouse lek sites. Lastly, in interviews and workshop discussions, AWE technology developers expressed the assumption that the flight height of AWE systems was an advantage for avoiding bird and bat species; however, this assumption was refuted by wildlife experts who say that a $200-\mathrm{m}$ to $500-\mathrm{m}$ operation range is within the primary use space and abundance for most species.

Ultimately, to determine the impact of various AWE designs on wildlife, the use of specific sites by individual species needs to be determined, which would enable evaluating exposure by species and finally lead to the ability to assess risk to individual species. Conducting this type of research for the operational range of AWE may require sophisticated radar, near infrared, and thermal videography. These monitoring technologies could be expensive and difficult to implement, especially in offshore environments.

\subsection{Social Siting Considerations}

Like the environmental siting considerations, little is known regarding the social dynamics and resulting considerations that may unfold for AWE given the lack of literature or deployment experience. To supplement what little is known, NREL conducted expert interviews with leading traditional wind energy social dynamics researchers. There were three primary concerns for AWE from a social perspective: safety concerns, required setbacks from civil infrastructure, and visual impacts. Traditional wind turbines must typically maintain a minimum distance between the turbine tower and buildings, roads, railroads, and transmission lines. Setbacks are established by cities and counties (and some states) and are encouraged as a best management practice by developers. Typical setbacks in the United States are 1.1 times the maximum tip height of the turbine (Lopez et al. 2021), but European countries have established setbacks as long as $1 \mathrm{~km}$ (Dalla Longa et al. 2018). As shown in Section 7.5, setback requirements will be the primary driver for the overall potential of AWE. Another point of concern for AWE in common with traditional wind turbines is viewshed impacts to society. Research has shown that for traditional wind, turbines spinning during the day have a greater visual impact than nonsynchronous lighting at night (Firestone et al. 2018). In addition, angling lighting away from populated areas has proven to be an effective strategy to minimize visual disturbance. However, this strategy may not be achievable for AWE devices following time-varying flight paths.

To better determine society's acceptance of AWE, we recommend conducting AWE simulations of lighting for varying sizes and proximity to settlements, assessing people's willingness to pay or be paid for AWE operational characteristics, and assessing deployment in underserved communities to determine their perceptions. Lastly, as is critical to all energy development, community acceptance (or annoyance) is vastly improved when individuals in the proximity of development feel they have a say in the siting and permitting process.

\subsection{Department of Defense, Radar, and Federal Aviation Administration Siting Considerations}

Siting AWE devices may be more challenging than traditional wind turbines because of the elevations at which AWE devices would function. Close coordination with the FAA and DOD 
early in the site-selection phase is critical to successfully deploying AWE devices. DOD and NORAD strongly encourage airborne wind energy developers to engage with the DOD Clearinghouse early and often in the site-selection process.

\subsubsection{Federal Aviation Administration}

The FAA excludes tethered aircraft from regulations that apply to other aircraft, treating AWES purely as obstacles. The FAA concludes that AWE should be studied on a case-by-case basis with respect to the surrounding aviation environment to ensure aviation safety (European Commission 2018). The FAA offers a service for obstruction evaluation and a website ${ }^{3}$ that is helpful in performing an initial screening for proposed AWE locations. These circumstances appear to offer a significant advantage over other jurisdictions (e.g., the European Union), where tethered aircraft are considered aircraft.

AWE devices will likely produce a radar signature and noise because of the motion of the AWE. The material of the AWE wing, flight speed, and turning rate will likely impact the signature of the AWE to radar. Guidelines for AWE flight heights near radar installations need to be established in a clear manner to provide AWE developers with clear directives regarding tether lengths and operational heights.

Traditional wind turbine tip heights are typically 500 feet, but tip heights are increasing. Avoidance of radar line of sight at these tip heights is unlikely, as 50-60 nautical miles from a radar installation is required for turbine tips to fall below the horizon. AWE devices may function at even higher flight heights, which will increase their visibility to radar.

In 2014, a memorandum of understanding was signed by DOD, DOE, FAA, and the U.S. Department of the Interior to form the Wind Turbine-Radar Interference Mitigation Working Group ${ }^{4}$ and develop the Federal Interagency Wind Turbine Radar Interference Mitigation Strategy. ${ }^{5}$ Leveraging these efforts by AWE developers may be advantageous for the demonstration and deployment of AWE devices.

\subsubsection{U.S. Department of Defense Airspace}

The DOD Clearinghouse offers a service at no cost to developers and private parties to assist in siting any structure within DOD airspace or radar viewshed. DOD and NORAD highly recommend coordinating "early and often" with the DOD Clearinghouse on potential evaluation or deployment locations (https://www.acq.osd.mil/dodsc/).

Figure 23 shows DOD training and operation airspace, which covers a large fraction of the continental and offshore United States. Many existing wind farms have been approved by DOD within these flight paths and DOD stressed that these flight paths are not exclusions to AWE but that coordination with DOD is highly recommended. The center of each flight path is the most

\footnotetext{
${ }^{3}$ https://oeaaa.faa.gov/oeaaa/external/portal.jsp

${ }^{4}$ https://windexchange.energy.gov/projects/radar-interference-working-group

5 https://www.energy.gov/eere/wind/downloads/federal-interagency-wind-turbine-radar-interference-mitigationstrategy
} 
valuable and frequently flown portion, which should be considered in the initial screening process of AWE sites.

For offshore AWE deployment, the elevations used by DOD are typically higher nearshore and lower farther offshore. Thus, siting large AWE devices farther offshore may require more consideration for DOD airspace. An additional consideration offshore relates to the acoustic monitoring of substructures, which — if used — could lead to additional DOD security concerns around surveillance.

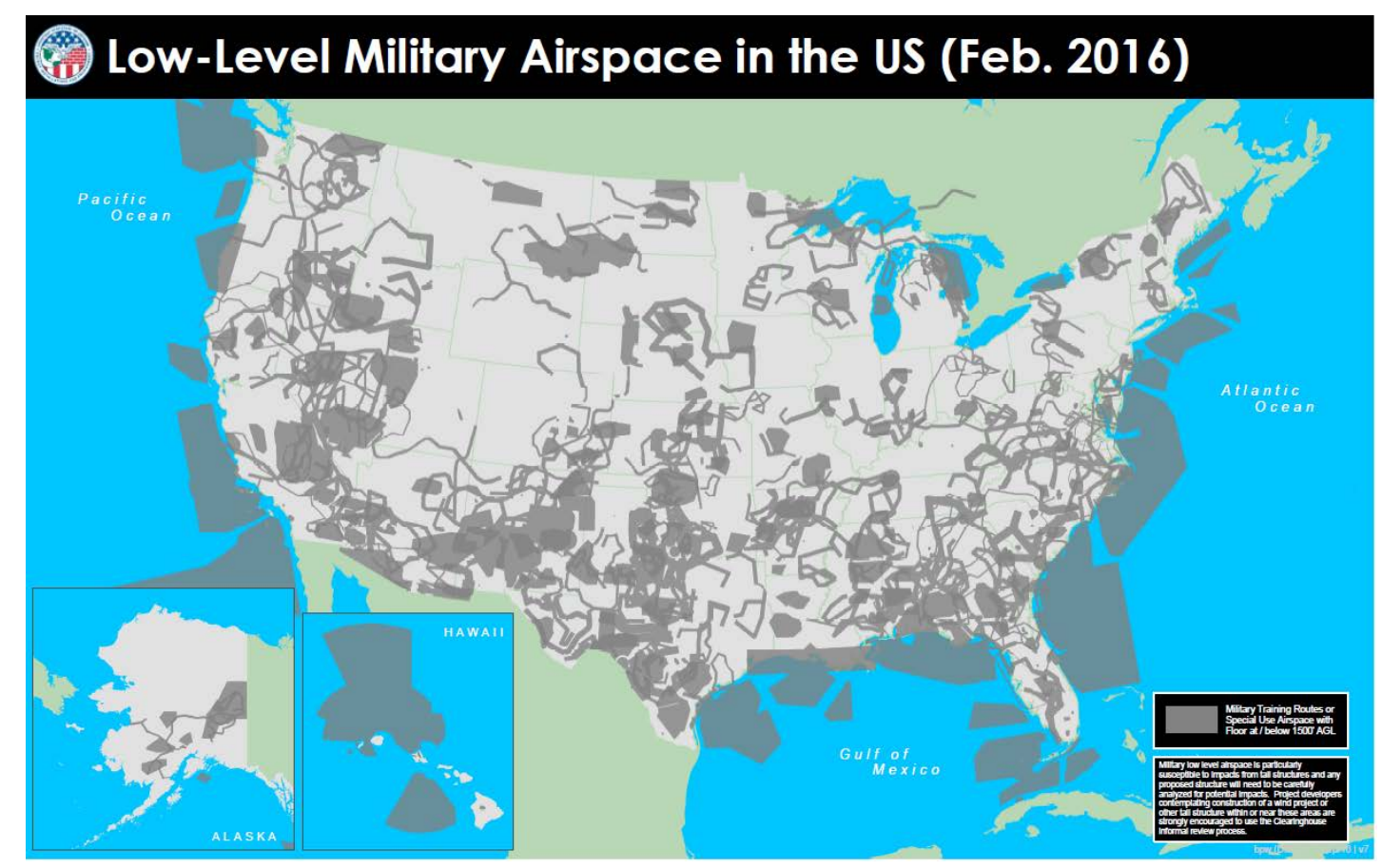

Figure 23. Low-level military flight paths. Image from the Military Aviation and Installation, Assurance Siting Clearing House

DOD will require review of all components and countries of origin because of security and surveillance concerns. DOD may require the ability to shut down both airborne and traditional wind turbines in case of a national emergency or training exercises. Traditional wind turbines can stop rotor rotation in less than 1 minute, whereas AWE devices may require more time to return to the ground depending on tether length, wind speed, and position of the AWE within its cycle. Coordination with DOD around the length of time required by AWE devices to be grounded is critical to siting those devices.

DOD suggested that AWE research facility sites within or around existing traditional wind turbine farms may be advantageous, as those farms have already been evaluated by DOD and additional radar impact by AWE devices may be minimal. Close coordination with DOD on these opportunities is highly recommended, depending on the impact to radar of the existing wind farm and the proposed AWE location, tether length, and flight path. 


\subsection{Technical Potential Results}

Notwithstanding the list of concerns listed in the previous sections, AWE has a large technical potential within the contiguous United States. To estimate technical potential for land-based AWE, we used key assumptions defined in Section 5. Those assumptions include the capacity density $\left(\mathrm{MW} / \mathrm{km}^{2}\right)$, power curve, wind speed at a 200-m height (the maximum height available in the wind data set used for land-based wind, discussed in Section 4), and tether length (meters) to determine approximate setback requirements from civil infrastructure. A notable limitation to this analysis is the use of wind speeds at $200 \mathrm{~m}$ for all AWE technologies regardless of tether length and operational height. This limitation is because of the lack of wind speed data above $200 \mathrm{~m}$ for the contiguous United States in the Wind Integration National Dataset Toolkit (WIND Toolkit) data. In addition, we also used plausible siting constraints based on traditional wind (Lopez et al. 2021) to restrict AWE deployment in unlikely or infeasible locations (e.g., legally, or administratively protected lands like national parks). A full list of exclusions used is provided in Table 6.

To estimate AWE technical potential, we use the Renewable Energy Potential model (Maclaurin et al. 2019), that assesses land availability on a 90-m spatial grid and leverages the WIND Toolkit (Draxl et al. 2015) for estimating generation potential given a power curve.

Table 6. Siting Restrictions for AWE Technical Potential Estimation

\begin{tabular}{|c|c|}
\hline Siting Exclusion Category & Exclusion Details \\
\hline \multicolumn{2}{|l|}{ Infrastructure } \\
\hline $\begin{array}{l}\text { Setbacks to transmission right of ways, railroads, } \\
\text { roads, building structures }\end{array}$ & $\begin{array}{l}\text { Setback }=1.25 x \text { tether length }=(1,250 \mathrm{~m}, 875 \mathrm{~m}, 750 \mathrm{~m}, 625 \mathrm{~m} \text {, } \\
438 \mathrm{~m}, 375 \mathrm{~m}, 250 \mathrm{~m})\end{array}$ \\
\hline Urban areas and airports & Excluded, airports w/10-km setback \\
\hline Radar & 4-km NEXRAD, 9-km short-range Radar/long-range radar \\
\hline \multicolumn{2}{|l|}{ Regulatory } \\
\hline $\begin{array}{l}\text { Protected public lands and conservation } \\
\text { easements }\end{array}$ & Excluded \\
\hline \multicolumn{2}{|l|}{ Physical } \\
\hline Slope $>25 \%$ & Excluded \\
\hline $\begin{array}{l}\text { Mountainous landforms and high }(>9,000 \mathrm{ft}) \\
\text { elevation }\end{array}$ & Excluded \\
\hline Water and wetlands (with a 305-m buffer) & Excluded \\
\hline
\end{tabular}

Tether lengths are an important driver for setbacks, and they are likely to vary between AWE designs and sites. Figure 24 demonstrates the importance of tether length and its influence on land availability when considering setbacks from civil infrastructure. Exploring a broad range of tether lengths was recommended by workshop participants and is included in this assessment. 

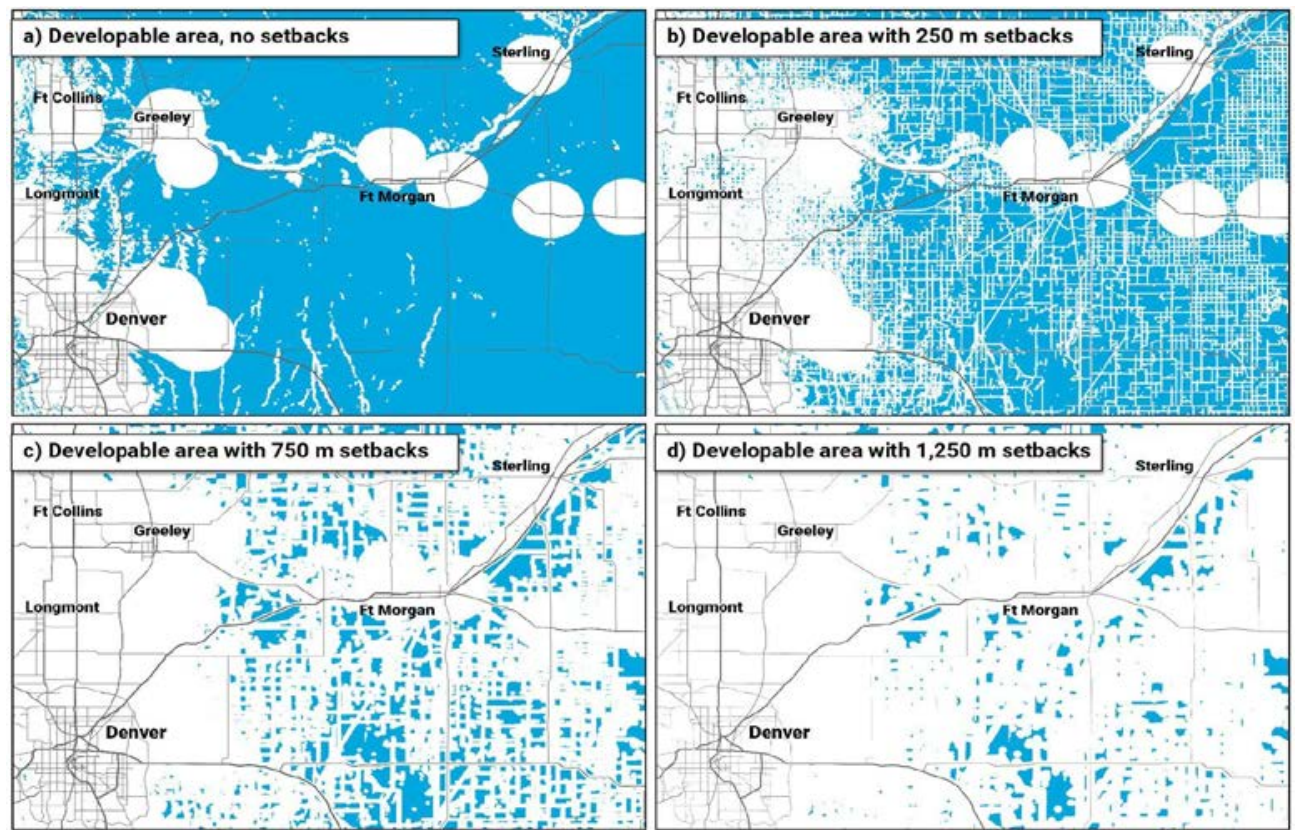

Figure 24. Four maps demonstrating the influences of tether length and setback on developable areas. Blue represents developable areas for AWE: a) all exclusions except setbacks, b) all exclusions plus a $250-\mathrm{m}$ setback requirement, c) all exclusions plus a $750-\mathrm{m}$ setback, and d) all exclusions plus a 1,250-m setback requirement.

Figure 25 shows developable areas across the contiguous United States considering all exclusions presented in Table 3 and using a 750-m setback requirement. Most of the technical potential exists in the western United States, where population and civil infrastructure are less dense, providing opportunities for AWE deployment, although these areas are also likely farther from the transmission infrastructure needed for grid interconnection. While implications for AWE deployment in forested areas were not explicitly discussed with environmental experts, it was discussed with workshop participants who expressed the view that operation within forested areas would be difficult and would likely require some forest clearing. Forest exclusions were not applied in this analysis, but they do merit further research and consideration and are likely to be an additional large driver of estimated technical potential. 


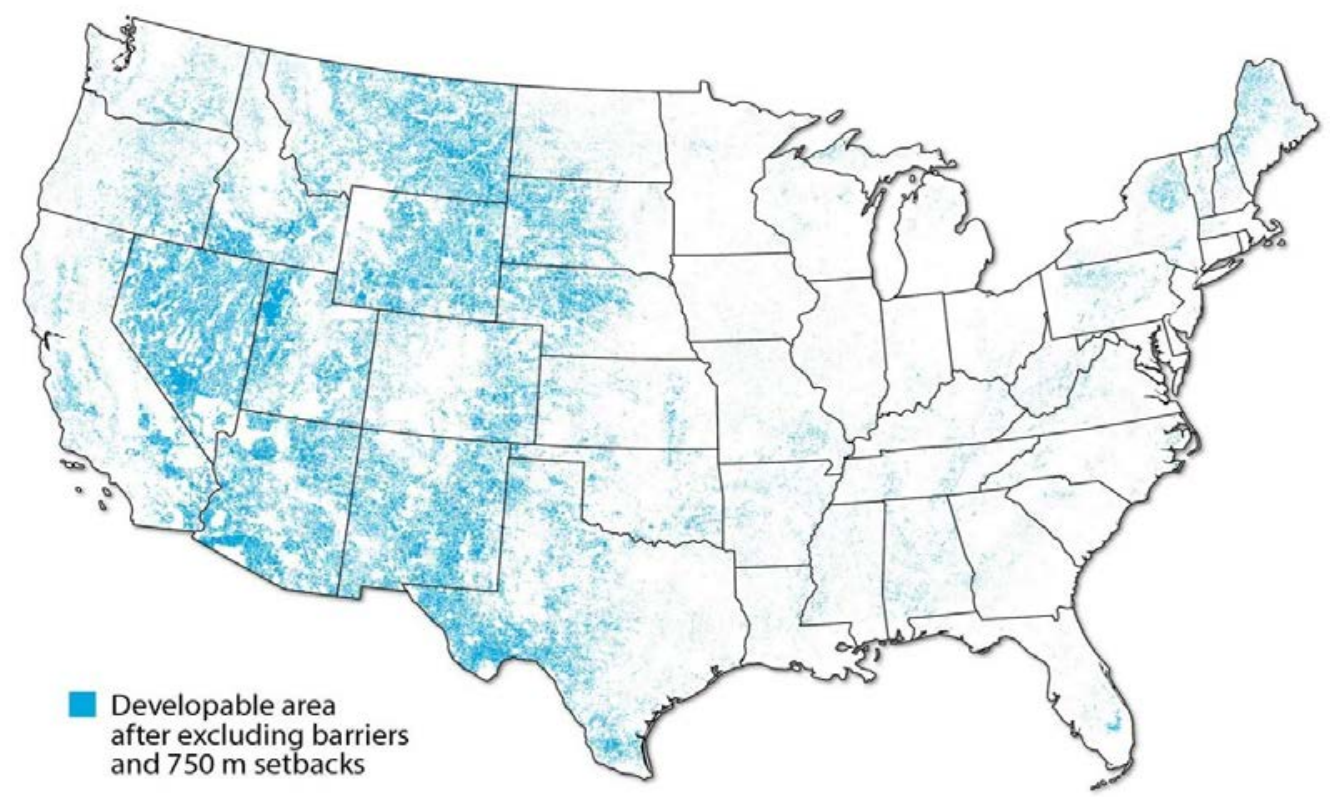

Figure 25. Developable areas for AWE considering all exclusions and a 750-m setback requirement from civil infrastructure

Technical potential results for AWE are presented in Table 7. Traditional wind technical potential from Lopez et al. (2021) is included for comparison purposes. Three levels of access scenarios are presented for comparison. Each scenario uses the same wind turbine and capacity density, but siting exclusions vary based on plausible siting restrictiveness. For AWE, all exclusions except setbacks are held constant across technology scenarios, revealing the large implications for tether length and its influence on technical potential for AWE.

While the assumed capacity density for traditional wind from Lopez et al. (2021) is $3 \mathrm{MW} / \mathrm{km}^{2}$, empirical wind farm capacities range from 1-18 MW/ $\mathrm{km}^{2}$ (Harrison-Atlas, Lopez, and Lantz, forthcoming) and offshore wind farm capacity densities range from 3.1 to $18.7 \mathrm{MW} / \mathrm{km}^{2}$ (Deutsche WindGuard GmbH 2018). These data illustrate the empirical variation of capacity densities that are observed for installed wind farms, which are influenced by resource, technology, power prices, siting constraints, specific power, and other factors. Thus, the wide range of technical potential capacities estimated here for AWE devices is plausible depending on the influences of the aforementioned factors. 
Table 7. Technical Potential Results for Modeled AWE Technologies with Varying Tether Lengths

\begin{tabular}{|c|c|c|c|c|c|c|}
\hline Technology & $\begin{array}{l}\text { Setback From } \\
\text { Civil } \\
\text { Infrastructure } \\
\text { (m) }\end{array}$ & $\begin{array}{l}\text { Capacity } \\
\text { Density } \\
\left(\mathrm{MW} / \mathrm{km}^{2}\right)\end{array}$ & $\begin{array}{l}\text { Available } \\
\text { Land Area } \\
\left(\mathrm{km}^{2}\right)\end{array}$ & $\begin{array}{l}\text { Nationwide } \\
\text { Mean Capacity } \\
\text { Factor (std) }\end{array}$ & GW & $\begin{array}{l}\text { Terawatt- } \\
\text { hours }\end{array}$ \\
\hline $\begin{array}{l}\text { Traditional Wind - } \\
\text { ATB Moderate, } \\
\text { Reference Siting } \\
\text { Regime }\end{array}$ & 228 & 3 & $2,616,687$ & $0.36(0.09)$ & 7,827 & 24,679 \\
\hline $\begin{array}{l}\text { Traditional Wind - } \\
\text { ATB Moderate, Open- } \\
\text { Access Siting Regime }\end{array}$ & 0 & 3 & $5,058,384$ & $0.36(0.09)$ & 15,175 & 47,717 \\
\hline $\begin{array}{l}\text { Traditional Wind - } \\
\text { ATB Moderate, } \\
\text { Limited Access Siting } \\
\text { Regime }\end{array}$ & 622 & 3 & 760,188 & $0.36(0.09)$ & 2,280 & 7,332 \\
\hline $\begin{array}{l}\text { Rigid-wing } 500 \mathrm{~kW} \\
\text { (short tether) }\end{array}$ & 250 & 3.98 & $2,269,240$ & $0.48(0.11)$ & 9,029 & 36,993 \\
\hline $\begin{array}{l}\text { Rigid-wing } 500 \mathrm{~kW} \\
\text { (long tether) }\end{array}$ & 625 & 0.64 & $1,142,870$ & $0.48(0.12)$ & 727 & 2,829 \\
\hline $\begin{array}{l}\text { Rigid-wing } 5 \mathrm{MW} \\
\text { (short tether) }\end{array}$ & 375 & 19.6 & $1,764,210$ & $0.32(0.1)$ & 34,573 & 92,469 \\
\hline $\begin{array}{l}\text { Rigid-wing } 5 \mathrm{MW} \\
\text { (long tether) }\end{array}$ & 1,250 & 8.72 & 530,285 & $0.3(0.1)$ & 4,623 & 11,209 \\
\hline $\begin{array}{l}\text { Flexible-wing } 500 \mathrm{~kW} \\
\text { (short tether) }\end{array}$ & 438 & 1.3 & $1,567,757$ & $0.48(0.11)$ & 2,036 & 8,125 \\
\hline $\begin{array}{l}\text { Flexible-wing } 500 \mathrm{~kW} \\
\text { (long tether) }\end{array}$ & 750 & 0.44 & 951,804 & $0.47(0.12)$ & 420 & 1,615 \\
\hline $\begin{array}{l}\text { Flexible-wing } 5 \mathrm{MW} \\
\text { (short tether) }\end{array}$ & 875 & 3.08 & 811,621 & $0.31(0.1)$ & 2,499 & 6,219 \\
\hline $\begin{array}{l}\text { Flexible-wing } 5 \mathrm{MW} \\
\text { (long tether) }\end{array}$ & 1,250 & 2 & 530,285 & $0.3(0.1)$ & 1,059 & 2,568 \\
\hline
\end{tabular}

While the national summaries provide a quantification of national potential, they obscure regional trends and opportunities. Maps presented in Figure 24 reveal these regional trends and opportunities for different AWE technologies. Flexible-wing technologies have relatively higher capacity factors than rigid-wind technologies, albeit the highest capacity factors are spatially coincident with the traditional wind belt (Great Plains and midwestern United States). However, because of a combination of longer tether lengths and lower capacity densities, there are fewer opportunities for development. Conversely, the rigid-wing technologies have lower relative capacity factors and higher capacity densities, which implies that larger quantities of rigid-wing technologies could be deployed, albeit with lower energy output per unit of land area. 

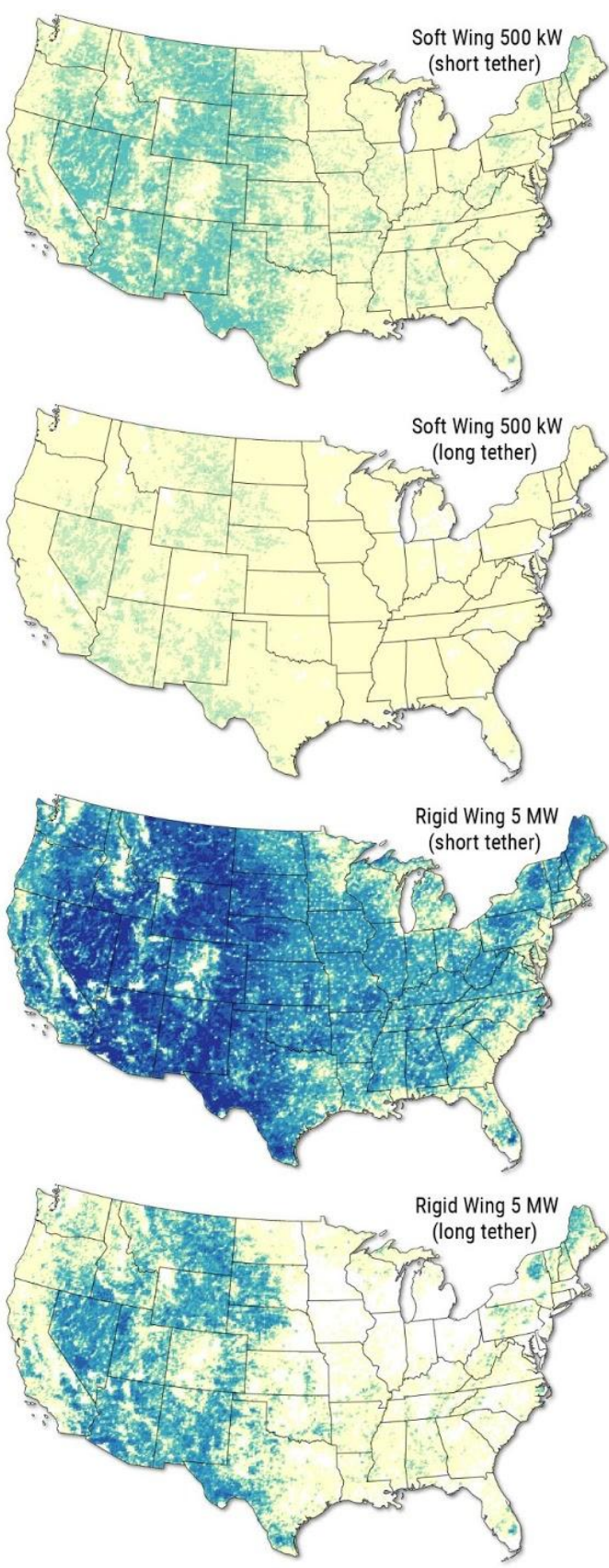

Capacity

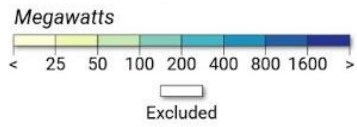

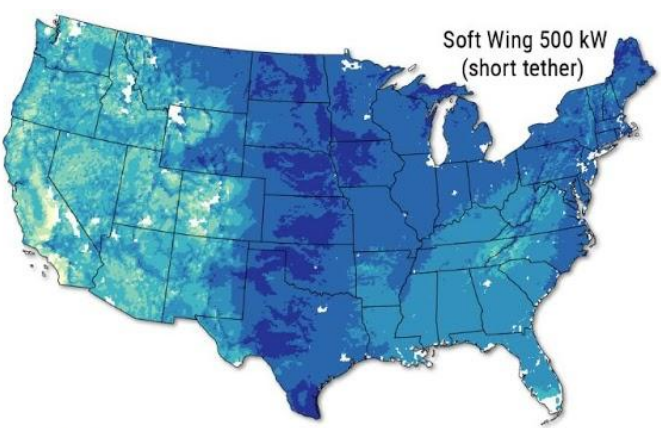
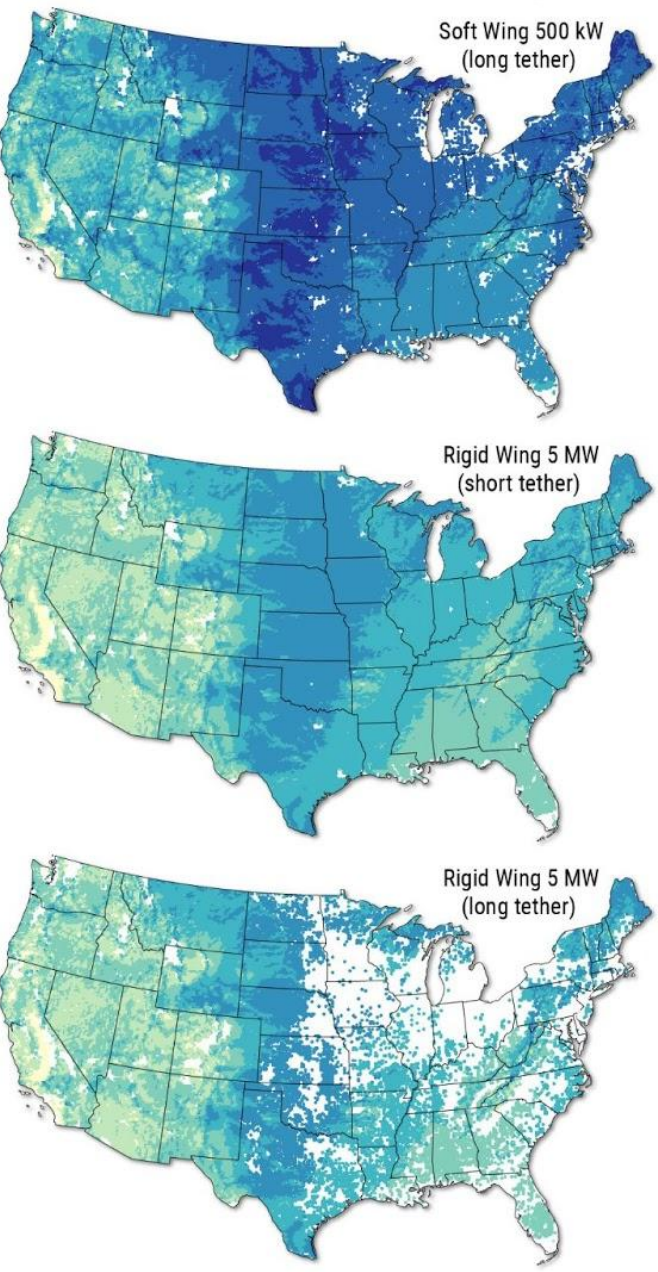

Capacity Factor

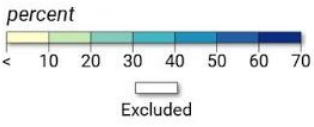

Figure 26. Capacity (left) and capacity factor (right) maps for select AWE technologies. Image created by Billy Roberts, NREL

While these results present a first attempt at estimating the technical potential of AWE, further research into the ecological, social, and technical constraints and considerations is needed to 
refine these estimates and provide a bracketed assessment of AWE's technical potential. A recent report published by the United States Geological Survey (Remington et al. 2021) on the state of America's sagebrush ecosystem revealed a need for broad conservation strategies.

Coincidentally, the research here shows a vast amount of AWE opportunities in sagebrush habitat that may need to be revisited. Lastly, participants in the AWE workshop said their current focus is on land-based applications; however, they do have a long-term goal of deploying offshore. Through simple extrapolation of traditional offshore wind technical potential (Musial et al. 2016), and by using an assumed capacity density of $1.43 \mathrm{MW} / \mathrm{km}^{2}$, which considers 1 nautical-mile spacing requirements for vessel navigation, we estimate the offshore AWE technical potential to be roughly 1,293 GW for a 5-MW system. Through this simple extrapolation, we find that AWE offshore potential is large; however, the unique challenges of deploying offshore require more rigorous assessment to determine the true potential and we recommend conducting further study of offshore environmental and social considerations for AWE. 


\section{Demonstration, Commercialization, and Road Map}

This section discusses requirements for demonstration and commercialization of AWE devices and presents a road map for future research, development, and deployment.

\subsection{Key Findings}

The following are key findings in demonstration and a road map for commercialization of AWE:

- Many companies target small device sizes and niche markets to gain operational hours, which reduces investors' perception of risks and enables production economies of scale and upscaling to reach larger markets.

- Research facility sites that can host both small- and large-scale devices will allow for critical operational hours to develop understanding of turbulence and the atmosphere, design codes, controls, and materials.

- A gap exists between prototype and commercial deployment.

- Funding methods are needed.

\subsection{Background in AWE Demonstration and Commercialization}

This section provides information on the background and context of assessing AWE demonstration and commercialization needs, including key research questions and challenges and methods and tools we identified.

\section{Research Questions and Challenges}

The following are key research questions and challenges we identified to advance AWE demonstration and commercialization:

- Future research should focus on gaining operational hours, evaluation, and development of funding-support structures from prototype stage to commercial deployment at various device scales and sizes.

- There is a need to characterize technology operational parameters to enable development of policies and procedures for permitting AWE devices at the community, state, and national levels, with engagement of FAA and DOD, among other stakeholders.

- Research on technical potential, siting, and environmental issues is critical to determining markets for all stages of deployment.

- What markets exist where traditional wind cannot be deployed? (e.g., markets saturated by solar but with a limited nighttime wind resource).

- What events may trigger a rollout of this technology? Extreme weather, hurricanes, or military operations could encourage a rollout.

- What funding methods may assist in creating the AWE industry?

- How can AWE reduce perceived risks associated with a new technology? If the LCOE of AWE is equal to the LCOE of traditional wind, developers will not choose a less mature technology with more risk.

- What additional factors or metrics can influence the viability of AWE? AWE levelized cost of energy will have to be lower than that of traditional wind for it to be attractive to developers, or other qualities will have to be valued, such as material usage and recyclability. 


\section{Methods and Tools Needed}

The following are key methods and tools we identified as needed for AWE demonstration and commercialization:

- A road map for developing an AWE industry not only for technical progress but also to advance deployment

- Analysis of national siting, device size, and market potential as technology matures

- Developing a plan and road map for government funding to support AWE companies financially and enable advancement along the learning curve as risk increases

- Programs such as the Competitiveness Improvement Project or design competitions like the Collegiate Wind Competition may also assist in accelerating the industry.

AWE technology is at an early stage of development, with few prototypes deployed and a low number of total operational hours. Demonstration and operation of AWE devices at various sizes are critical to developing understanding of these complex systems and scaling relationships. Developing and securing locations suitable for AWE demonstration are critical to the advancement of AWE. Research locations suitable for a wide range of device sizes help evaluate larger devices suitable for land-based and offshore wind applications. A research facility large enough to allow an array of devices to operate would also enable research on device wake interaction and grid integration. AWE devices may function at elevations above traditional wind turbines and will operate in significantly different areas of the atmosphere, which may impact airspace, wildlife, and radar in ways not yet understood. Evaluating and demonstrating AWE devices to develop best practices for commercial deployment of devices is critical to a future AWE industry.

\subsection{Market Development}

The Airborne Wind Europe "Policies for Airborne Wind Energy" 2018 report (Petrick 2018) details potential policy and support pathways to enable the AWE industry to reach commercialization. This report is an excellent reference to U.S. policymakers, private investors, local communities, and AWE companies that communicate a need for and potential pathways to developing a commercial AWE industry. As technology concepts advance from prototype evaluations to demonstrations, a "valley of death" gap may exist in which required investment to upscale increases while perceived risk by investors is also high (Petrick 2018; see Figure 27). Many AWE companies are nearing or within the demonstration phase and need policy, infrastructure, and funding support to reach commercial viability. 


\section{Maturity}

\begin{tabular}{|c||c||c||c||c|}
\hline Basic R\&D & $\begin{array}{c}\text { Applied R\&D, } \\
\text { Prototype }\end{array}$ & Demonstration & $\begin{array}{c}\text { Commercial } \\
\text { viability }\end{array}$ & Deployment \\
\hline \begin{tabular}{c|c|} 
Science or \\
industry led
\end{tabular} & Research Centers & $\begin{array}{c}\text { Part-scale Full- } \\
\text { scale }\end{array}$ & Dominant design & Fully-commercial \\
\hline
\end{tabular}

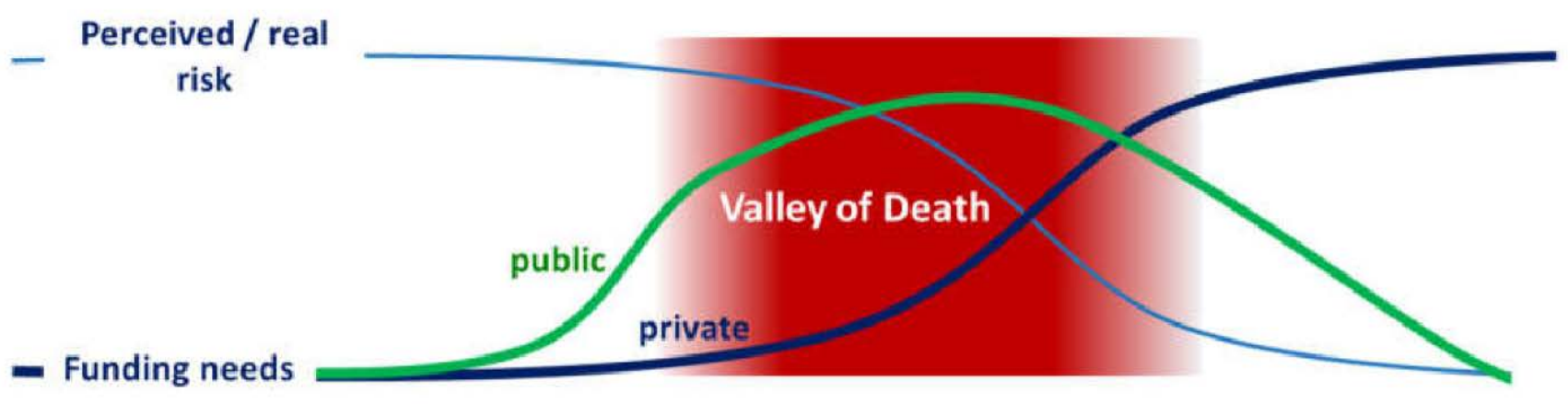

Figure 27. Funding needs increase and risks (perceived and real) decrease as prototype evaluation advances to demonstrations, but a "valley of death" gap exists, wherein funding needs and perceived risk by investors is also high. Image from Petrick (2018)

Demonstrating small-scale systems may be necessary to gain operational hours and reduce technical risk to utilities and investors. Some companies may elect to upscale devices for demonstration, which can accelerate commercialization of the concept but increase the capital requirements for upscaling, thereby increasing the risk of perceived failures. While small-scale systems may not be the intended final market, they must be commercialized to ensure an early revenue stream and show product potential to investors and utilities. In interviews, AWE companies and developers state that a research facility site would be very beneficial, as space is especially hard to find in Europe. A research facility site suitable for upscaled offshore devices on land would also reduce deployment cost, risk, and time. A land-based research facility site would accelerate timelines for developing siting and permitting policies and procedures by engaging stakeholders such as local, state, and national policymakers including DOD and FAA. A research facility site could also aid in conducting research around environmental impacts and shaping policy.

Markets identified for initial demonstration and early commercialization include the following:

- Military bases/operations

- Distributed generation and agriculture

- Island communities

- High-energy-cost communities (diesel grids)

- Communities susceptible to extreme winds such as hurricanes

- Sites with highly complex terrain

- International communities without access to reliable power. 
The markets identified here may represent high profit potential but typically high risk to operation and deployment with low total market volumes. Many companies identify these markets with 100 - to $500-\mathrm{kW}$ devices as an opportunity to gain operational experience and climb the learning curve while aiming toward an end goal of megawatt-scale land-based and offshore devices.

\subsubsection{Government and Stakeholder Commercialization Support}

Governments can greatly accelerate technology learning not only through financial support but also physical and social investment and learning. Many of the potential barriers to commercial deployment of AWE come from not only the technical learning required but also the ability to access markets. These considerations include the ability to site AWE devices, and a large contribution to the AWE industry can come from establishing policy and regulations. Specifically:

- Research covering the wind resource and profile at elevation, turbulence, and development of design code simulation and validation is critical to accelerating the AWE industry. Research facility sites are key to gaining operational hours for AWE devices. Governments can assist in identifying and permitting research facility sites to enable $\mathrm{R} \& \mathrm{D}$ of design software.

- DOD and FAA permitting and procedure development is a large task that cannot be achieved by a single company or group of companies. Governmental assistance in coordinating and developing policies and procedures for siting AWE devices would be of great value to the AWE industry.

- Standards regarding design and public safety are needed to gain public acceptance of AWE devices. Developing standards with federal, state, and local governments in concert with component and system design safety standards is critical to enabling deployment of AWE devices.

- Environmental research and policy creation can be enabled by governments through research facility sites and funding of research in coordination with the U.S. Fish and Wildlife Service and others.

- Precommercial demonstrations in coordination with local communities and authorities willing to host demonstrations are a critical step to reducing investors' perceived risk and enabling deployment and technology upscaling. Identifying communities interested in precommercial demonstrations is recommended to show the AWE industry pathways toward commercialization.

- Grid integration standards may be critical to AWE adoption depending on the device generation concept. Ground-gen systems require significant power consumption to reel in the aircraft and dedicated energy storage systems at the device level may become a significant system capital and operational cost. 


\subsection{Commercialization Scenarios}

Most renewable energy technologies have relied on incentives or support from governments. Solar photovoltaics, land-based wind, and offshore wind have all been supported by direct funding and revenue support. As technologies progress through the basic and applied R\&D stages toward demonstration, "push" policies, which provide investment or financial support, may be employed to encourage this research and learning. Once technologies reach demonstration and near commercial viability, "pull" policies, which provide revenue support, may be employed to enable the technology to reach a commercial, large-scale deployment.

"Just as subsidies like the production tax credit in the U.S. were essential to get traditional wind off the ground, substantial policy backing will likely be the only way airborne wind could see widespread adoption at competitive prices." (Shifman 2019)

Developing a plan for stages of financial support is critical to enabling a commercial selfsupporting AWE industry. Coordination between local, state, and federal governments is recommended to avoid gaps in technology evolution and learning (see Figure 28).

\begin{tabular}{|c|c|c|c|}
\hline Applied R\&D & Demonstration & $\begin{array}{l}\text { Commercial } \\
\text { viability }\end{array}$ & Deployment \\
\hline \multicolumn{4}{|c|}{ Valley of Death } \\
\hline \multicolumn{4}{|c|}{ 1. Push policies } \\
\hline \multirow{2}{*}{$\begin{array}{c}\text { Investment / Innovation support: } \\
\text { Grants, public equity, } \\
\text { low-interest loans, } \\
\text { tax credits }\end{array}$} & \multicolumn{3}{|c|}{ 2. Pull policies } \\
\hline & \multicolumn{3}{|c|}{$\begin{array}{l}\text { Revenue-support: } \\
\text { Feed-in-Tariffs / Premiums, } \\
\text { Contract for Difference, } \\
\text { Technology-specific auctions }\end{array}$} \\
\hline
\end{tabular}

Figure 28. The sequence and types of financial support mechanisms used to support a potential AWE industry. Image from Zillmann (2020) 


\section{Research and Technology Development Needs}

The AWE industry is currently limited by a lack of readily available resources for simulating and characterizing the physical response, power performance, structural loads, and cost of existing and future systems. Without these resources, designs must include safety factors that result in oversizing components and driving up costs while adding significant obstacles in the effort to identify the most effective design space. Here, we outline the types of challenges in the AWE industry and propose solutions through simulation software and physical characterization infrastructure.

\subsection{Key Findings}

The following are key findings in our assessment of infrastructure and technology required by the AWE industry to conduct R\&D activities:

- Knowledge sharing via open-source simulation software is key for the industry to mature.

- Types of software applications required for AWE development include:

○ Design exploration (e.g., conceptual design, system architecture, systems engineering)

- Detailed design (e.g., aerodynamic, structures, control systems, offshore support platforms)

○ Highly resolving (e.g., understanding fundamental physics, calibrating/validating lower-fidelity tools)

- Plant layout and optimization

○ Technoeconomic analysis

- Certification

- An AWE-specific simulation environment would comprise a suite of tools of multiple fidelities and applications such as design, analysis, and cost modeling.

- Workforce development is critical to support these needs; specifically targeting the following areas:

- Domain experts in aircraft, rotorcraft, autonomous vehicles, controls, optimization, and power systems

- Experts in systems engineering and analytical, engineering, and high-fidelity models

- Computational scientists with scientific software development expertise. 


\subsection{Background in AWE Technology Development Needs}

This section provides background and contextual information on the infrastructure and technology required by the AWE industry to conduct R\&D activities, including key research questions and challenges:

- Reference models and data sets are needed for each system architecture and power generation scale, including:

- Coordinating with the recently submitted IEA Wind Task proposal that covers reference model development

- Coordinating with field campaigns of AWE technologies using publicly available measurement data to validate modeling tools

- Developing industrywide design standards for AWE technologies

- New physics models are needed to simulate the system dynamics and interactions with the atmosphere and environment

- The ability to leverage next-generation computing technologies is needed, such as:

○ Support for high-performance computing resources ([GPU], heterogenous hardware)

○ Integration with optimization, artificial intelligence, and machine-learning ecosystems.

\subsection{Simulation Software Environment}

Developing a comprehensive simulation environment for addressing AWE design and modeling problems is a complex and major effort. The traditional wind energy industry and its collection of simulation tools are well-suited to serve as a model for how a cohesive, open-source software suite can stimulate technological innovation and encourage research collaboration. The industry challenges addressed by a simulation environment are design exploration (e.g., conceptual design, system architecture, systems engineering), detailed design (e.g., aerodynamic, structures, control systems, offshore support platforms), highly resolving (e.g., understanding fundamental physics, calibrating/validating lower-fidelity tools), plant layout and optimization, technoeconomic analysis, and certification. In all use cases, adequate software will save the industry both money and time, as well as position it to solve existing and future energy challenges.

Knowledge sharing through open-source software is important for the industry to mature. One or a handful of key research institutions must lead the effort to develop the infrastructure with which the industry will refine for their technology-specific requirements. It is critically important for the open-source simulation environment to have a flexible and open license that enables ongoing R\&D without the need for each industry member to develop and validate their own unique, proprietary tools.

Simulation software can be divided by fidelity of the underlying models in a range from low to high. All fidelity levels are critical to a comprehensive simulation environment. In addition to their importance to AWE developers, the full range of models are often used in research where 
higher-fidelity models (e.g., computational fluid dynamics, finite-element modeling, and so on) inform reduced-order models and provide validation for engineering (midfidelity) and analytical (low fidelity) models.

Generally, low-fidelity models yield results in a very short amount of time, but the accuracy or applicability is dictated by the underlying assumptions of the model. These models can be used for design exploration, especially when coupled with optimization systems and data-driven approaches for traversing a design space. Low-fidelity models are often analytical, steady-state, first-order approximations with a runtime for a single data point on the order of a fraction of a second. These types of models enable system developers to explore how the topology of a concept impacts performance and enable technology trade-offs. Other types of low-fidelity models could predict the impact of a kite's wake on other kites downwind and assess the impact on power production; such models would provide important tools for farm layout design, controls design, and cost modeling.

For detailed design, engineering models provide higher-order mathematics and physics at a higher computational cost. These midfidelity models typically simulate nonlinear, time-marching dynamics of a system in near-real time; that is, 1 second of simulation time is computed in 1 second of clock time. Midfidelity models would provide the industry with full individual kite dynamics (e.g., translations, rotations, accelerations), as well as aeroelastic analysis, onedimensional structural analysis, controls modeling, and farm-scale kite-kite interaction. These tools would integrate with in-depth design tools like systems for optimization, loads analysis, and controls co-design, wherein the controller design is incorporated into the mechanical design at an early stage. Linearization of the underlying nonlinear time-domain engineering models is also important to understand the system response, with applications including eigenanalysis (to identify system natural frequencies, mode shapes, and damping), controls design, and stability analysis. KiteFAST, developed at NREL under contract with Makani, is an example of a midfidelity simulation tool for land-based- and offshore-tethered fly-gen AWE systems and was developed to integrate with OpenFAST, a widely adopted aeroelastic simulation environment for traditional wind turbines.

High-fidelity simulation software provides users with fully resolved physics at a high computational cost. These simulations are often time-consuming to configure and may require days of runtime for a single simulation. However, the result is a time-marching simulation with high-order models that can simulate an AWE system that fully resolves three-dimensional aerodynamics and three-dimensional structural analysis, as well as detailed componentcomponent interaction (i.e., wing wake effects on the horizontal stabilizer for a rigid kite) and farm-scale kite-kite interaction. This level of fidelity is generally used for fundamental research and for calibrating and validating lower-order models.

\subsubsection{New Research Areas}

New areas of research are required to develop a comprehensive simulation environment for AWE systems. Specifically, reference models detailing targeted technology architectures, physics models for simulating system dynamics, and cost models to determine economic viability are required. Models exist for the traditional wind energy industry and can serve as a basis for the additional research required to accurately describe AWE systems. 
The requirements embedded in AWE systems combine the physical performance of aircraft, reliability of autonomous vehicles, and cost performance of typical energy production systems. These extreme requirements will yield designs that push the limits of existing numerical models, requiring additional research for accurate simulation. At the farm scale, new analytical wake models should be developed to capture kite and tether impacts. Further, atmospheric turbulence models should be customized for the operating altitudes of AWE systems. Vortex-based aerodynamic engineering models for aircraft application, coupled with beam-type structural models for kite component-component interaction, will be required to predict critical performance characteristics of individual systems, such as flight qualities and stall behavior. For flexible wing systems, additional research is needed to develop coupled aerostructural models capable of simulating highly elastic components like a fabric wing deforming under dynamic loads and controlled by elastic cables.

Reference models capable of operating in a design condition along with fully capable flight controllers, tether models, tether controllers, and ground station conditions are required. Each AWE system architecture brings unique dynamics, cost, and performance, requiring a full reference model. Furthermore, architecture designs are not expected to scale geometrically, requiring additional reference models for each target power generation scale. The development of this set of reference models will establish baseline technology solutions from which the industry can generate more advanced AWE concepts.

However, a co-dependency exists in that reference models and data sets are required to complete software validation, but the simulation software is required to design AWE systems. For rigidwing, fly-gen architectures, the open-source Makani models (Oktoberkite and M600) and test data are a major resource for establishing a reference model. For other architectures, an iterative approach to expanding the design space while developing and validating software tools should be employed. Dynamically stable systems with simple components, such as straight beams and well-defined airfoils, can provide the basis for early numerical model validation. Additionally, model validation should be conducted in coordination with industry partners engaging in field campaigns for existing designs.

Controller software in the reference models is an area requiring significant additional research in the industry. It may be feasible to establish a simple controller for ground-gen systems, but the crosswind flight of rigid-wing fly-gen systems present an extremely complex problem. During the NREL effort to develop the KiteFAST software, a significant portion of time was spent characterizing controller behavior and configuring the simulation system so that it could simulate a full crosswind loop without manual input. As this "hands-off" simulation mode was not achieved by the project conclusion, the simulation environment was not fully validated.

The computational landscape for simulation environments continues to change dramatically. Software that supports high-performance computing hardware and heterogeneous hardware systems is increasingly common in the present day and should be anticipated to be the norm within the next 5 years. There is also a trend of integration of very complex algorithms, such as optimization, machine learning, and artificial intelligence, into scientific computing workflows. These tools are becoming increasingly ubiquitous, and it should be expected that the next generation of engineers and researchers will choose software that integrates with these frameworks. 
Developing these tools will require integrating aerospace industry expertise with established research fields in the wind energy industry. It will require domain experts in aircraft, rotorcraft, and autonomous vehicle dynamics and controls to establish the high-level requirements for the physical simulation capabilities. Researchers experienced in wind power plant and component design and optimization should inform the specific use cases to target. The development and implementation of the physics models will require experts in analytical wake modeling, systems engineering, and high-fidelity numerical modeling, along with computational scientists with scientific software development expertise. Additional time will be required to validate the numerical models and implementations as the AWE technology landscape changes and new designs are introduced and characterized.

\subsection{Physical Characterization and Validation}

Close coordination between theoretical modeling, numerical simulation, and physical characterization and validation is required in any science and engineering discipline, especially as new research areas and modeling domains are explored (as described in the previous section). Physical characterization and validation equipment and setups require detailed specification to address the research questions. Example physical domains include:

- Materials science: tensile strength, fatigue, conductivity, specific weight, and multifunctionality

- Aerodynamics: wing flow, turbine flow, load assumption, tether drag, and flow-induced vibration

- Mechanical: structural integrity, deformation, oscillation, and system dynamics

- Electrodynamics: generator efficiency and conductor losses

- Thermodynamics: heat transfer in conductor and generator and environmental conditions

- Control: sensors, data acquisition, control units, and actuators.

At this point, only a high-level exemplary theme specification of physical setups and equipment for exploration, characterization, and validation needs can be provided at different system levels, such as the following material and components, subsystems, and integrated systems:

- Material and components: tether, soft kite fabric, connectors, force introduction: strength, fatigue, wear, elasticity

- Subsystems: control systems, wing structure, base station, tether reel and spooling mechanism, and back-to-back winch setups

- Integrated systems: on-ground base station and on-ground flight unit system validation; in-flight system validation on a dedicated, fully licensed site, suitable for different archetypes, operational concepts; scales; flight dynamics for all states and modes; launch; and landing. 


\subsection{Procedures, Guidelines, and Standards}

Alongside theoretical modeling, numerical simulation, and physical characterization and validation, the development and adaptation of relevant procedures, design, and validation guidelines is critical to preparing processes and systems toward standards and certification. Further details can be found in the IEA Wind AWE task proposal (Petrick et al. 2021) and include the following list of themes:

- Failure mode effect analysis

- Design basis and load cases for structural design

- Risk management framework

- Technology design space definition and archetype classification

- Technology readiness level definition specific to AWE

- Technology performance level definition for AWE specific to key markets: grid, onshore, offshore, early adopter (such as remote and microgrid); see analogous, market-specific technology assessment framework

- Technology assessment frameworks

- Development of a full set of functional requirements for key markets

- Stakeholder outreach development or outreach material, identification of stakeholder needs

- Life cycle assessments. 


\section{Conclusions and Recommendations}

Based on the insights gained from a literature review, internal analysis, domestic and global outreach through the U.S. AWE workshop, numerous industry interviews, and an overall assessment, the following conclusions are drawn about the potential for and technical viability of AWE to provide a significant source of energy in the United States:

- The AWE resource technical potential is similar in magnitude to the traditional wind potential in the United States; two or more times the total electricity consumption in the United States; and therefore, AWE could provide a significant contribution to the U.S. renewable energy supply. ${ }^{6}$

- AWE technologies are fundamentally new and different from traditional wind turbines because they have different modes of operation and design characteristics, with unique manufacturer supply chains, transport, and installation methods, as well as different operation, maintenance, and upgrade procedures.

- Because AWE is significantly different from traditional wind energy, it requires different pathways for developing policies and procedures for permitting airspace, grid integration, environmental and wildlife impacts, and social perception, including viewshed, noise, and general social acceptance.

- The development of AWE technologies faces unique challenges, and their resolution through R\&D requires novel analysis methods, tools, equipment, facilities, and a workforce with new skills.

- Existing AWE system designs remain diverse, and the technology has not converged on configurations that satisfy the requirements of various markets. Several designs under development show promise, and the overall design space has not been fully explored.

- The path to an optimal AWE system design, manufacture, and operation is being investigated by universities and small, entrepreneurs in the United States, whereas AWE is a funded research program in the European Union (European Commission 2018) where most AWE advancements have occurred.

- The R\&D challenges of AWE are similar in complexity to the challenges of marine and hydrokinetic technologies of DOE's Water Power Program, and commercializing AWE would likely require a similar or larger level of effort to make progress and rapidly accelerate toward commercial deployment and achieve significant impact.

- The technical complexity of developing successful AWE technologies has similar challenges to developing autonomous flight vehicles and may represent additional challenges related to tethered flight; nonetheless, autonomous flight vehicles are progressing toward commercialization and represent an enabling technology sector for AWE.

The following research, development, demonstration, and commercialization recommendations outline a 10-year program to examine and validate the technical and economic viability of AWE technologies.

\footnotetext{
${ }^{6}$ Assuming capacity densities of $3.98 \mathrm{MW} / \mathrm{km}^{2}, 500-\mathrm{kW}$ short tether $(250 \mathrm{~m})$ of AWE and $3 \mathrm{MW} / \mathrm{km}^{2}, 5 \mathrm{MW}, 120$ $\mathrm{m}$ hub height for traditional wind. Technical potential for AWE and traditional wind occur in similar areas spatially and further investigation into where AWE may represent an increase in technical potential is recommended.
} 


\section{Years 1 to 4: Initiate Fundamental Research and Craft a Plan for Commercialization}

The following are steps to be taken to advance fundamental research and develop a commercialization plan for AWE:

- Develop a national AWE research, development, and flight research facility that is permitted, flight-certified, fully instrumented (including measurements of inflow turbulence at flight altitude) and staffed for evaluating industry-developed and national laboratory technologies. This research facility covers system characterization and validation at component, subsystem, and system levels, and on bench, rig, and in flight.

- Facilitate collaboration between stakeholders, permitting agencies, and researchers to develop policies and procedures to address airspace restrictions, radar impacts, device lighting, avian impact studies, and social perception to enable development and commercialization of AWE technologies in alignment with existing co-located industries and communities.

- Develop complete sets of functional requirements of AWE systems for the diverse applications and markets to fully capture the problem statements. These are to cover all life cycle stages; the complete range of stakeholder requirements and interactions with ecology, economy, and society; and are expressed in detailed technical specifications, cost, and performance goals; to successfully commercialize AWE technologies.

- Support national and regional cost and feasibility studies to evaluate key cost drivers; market potential; supply chain and workforce development; risk; installation and operational strategies; economic impact; social acceptance; and environmental issues of AWE systems.

- Develop holistic technology assessment methods and tools to identify potential technology showstoppers and critical areas of attention; quantify technology performance and readiness at all system levels and development stages; compare technologies; and drive the technology development along the most cost-, time-, and risk-effective development trajectories.

- Initiate fundamental research on critical issues on aerodynamics; controls; materials; siting; cost; performance and feasibility drivers; environmental issues; reliability; safety; system dynamics; controls; flight optimization; and social acceptance.

- Attract global expertise and technology developers through accelerator programs via operational and evaluation campaigns and fly-offs, as well as tool development and simulation competitions.

- Develop open-source, multifidelity simulation capabilities that model AWE systems in a suite of numerical tools, with a focus on design exploration, detailed design, and highly resolving AWE technology solutions with respect to physical response and dynamics, cost, and environmental and social impact. The open-source framework will provide a means of distributing fundamental knowledge throughout the industry, as well as allow for individual members to enhance proprietary tools through validation and cross-model comparison.

- Establish reference models (including controllers) for various AWE technologies and sizes to enable demonstration and verification of the simulation capability and to 
establish baseline technology solutions from which to develop more advanced AWE designs.

- Support hardware development of next-generation AWE systems to advance the technology and improve the designs through proven inventive techniques.

- Perform scenario development, evaluation, and refinement of the most effective support and assistance mechanisms for technology development, market entry, commercialization, deployment, and rollout.

- Coordinate aspects of the AWE R\&D agenda with the new IEA Wind Task on AWE, where appropriate, and align with international standards and guidelines.

\section{Years 3 to 10: Evaluation Campaigns and Research to Accelerate Technology Development}

The following are steps to be taken to accelerate AWE technology development:

- Engage industry by funding industry designs, supporting the use of the new simulation capabilities, and providing a research facility site with space, instrumentation, and expert personnel to get flying time on prototypes and precommercial systems.

- Analyze, document, and disseminate data from evaluation campaigns to validate simulation models and foster sector collaboration while protecting individual participants' intellectual property.

- Hold an AWE program review within 5 years, based on industry engagement, evaluation campaign results, and advanced simulation results. The review results will be used to chart the future course of the R\&D program and the development of an out-year program plan for years 6 to 10 .

- Establish an international working group - e.g., through the International Electrotechnical Commission - to develop international design requirements to ensure the integrity of promising AWE technologies. The purpose of these design requirements is to establish an appropriate level of safety against damage from all anticipated hazards during the planned lifetime of each AWE unit. Design requirements go together with the needs of the simulation capabilities and evaluation campaigns.

\section{Years 6 to 10: Technology Advancement and Fundamental Research}

To advance AWE technology, the following steps need to be taken:

- In accordance with the 6- to 10-year program plan, select the most promising concepts for long-term reliability evaluation at the national research facility to prove system durability. This phase of the program would require funding multiunit advanced systems for reliability evaluation.

- Fund development of demonstration projects in real early-adopter markets, such as remote communities, agriculture, microgrids, and progressive utilities, to gather operational data on market issues and required improvements.

- Continue fundamental research in support of industry on aerodynamics; controls; materials; siting; cost and feasibility drivers; environmental issues; reliability; safety; flight optimization; and social acceptance. 


\section{References}

Ahrens, U., M. Diehl, R. Schmehl. 2014. Airborne Wind Energy. Springer.

Anderson, M. 2019. "Ready Flyer One: Airborne Wind Energy Simulations Guide the Leap to Satisfying Global Energy Demand.” IEEE Spectrum: Technology, Engineering, and Science News. https://spectrum.ieee.org/energywise/energy/renewables/ready-flyer-one-airborne-windenergy-simulations-guide-the-leap-to-satisfying-global-energy-demand.

Archer, C., K. Caldeira. 2009. “Global Assessment of High-Altitude Wind Power.” Energies. https://doi.org/10.3390/en20200307.

Archer, C. L., L. Delle Monache, D. L. Rife. 2014. "Airborne wind energy: Optimal locations and variability." Renewable Energy 64, 180-186. https://doi.org/10.1016/j.renene.2013.10.044.

Arent, D. J., A. Wise, R. Gelman. 2011. "The status and prospects of renewable energy for combating global warming." Energy Economics, Special Issue on The Economics of Technologies to Combat Global Warming 33, 584-593. https://doi.org/10.1016/j.eneco.2010.11.003.

Beaupoil, C. 2019. "Practical Experiences with a Torsion Based Rigid Blade Rotary Airborne Wind Energy System with Ground Based Power Generation.” Airborne Wind Energy Conference 2019. https://repository.tudelft.nl/islandora/object/uuid:c50f7eb6-f116-4158-9e9baa1b05092ab2? collection=research.

Bechtle, P., and U. Zilmann. 2021. "High-Altitude Wind Energy Map Published." Airborne Wind Europe.https://airbornewindeurope.org/resources/high-altitude-wind-energy-mappublished-2/. Accessed May4, 2021.

Bechtle, P., M. Schelbergen, R. Schmehl, U. Zillmann, S. Watson. 2019. “Airborne wind energy resource analysis." Renewable Energy 141, 1103-1116.

https://doi.org/10.1016/j.renene.2019.03.118.

Beiter, P., W. Musial, A. Smith, L. Kilcher, R. Damiani, M. Maness, S. Sirnivas, T. Stehly, V. Gevorgian, M. Mooney, G. Scott. 2016. A Spatial-Economic Cost-Reduction Pathway Analysis for U.S. Offshore Wind Energy Development from 2015-2030 (Technical Report). Golden, CO: National Renewable Energy Laboratory (NREL). NREL/TP-6A20-66579.

https://www.nrel.gov/docs/fy16osti/66579.pdf.

Shifman, R.,, Airborne Wind Energy: Waiting For Take-Off", 2019, 19 pages, Bloomberg NEF, Bloomberg Finance L.P.

Bormann, A., 2021. Private communication in stakeholder outreach with Enerkite.

Brabeck, S., 2021. Private communication in stakeholder outreach with SkySails. 
Brown, A., P. Beiter, D. Heimiller, C. Davidson, P. Denholm, J. Melius, A. Lopez, D. Hettinger, D. Mulcahy, G. Porro. 2016. Estimating Renewable Energy Economic Potential in the United States. Methodology and Initial Results (Technical Report). Golden, CO: National Renewable Energy Laboratory (NREL). NREL/TP-6A20-64503.

https://www.nrel.gov/docs/fy15osti/64503.pdf.

Bureau of Ocean Energy Management. 2021. "Vineyard Wind 1 Offshore Wind Energy Project Final Environmental Impact Statement Volume 1 (OCS EIS/EIA BOEM 2021-0012)."

https://www.boem.gov/sites/default/files/documents/renewable-energy/state-activities/VineyardWind-1-FEIS-Volume-1.pdf.

Calverley, G., 2021. Private communication in stakeholder outreach with Abound.

Cherubini, A., A. Papini, R. Vertechy, M. FontanaS. . 2015. "Airborne Wind Energy Systems: A review of the technologies." Renewable and Sustainable Energy Reviews 51, 1461-1476. https://doi.org/10.1016/j.rser.2015.07.053.

Craig, M. T., S. Cohen, J. Macknick, C. Draxl, O. J. Guerra, M. Sengupta, S. E. Haupt, B.-M. Hodge, C. Brancucci. 2018. "A review of the potential impacts of climate change on bulk power system planning and operations in the United States." Renewable and Sustainable Energy Reviews 98, 255-267. https://doi.org/10.1016/j.rser.2018.09.022.

Craig, M. T., I. L. Carreño, M. Rossol, B.-M. Hodge, C. Brancucci. 2019. "Effects on power system operations of potential changes in wind and solar generation potential under climate change." Environ. Res. Lett. 14, 034014. https://doi.org/10.1088/1748-9326/aaf93b.

Creighton, R., 2021. Private communication in stakeholder outreach with Windlift.

Dalla Longa, T. Kober, J. Badger, P. Volker, C. Hoyer-Klick, I. Hidalgo Gonzalez, H. Medarac, et al. 2018. Wind potentials for EU and neighbouring countries: Input datasets for the JRC-EUTIMES Model. Publications Office, LU. https://publications.jrc.ec.europa.eu/repository/handle/JRC109698.

De Lellis, M., A. K. Mendonça, R. Saraiva, A. Trofino,Á Lezana. 2016. "Electric power generation in wind farms with pumping kites: An economical analysis." Renewable Energy 86, 163-172. https://doi.org/10.1016/j.renene.2015.08.002.

De Lellis, M., R. Reginatto, R. Saraiva, A. Trofino. 2018. "The Betz limit applied to Airborne Wind Energy." Renewable Energy 127, 32-40. https://doi.org/10.1016/j.renene.2018.04.034.

De Rose, A., M. Buna, C. Strazza, N. Olivieri, T. Stevens, L. Peeters, D. Tawil-Jamault. 2017. Technology Readiness Level: Guidance Principles for Renewable Energy Technologies. European Commission: Petten, The Netherlands. https://op.europa.eu/en/publication-detail//publication/d5d8e9c8-e6d3-11e7-9749-01aa75ed71a1.

De Schutter, J., R. Leuthold, T. Bronnenmeyer, R. Paelinck, M. Diehl. 2019a. "Towards a Modular Upscaling Strategy for Utility-Scale Airborne Wind Energy." https://repository.tudelft.nl/islandora/object/uuid\%3Ac7970efe-b007-4d26-a00f-14c0cdba0ba1. 
De Schutter, J., R. Leuthold, T. Bronnenmeyer, R. Paelinck, M. Diehl. 2019b. "Optimal control of stacked multi-kite systems for utility-scale airborne wind energy." https://doi.org/10.1109/CDC40024.2019.9030026.

Deutsche WindGuard GmbH. 2018. Capacity Densities of European Offshore Wind Farms . Bundesamt fur Seeschifffahrt und Hydrographie. https://vasab.org/wpcontent/uploads/2018/06/BalticLINes_CapacityDensityStudy_June2018-1.pdf.

Draxl, C., A. Clifton, B.-M. Hodge, J. McCaa. 2015. "The Wind Integration National Dataset (WIND) Toolkit." Applied Energy 151, 355-366. https://doi.org/10.1016/j.apenergy.2015.03.121.

Echeverri, P., T. Fricke, G. Homsy, N. Tucker. 2020. The Energy Kite: Selected Results from the Design, Development, and Testing of Makani's Airborne Wind Turbines. Makani Technologies, LLC.

http://www.energykitesystems.net/AWEC2020Teleconference/PostersAWEC2020/AWEC2020P OSTER023DocumentMakaniPowerLLC.pdf.

Eijkelhof, D., S. Rapp, U. Fasel, M. Gaunaa, R. Schmehl. 2020. "Reference Design and Simulation Framework of a Multi-Megawatt Airborne Wind Energy System." J. Phys.: Conf. Ser. 1618, 032020. https://doi.org/10.1088/1742-6596/1618/3/032020.

European Commission., 2018. Study on challenges in the commercialisation of airborne wind energy systems. https://op.europa.eu/en/publication-detail/-/publication/a874f843-c137-11e89893-01aa75ed71a1/language-en.

Faggiani, P., R. Schmehl. 2018. Design and Economics of a Pumping Kite Wind Park, in: Schmehl, R. (Ed.), Airborne Wind Energy: Advances in Technology Development and Research. Springer, Singapore, pp. 391-411. https://doi.org/10.1007/978-981-10-1947-0 16.

Fagiano. L. 2019. "Automation Challenges in Airborne Wind Energy Systems and the Role of Academic Research" Airborne Wind Energy Conference 2019, https://www.youtube.com/watch?v=ZptcYca_JBs

Firestone, J., D. Bidwell, M. Gardner, L. Knapp. 2018. "Wind in the sails or choppy seas? People-place relations, aesthetics and public support for the United States' first offshore wind project." Energy Research \& Social Science 40, 232-243.

https://doi.org/10.1016/j.erss.2018.02.017.

Fitzgerald, J., B. Bolund. 2012. Technology Readiness for Wave Energy Projects; ESB and Vattenfall classification system, in: Proceedings of the 4th International Conference on Ocean Energy, Dublin, Ireland. pp. 17-19. https://www.icoeconference.com/publication/technology_readiness for_wave energy projects_esb and vattenfa 11 classification system/.

Gambier, A. 2014. Projekt OnKites: Untersuchung zu den Potentialen von Flugwindenergieanlagen (FWEA); Abschlussbericht. Technische Informationsbibliothek $u$. Universitätsbibliothek, Bremerhaven. https://doi.org/10.2314/GBV:81573428X. 
Haas, T., J. Meyers. 2017. Comparison study between wind turbine and power kite wakes. J. Phys.: Conf. Ser. 854, 012019. https://doi.org/10.1088/1742-6596/854/1/012019.

Håland, A. 2018. Testing of Kitemill's Airborne Wind Energy System at Lista, Norway. Assessing the Impacts on birds. A pilot study. https://airbornewindeurope.org/wpcontent/uploads/2020/10/NNI-Report-520-2018-Testing-of-Kitemill-AWES-at-Lista Norway Assessment-of-impacts-on-birds_A-pilot-study_December-2018.pdf.

Harklau, T., 2021. Private communication in stakeholder outreach with Ampyx Power.

Harrison-Atlas, D., A. Lopez, E. Lantz. forthcoming. National land use implications of an expanding wind energy portfolio.

Haupt, S. E., J. Copeland, W. Y. Y. Cheng, Y. Zhang, C. Ammann, P. Sullivan. 2016. “A Method to Assess the Wind and Solar Resource and to Quantify Interannual Variability over the United States under Current and Projected Future Climate." Journal of Applied Meteorology and Climatology 55, 345-363. https://doi.org/10.1175/JAMC-D-15-0011.1.

Hayek, N. E. 2020. Airborne Wind Energy: Challenges and Opportunities. Proceedings of IEA Wind, Topical Expert Meeting \#102. IEA Wind Task 11. September 23-24, 2020. Online Meeting.

Heilmann, J. 2012. Technical and Economic Potential of Airborne Wind energy M.Sc. Thesis, Utrecht University. http://dspace.library.uu.nl/handle/1874/258716.

Ippolito, M., 2021. Private communication in stakeholder outreach with KiteGen.

Isensee, M. 2021. Private communication in stakeholder outreach with KiteKraft.

Jonkman, J., S. Butterfield, W. Musial, G. Scott. 2009. Definition of a 5-MW Reference Wind Turbine for Offshore System Development (Technical Report). Golden, CO: National Renewable Energy Laboratory (NREL). NREL/TP-500-38060. https://www.nrel.gov/docs/fy09osti/38060.pdf.

Junginger, M., and A. Louwen. 2019. Technological Learning in the Transition to a Low-Carbon Energy System: Conceptual Issues, Empirical Findings, and Use, in Energy Modeling. Academic Press.

Karnauskas, K. B., J. K. Lundquist, L. Zhang. 2018. "Southward shift of the global wind energy resource under high carbon dioxide emissions." Nature Geoscience 11, 38-43. https://doi.org/10.1038/s41561-017-0029-9.

Kaufman-Martin, S., N. Naclerio, P. May, P. Luzzatto-Fegiz. 2021. An entrainment-based model for annular wakes, with applications to airborne wind energy.

Kiteswarms. "Developing the future of airborne wind energy" https://www.youtube.com/watch?v=URyacqV5xI0. 
Kruijff, M., 2021. Private communication in stakeholder outreach with Ampyx Power.

Kruijff, M., and R. Ruiterkamp. 2018. "A Roadmap Towards Airborne Wind Energy in the Utility Sector" in: Airborne Wind Energy; Advances in Technology Development and Research. pp. 643-662. https://doi.org/10.1007/978-981-10-1947-0_26.

Leuthold, R., S. Gros, M. Diehl. 2017. "Induction in Optimal Control of Multiple-Kite Airborne Wind Energy Systems." IFAC-PapersOnLine, 20th IFAC World Congress 50, 153-158. https://doi.org/10.1016/j.ifacol.2017.08.026.

Leuthold, R., J. De Schutter, E. C. Malz, G. Licitra, S. Gros, M. Diehl, M. 2018. "Operational Regions of a Multi-Kite AWE System" in 2018 European Control Conference (ECC). Presented at the 2018 European Control Conference (ECC), pp. 52-57.

https://doi.org/10.23919/ECC.2018.8550199.

Li, Y., E. Kalnay, S. Motesharrei, J. Rivas, F. Kucharski, D. Kirk-Davidoff, E. Bach, N. Zeng. 2018. "Climate model shows large-scale wind and solar farms in the Sahara increase rain and vegetation." Science 361, 1019-1022. https://doi.org/10.1126/science.aar5629.

Lopez, A., T. Mai, E. Lantz, D. Harrison-Atlas, T. Williams, G. Maclaurin. 2021. "Land use and turbine technology influences on wind potential in the United States." Energy 223, 120044. https://doi.org/10.1016/j.energy.2021.120044.

Losada Carreño, I., M. T. Craig, M. Rossol, M. Ashfaq, F. Batibeniz, S. E. Haupt, C. Draxl, B.M. Hodge, C. Brancucci. 2020. "Potential impacts of climate change on wind and solar electricity generation in Texas." Climatic Change 163, 745-766. https://doi.org/10.1007/s10584020-02891-3.

Loyd, M. L. 1980. "Crosswind kite power (for large-scale wind power production)." Journal of Energy 4, 106-111. https://doi.org/10.2514/3.48021.

Luchsinger, R. H. 2013. Pumping Cycle Kite Power, in: Ahrens, U., M. Diehl, R. Schmehl, eds. Airborne Wind Energy. pp. 47-64. https://doi.org/10.1007/978-3-642-39965-7.

Lunney, E., M. Ban, N. Duic, N A. Foley. 2017. “A state-of-the-art review and feasibility analysis of high-altitude wind power in Northern Ireland." Renewable and Sustainable Energy Reviews 68, 899-911. https://doi.org/10.1016/j.rser.2016.08.014.

Maclaurin, G. J., N. Grue, A. Lopez, D. Heimiller. 2019. The Renewable Energy Potential (reV) Model: A Geospatial Platform for Technical Potential and Supply Curve Modeling (Technical Report). Golden, CO: National Renewable Energy Laboratory (NREL). NREL/TP-6A20-73067. https://www.nrel.gov/docs/fy19osti/73067.pdf.

Malz, E. 2020. "Airborne Wind Energy - To fly or not to fly?" PhD thesis. Chalmers University of Technology. https://research.chalmers.se/en/publication/518841.

Marsh, R., 2021. Private communication. 
Marvel, K., B. Kravitz, K. Caldeira. 2013. Geophysical limits to global wind power. Nature Climate Change 3, 118-121. https://doi.org/10.1038/nclimate1683.

Miller, L.M., D.W. Keith. 2018. “Climatic impacts of wind power” Joule 2, 2618-2632. https://doi.org/10.1016/i.joule.2018.09.009.

Miller, L. M., F. Gans, A. Kleidon. 2011. "Jet stream wind power as a renewable energy resource: little power, big impacts.” Earth System Dynamics 2, 201-212. https://doi.org/10.5194/esd-2-201-2011.

Musial, W., P. Beiter, P. Spitsen, J. Nunemaker, V. Gevorgian, A. Cooperman, R. Hammond, M. Shields. 2020. 2019 Offshore Wind Technology Data Update (Technical Report). Golden, CO: National Renewable Energy Laboratory (NREL). NREL/TP-5000-77411. https://www.nrel.gov/docs/fy21osti/77411.pdf.

Musial, W., D. Heimiller, P. Beiter, G. Scott, C. Draxl. 2016. 2016 Offshore Wind Energy Resource Assessment for the United States (Technical Report). Golden, CO: National Renewable Energy Laboratory (NREL). NREL/TP-5000-66599. https://www.nrel.gov/docs/fy16osti/66599.pdf.

National Wind Coordinating Collaborative. 2010. Wind Turbine Interactions with Birds, Bats, and their Habitats: A Summary of Research Results and Priority Questions. https://www1.eere.energy.gov/wind/pdfs/birds_and_bats_fact_sheet.pdf.

National Renewable Energy Laboratory. 2020. "Annual Technology Baseline.” https://atb.nrel.gov/.

Optis, M., A. Rybchuk, N. Bodini, M. Rossol, W. Musial. 2020. 2020 Offshore Wind Resource Assessment for the California Pacific Outer Continental Shelf (Technical Report). Golden, CO: National Renewable Energy Laboratory (NREL). NREL/TP-5000-77642. https://www.nrel.gov/docs/fy21osti/77642.pdf.

Peschel, J. 2021. Private communication in stakeholder outreach with KitePower.

Peschel, J. 2019. "Kitepower and the Journey Towards 24/7 Operation.” Airborne Wind Energy Conference 201, http://resolver.tudelft.nl/uuid:5bea59d6-be63-46c6-aba5-d60967d7783b.

Petrick, K. 2018. "Policies for Airborne Wind Energy - Preparing the grounds for AWE-specific incentive schemes - Scoping Study." Airborne Wind Europe.

https://airbornewindeurope.org/policies-for-airborne-wind-energy-scoping-study-now-in-the-euopen-access-repository/.

Petrick et al. 2021. IEA Wind AWE task proposal. Implementing Agreement for Co-operation in the Research and Development of Wind Energy Systems (IEA Wind TCP). Internal distribution only. 
Pryor, S. C., R. J. Barthelmie, T. J. Shepherd. 2020. " $20 \%$ of US electricity from wind will have limited impacts on system efficiency and regional climate." Scientific Reports 10, 541. https://doi.org/10.1038/s41598-019-57371-1.

Read, R. 2018. Kite Networks for Harvesting Wind Energy, in: Schmehl, R. (Ed.), Airborne Wind Energy, Advances in Technology Development and Research. Springer Singapore, Singapore, pp. 515-537. https://doi.org/10.1007/978-981-10-1947-0_21.

Remington, T. E., Deibert, P.A., Hanser, S. E., Davis, D. M., Robb, L. A., Welty, J. L., 2021. Sagebrush Conservation Strategy-Challenges to Sagebrush Conservation (Open-File Report No. 2020-1125). U.S. Geological Survey, Reston, VA. https://pubs.er.usgs.gov/publication/ofr20201125.

Santos, D., 2021. Private communication in stakeholder outreach with kPower.

Schaefer, D., 2021. Private communication in stakeholder outreach with eWindSolutions.

Schmehl, R. (Ed.). 2018. Airborne Wind Energy: Advances in Technology Development and Research. Springer Singapore. https://doi.org/10.1007/978-981-10-1947-0.

Schmehl, R. 2020. "Airborne Wind Energy" PowerWeb webinar lecture https://airbornewindeurope.org/wp-content/uploads/2020/06/20200520-Powerweb.pdf.

Schmehl, R. 2021. Private communication in stakeholder outreach with the Delft University of Technology.

Shields, M., P. Beiter, W. Kleiber. 2021. "Spatial impacts of technological innovations on the levelized cost of energy for offshore wind power plants in the United States." Sustainable Energy Technologies and Assessments 45, 101059. https://doi.org/10.1016/j.seta.2021.101059.

Stehly, T., P. Beiter, P. Duffy. 2020. 2019 Cost of Wind Energy Review (Technical Report). Golden, CO: National Renewable Energy Laboratory (NREL). NREL/TP-5000-78471. https://www.nrel.gov/docs/fy21osti/78471.pdf.

The Dutch Offshore Wind Atlas. 2021. The ECN part of TNO, Whiffle, KNMI, and the Ministry of Economic Affairs and Climate Policy. https://www.dutchoffshorewindatlas.nl/.

Tulloch, O., A. Amiri Kazemi, H. Yue, J. Feuchtwang, R. Read. 2019. "Modeling Studies on Tensile Rotary Power Transmission for Airborne Wind Energy Systems." https://repository.tudelft.nl/islandora/object/uuid:fa2a20d6-51d7-4f85-9f64$\underline{65 \mathrm{~b} 6 \mathrm{dfl} 1 \mathrm{ca} 3 \mathrm{e} 0 \text { ? } \text { collection }=\text { research. }}$.

Sanchez, R. 2011. Technology Readiness Assessment Guide. U.S. Department of Energy, Washington, DC. https://www.directives.doe.gov/directives-documents/400-series/0413.3EGuide-04a. 
Vautard, R., F. Thais, I. Tobin, F.-M. Bréon, J.-G.-D. de Lavergne, A. Colette, P. Yiou, P. M. Ruti. 2014. "Regional climate model simulations indicate limited climatic impacts by operational and planned European wind farms." Nature Communications 5, 3196.

https://doi.org/10.1038/ncomms4196.

Vermillion, C., Cobb, M., Fagiano, L., Leuthold, R., Diehl, M., Smith, R., Wood, T., Rapp, S., Schmehl, R., Olinger, D., Demetriou, M., 2021. "Electricity in the air: Insights from two decades of advanced control research and experimental flight testing of airborne wind energy systems", Annual Reviews in Control, https://doi.org/10.1016/j.arcontrol.2021.03.002.

Vimalakanthan, K., M. Caboni, J. G. Schepers, E. Pechenik, P. Williams. 2018. “Aerodynamic analysis of Ampyx's airborne wind energy system.” J. Phys.: Conf. Ser. 1037, 062008. https://doi.org/10.1088/1742-6596/1037/6/062008.

Vineyard Wind. 2020. Draft Construction and Operations Plan (Construction and Operations Plan). Vineyard Wind LLC. https://www.boem.gov/sites/default/files/documents/renewableenergy/Vineyard\%20Wind $\% 20 \mathrm{COP} \% 20$ Volume $\% 20$ I_Complete.pdf.

Weber, J., 2012. "WEC Technology Readiness and Performance Matrix-finding the best research technology development trajectory" in: Proceedings of the 4th International Conference on Ocean Energy, Dublin, Ireland.

https://www.researchgate.net/publication/233810908 WEC Technology_Readiness and Perfor mance Matrix - finding the best research technology development trajectory.

Weber, J., R. Costello, J. Ringwood. 2013. "WEC Technology Performance Levels (TPLs)Metric for Successful Development of Economic WEC Technology." Proceedings EWTEC 2013.

https://www.researchgate.net/publication/326986433 WEC Technology_Performance_Levels TPLs - Metric for Successful Development of Economic WEC Technology.

Weber, J., Laird, D., Costello, R., Roberts, J., Bull, D., Babarit, A., Nielsen, K., Bittencourt Ferreira, C., Kennedy, B. 2017. "Cost, Time, and Risk Assessment of Different Wave Energy Converter Technology Development Trajectories," in Proc. Eleventh European Wave and Tidal Energy Conference.

Weber, J. 2019. "AirborneMax - Scaling as the Key Issue for Airborne Wind." Airborne Wind Energy Conference 2019. https://repository.tudelft.nl/islandora/object/uuid:ffd965bc-39ed-41cb$\underline{8 \mathrm{~d} 91-46504 \mathrm{f} 9 \mathrm{aef} 12 .}$

Weber, J., M. Marquis, A. Lemke, C. Draxl, A. Lopez, O. Roberts, A. Cooperman, M. Shields. 2021. Proceedings of the 2021 Airborne Wind Energy Workshop. Golden, CO: National Renewable Energy Laboratory (NREL). NREL/TP-5000-80017. nrel.gov/docs/fy21osti/80017.pdf.

Wiser, R., M. Bolinger, B. Hoen, D. Millstein, J. Rand, J., G. Barbose, N. Darghouth, W. Gorman, S. Jeong, A. Mills, B. Paulos. 2020. Wind Energy Technology Data Update: 2020 Edition. Lawrence Berkeley National Laboratory, Berkley, CA. https://emp.lbl.gov/sites/default/files/2020 wind energy technology data update.pdf. 
Wu, G. C., E. Leslie, O. Sawyerr, D. R. Cameron, E. Brand, B. Cohen, D. Allen, M. Ochoa, A. Olson. 2020. "Low-impact land use pathways to deep decarbonization of electricity." Environ. Res. Lett. 15, 074044. https://doi.org/10.1088/1748-9326/ab87d1.

Yip, C. M. A., U. B. Gunturu, G. L. Stenchikov. 2017. "High-altitude wind resources in the Middle East." Scientific Reports 7, 9885. https://doi.org/10.1038/s41598-017-10130-6.

Zerweckh, S. 2021. Private communication.

Zywietz, D. 2019. What Will it Take for AWE to be Successful in Remote \& Mini-grid Applications? Airborne Wind Energy Conference 2019. http://resolver.tudelft.nl/uuid:dbe7de7e151d-483e-9658-0b4f9f26d26a.

Zillmann, U. 2020. Introduction to Airborne Wind Energy. Airborne Wind Europe.

https://airbornewindeurope.org/wp-content/uploads/2020/07/AWEurope_Intro-Airborne-WindEnergy 2020-03-23.pdf. 